INCREASING THE NUMBER OF WOMEN ON CORPORATE BOARDS: COMPARING THE “COMPLY OR EXPLAIN” AND QUOTA APPROACHES, WHICH IS THE MOST PRACTICAL AND EFFECTIVE FOR CANADA?

\author{
by \\ Vedrana Krunic, B.Comm. Ryerson University, 2017 \\ A thesis \\ presented to Ryerson University \\ in partial fulfillment of the \\ requirements of the degree of \\ Master of Science in Management \\ in the program of \\ Master of Science in Management \\ Toronto, Ontario, Canada, 2020 \\ (C) Vedrana Krunic, 2020
}




\section{Author's Declaration}

I hereby declare that I am the sole author of this thesis. This is a true copy of the thesis, including any required final revisions, as accepted by my examiners. I authorize Ryerson University to lend this thesis to other institutions or individuals for the purpose of scholarly research.

I further authorize Ryerson University to reproduce this thesis by photocopying or by other means, in total or in part, at the request of other institutions or individuals for the purpose of scholarly research. I understand that my thesis may be made electronically available to the public. 


\title{
INCREASING THE NUMBER OF WOMEN ON CORPORATE BOARDS: COMPARING THE “COMPLY OR EXPLAIN” AND QUOTA APPROACHES, WHICH IS THE MOST PRACTICAL AND EFFECTIVE FOR CANADA?
}

Master of Science in Management (MScM), 2020

\author{
Vedrana Krunic
}

Ryerson University, 2020

\begin{abstract}
This thesis investigates the practicality and effectiveness of comply or explain and quota approaches to improving the participation of women on corporate boards, drawing on the experience in Canada (focusing on Ontario) and Europe (focusing on Norway). Relevant institutional and contextual factors that have a bearing on gender diversity are explored, using the ecological model and sustainable governance framework. This research utilizes semistructured interviews with key participants from government, the private sector and civil society. The thesis finds that due to particular characteristics of the Canadian comply or explain law (with disclosure being the starting point for involvement of non-state actors in implementation), as well as distinctive characteristics of the Canadian institutional context (where increased participation has been achieved through a combination of state and non-state action without use of quotas), the comply or explain approach appears to be the most practical and effective in Canada's distinctive institutional context at this time. The thesis also recommends changes to improve the effectiveness of the current Canadian comply or explain approach.
\end{abstract}




\section{Acknowledgments}

I would like to acknowledge all of the professors that had a role in making this thesis possible. Specifically, I would like to thank Dr. Kernaghan Webb for all of the guidance that was provided throughout the completion of my thesis paper. I would also like to thank Dr. Wendy Cukier and Dr. Chris MacDonald for their additional guidance. 


\section{Dedication}

I would like to dedicate this thesis to my parents, Snezana and Dobrislav Krunic, and brother, Ilija Krunic, who have supported me throughout all of my educational endeavors. I could not have done any of it without them. I am also grateful for the support of a very special person, Nikola Milinkovic, and a dear friend of mine, Romana Mirza. I am thankful to you all. 


\section{Table of Contents}

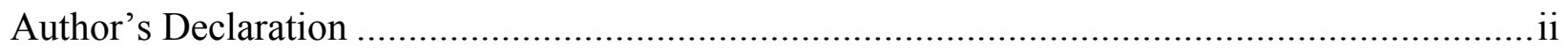

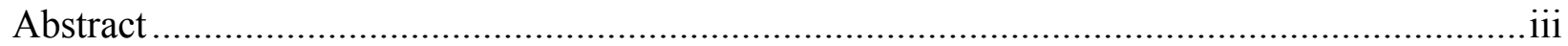

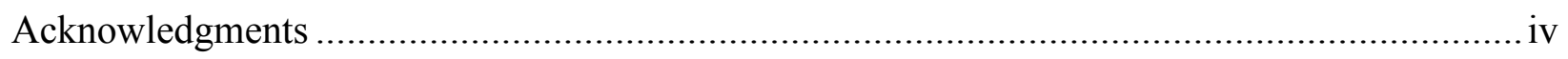

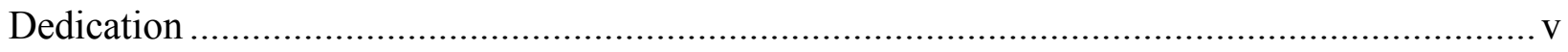

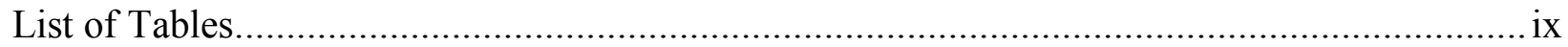

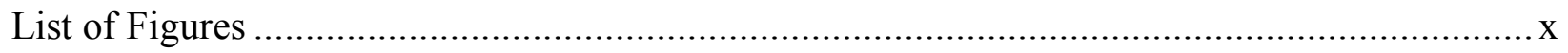

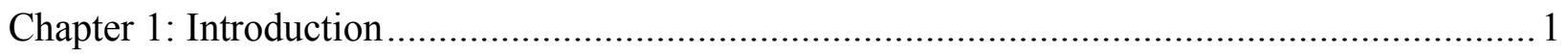

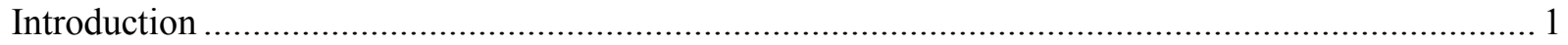

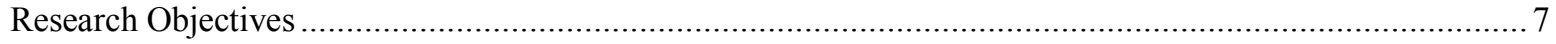

The Value of Gender Diversity ……………………………………………………………. 8

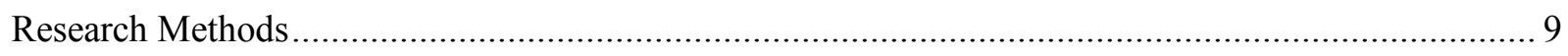

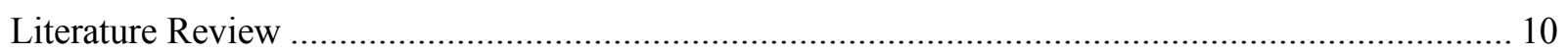

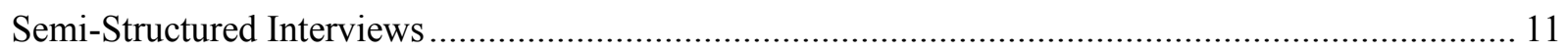

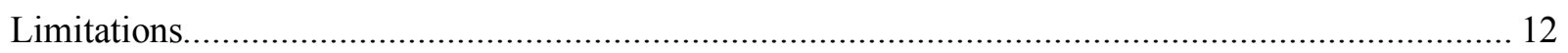

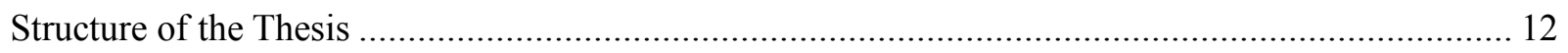

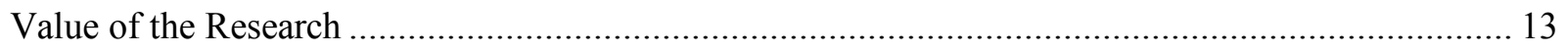

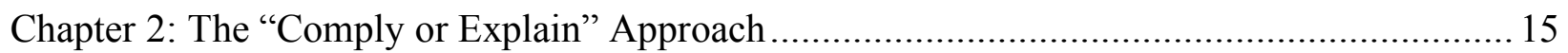

The "Comply or Explain" Approach: What it Entails and How it Works............................................ 15

The Strengths and Weaknesses of Comply or Explain .................................................................. 16

The "Comply or Explain" Approach Implementation to Date ……………………………………..... 22

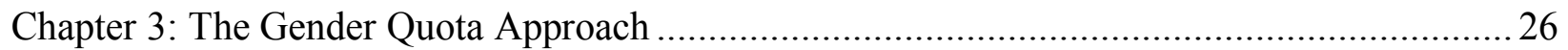

The Gender Quota Approach: How it Works focusing on the European-Norway Experience ............. 26

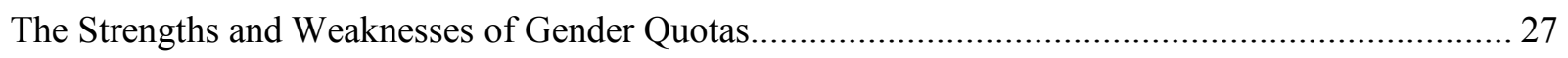

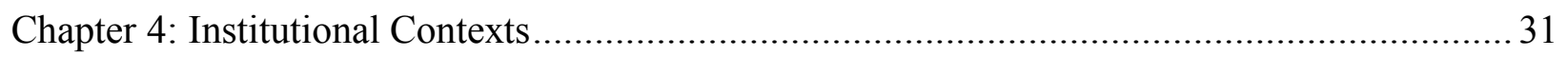

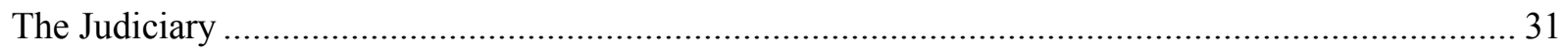

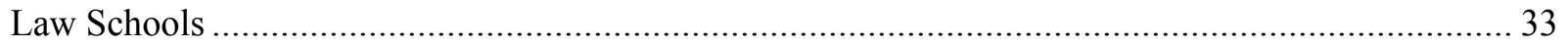

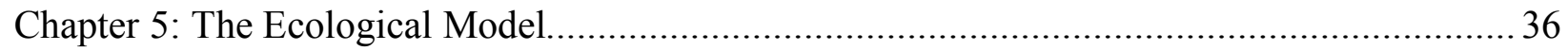

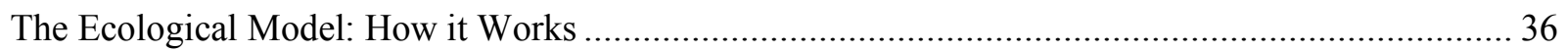

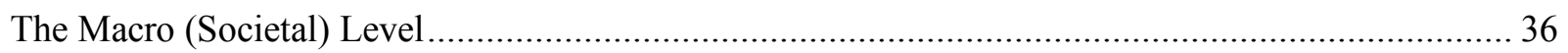

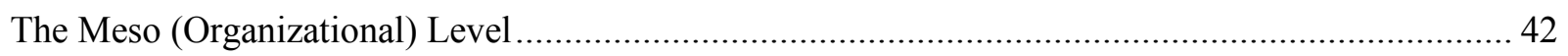

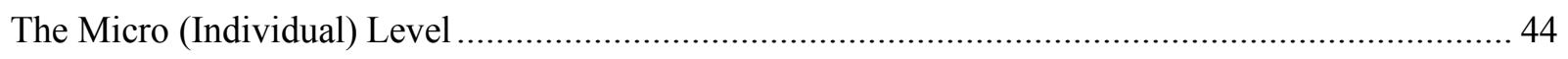

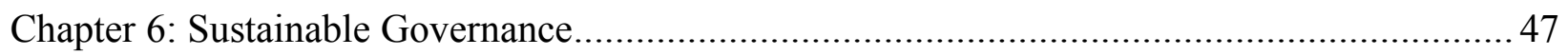


Sustainable Governance: Rules Instruments, Processes, Institutions, and Actors

Sustainable Governance: Governance Institutions, Processes, Rule Instruments, and Actors Applying

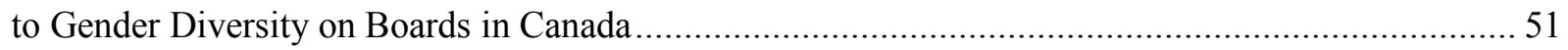

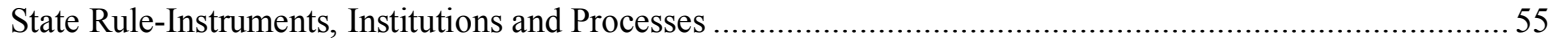

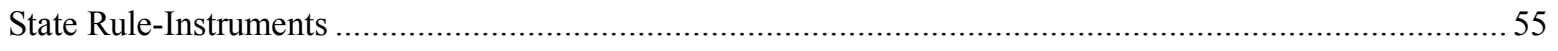

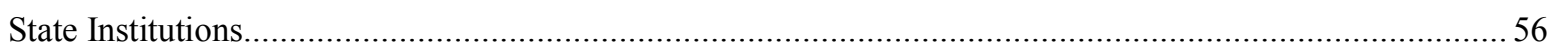

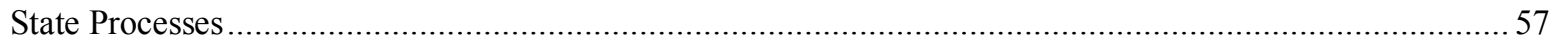

Non-State Rule Instruments, Institutions and Processes......................................................................... 57

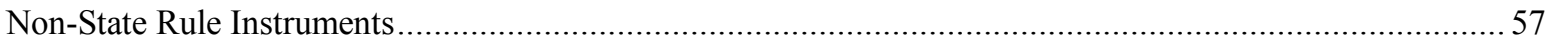

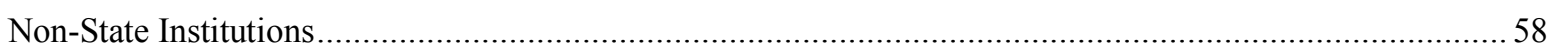

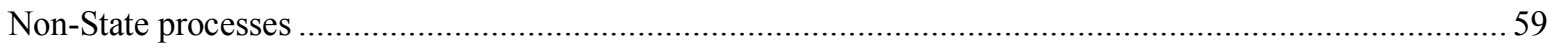

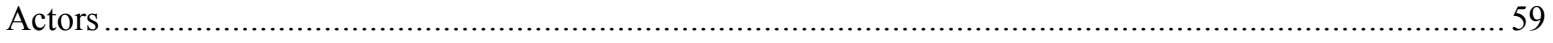

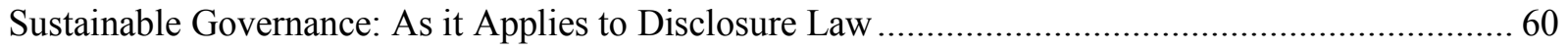

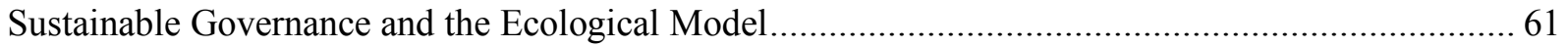

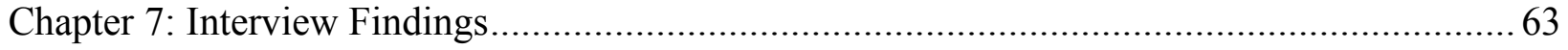

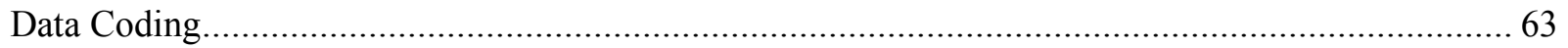

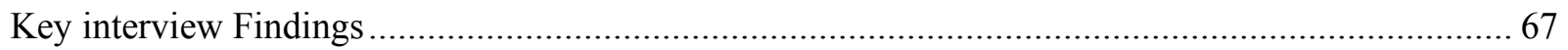

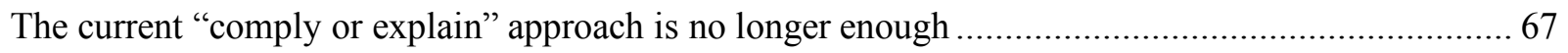

The gender quota approach is not the best option for Canada at this time..................................... 69

Investors, NGOs, and industry associations, devoted to encouraging greater diversity, as well as,

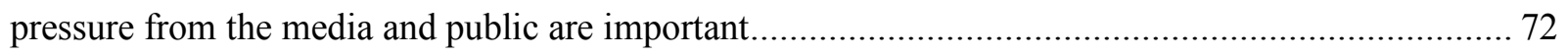

There are underlying factors that negatively impact female representation on boards ...................... 74

Chapter 8: Improving Gender Diversity on Corporate Boards in Canada............................... 78

Changes to the Current "Comply or Explain" Approach .............................................................. 78

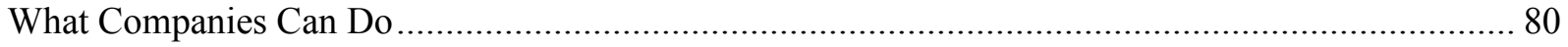

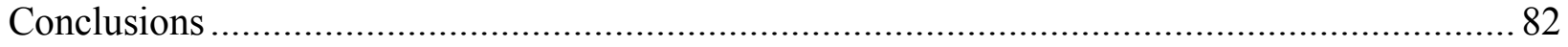

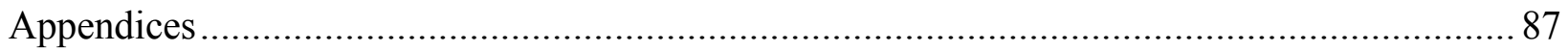

Appendices A - E: Semi-Structured Interview Questions ....................................................... 87

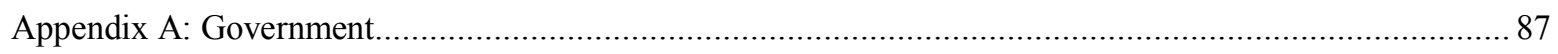

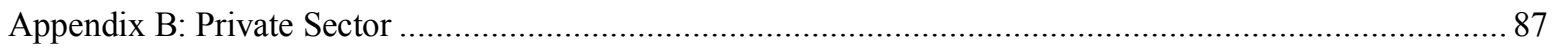

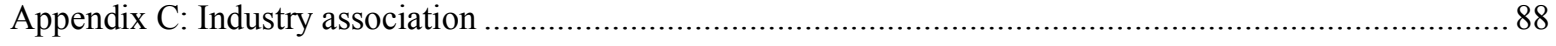

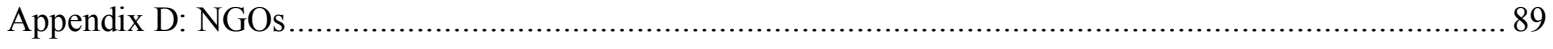

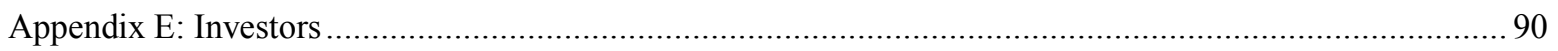

Appendix F: Date of Origin of Non-State Actors, Instruments, Institutions and Processes Addressing Gender

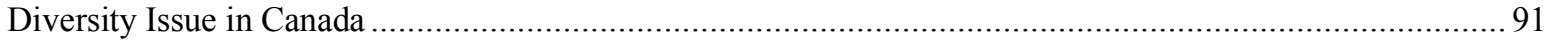




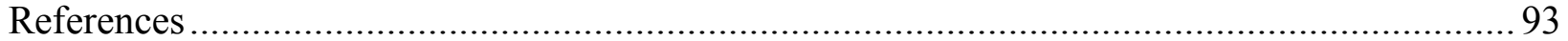




\section{List of Tables}

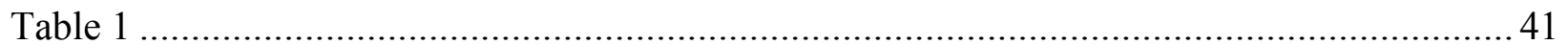




\section{List of Figures}

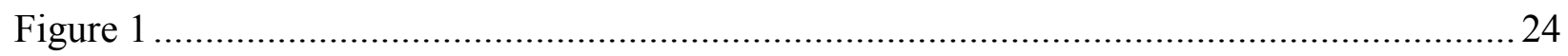

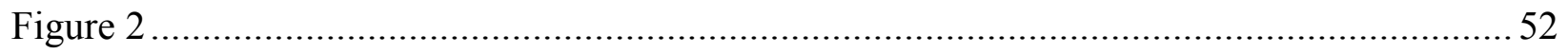

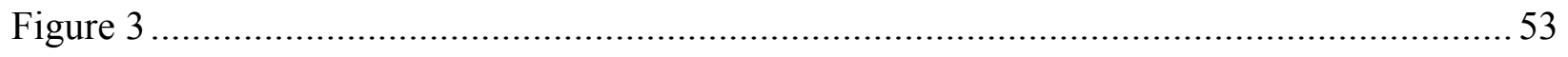

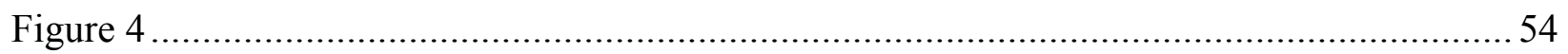

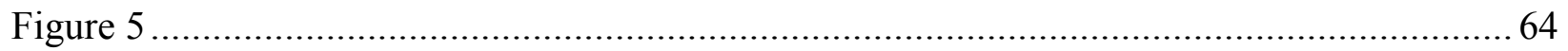

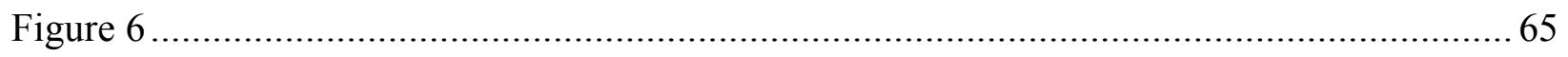

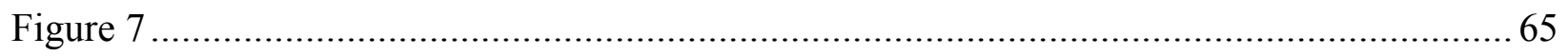

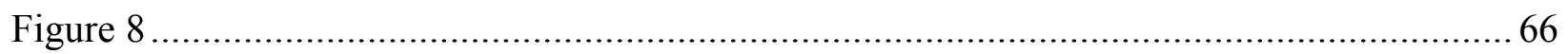

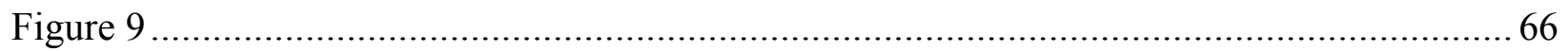

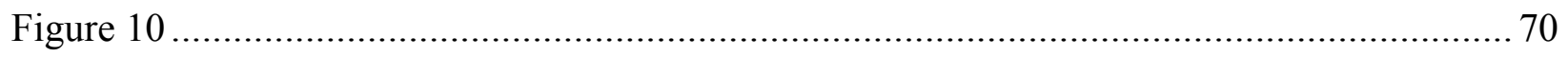




\section{Chapter 1: Introduction}

\section{Introduction}

Around the world and in Canada, gender diversity and more particularly the small number of women on corporate boards is an issue receiving considerable attention in the popular press (Lundy, 2020; Gupta, 2020) in business circles (Canadian Centre and Good Governance Alliance, 2018) and in scholarly literature (Carrasco et al., 2015; Grosvold et al., 2016; Chizema et al., 2015). While more on this will be said later in the thesis, it will briefly be noted here that there is considerable scholarly support for the proposition that increasing the number of women on boards will lead to better decision making (Campbell \& Mínguez-Vera, 2008).

In Ontario in 2014, the Ontario Securities Commission introduced a "comply or explain" law for Ontario public issuers, whereby firms must disclose the initiatives they have in place to promote gender diversity (understood in this thesis as referring to increasing the appointments of women to corporate boards) and if they have none, they must explain why (Ontario Securities Commission, 2015). Ontario was the first jurisdiction in Canada to adopt the comply or explain approach. Six other provincial jurisdictions in Canada followed the Ontario approach (Willey, 2017). As of January 1, 2020, the "comply or explain" rule also came into effect under the Canada Business Corporations Act (CBCA), where publicly traded companies under the CBCA have to provide disclosure in regards to four categories of underrepresented persons, including women (Canadian Business Corporations Act, 1985). Outside of Canada, a number of other jurisdictions have also adopted comply or explain laws (Ontario Securities Commission, 2015) but others have adopted a quota approach (Hughes et al., 2017).

A comply or explain approach does not require that corporations appoint women to their boards. Instead, it simply requires that businesses disclose information concerning their approach to gender diversity (or why they haven't put in place such an approach). In contrast, a quota approach mandates that a certain number or percentage of women be included on corporate boards. The comply or explain approach requires disclosure on the issue of gender diversity, but allows boards considerable leeway concerning what they actually choose to do, whereas the quota approach simply makes the decision for corporate boards, regardless of the preferences or situations of particular boards. The details of the comply or explain and quota approaches are the subjects of Chapters 2 and 3 of this thesis. 
It has been reported that in Canada, at the beginning of 2015, the percentage of boards seats held by women was $11 \%$ (CSA, 2019). Based on the latest report released on October $2^{\text {nd }}$, 2019, women hold $17 \%$ of board seats (CSA, 2019). This $6 \%$ change from $11 \%$ in 2015 to $17 \%$ in 2019 , represents a $54.55 \%$ increase in the number of women on boards over the 5 year period. According to a report released by the legal firm Osler in 2019, the percentage of Canadian corporations listed on the TSX with at least one woman on their boards rose from 54\% in 2016 to $62.7 \%$ in 2017 , to $68.7 \%$ in 2018, to $74.5 \%$ in 2019 (MacDougall et al., 2019). It is not possible to attribute causality between the introduction of the law in 2015 (the law came into effect in December 2014) and the above-mentioned gradual but noteworthy increases in women on Canadian corporate boards up to 2019. Some in Canada are now suggesting that there has not been enough progress with the comply or explain approach (Calleja et al., 2019; Catalyst, 2016; Halabi, 2019), and that a mandatory gender quota approach should be implemented (Willey, 2017).

The purpose of this thesis is to examine the experience with the comply or explain approach in Canada, to determine how practical and effective it is, when compared with the quota approach as used in other jurisdictions. As part of this research, the relevance of institutional and contextual factors bearing on gender diversity is considered. The thesis sets out to better understand which is the most practical and effective legal approach to increase gender diversity on corporate boards for Canada at this time, and what possible improvements could be made.

The terms "practical" and "effective" first need to be defined. Practical is defined as "(of an idea, plan, or method) likely to succeed or be effective in real circumstances; feasible" (Stevenson \& Lindbery, 2010). Effective is defined as "Successful in producing a desired or intended result" (Stevenson \& Lindbery, 2010). Note that the definition of practical includes the phrase "in real circumstances". The importance of this phrase is that it focuses on the "real circumstances" (i.e., the context) in which success in achieving a result is to be achieved. Drawing on these definitions, analysis undertaken here can be framed as follows: given current available information about how A and B approaches operate and based on understanding the socio-cultural, legal and broader institutional contexts (the real circumstances) in which the A and B approaches operate, it is more likely at a particular point in time that approach A rather than B will produce the desired result in the institutional context under consideration. 
There are significant challenges associated with making a claim that the comply or explain approach is practical and effective in achieving the goal of increasing the number of women on boards in Canada, when compared with a quota approach. Challenges include the following: (a) with respect to observed increases in numbers of women on boards of public issuers in Canada in the years since the comply or explain law has been introduced (e.g., a $54.5 \%$ increase from 2015 to 2019), there is an inability to conclusively attribute causality to the introduction of the comply or explain law as the reason for the increase, when other factors could also explain the increase (e.g., growing general societal acceptance of the idea that gender diversity is a positive attribute, regardless of whether there is a law in place encouraging board gender diversity); (b) the comparatively short period of time in which the law has been in operation, thus decreasing the ability to ascertain with certainty the longer term impact of the law; (c) the fact that in Canada, there does not exist a situation where one jurisdiction (e.g., province $\mathrm{X}$ ) has tried the comply or explain approach to address the issue of increasing the number of women on corporate boards, and another (province $\mathrm{Y}$ ) has tried the quota approach, so that a comparison of the two approaches in more-or-less similar institutional contexts can be undertaken; (d) differential access to information concerning the laws and institutional contexts of the countries where a quota has been adopted, when compared to accessible information concerning the Canadian situation (e.g., I do not speak Norwegian and therefore have been unable to get access to and gain a full appreciation of the "real circumstances" concerning quota law application and the institutional context of Norway, a pioneer in use of quotas in Europe).

Bearing these points in mind that detract from the ability to make inductive and deductive inferences concerning the practicality and effectiveness of the two types of laws operating in society, the thesis adopts an abductive mode of analysis. Pursuant to an abductive analytical mode, an attempt is made to interpret a phenomenon in terms of some theoretical frame of reference, "but the social constructed outcome does not constitute the only "true" interpretation or construction, but rather - given the theoretical frame of reference — constitutes a possible and meaningful interpretation or construction given the phenomenon of interest" (Blindheim, 2012, following Danermark et al., 1997). It has been said that with the abductive analytical approach there are no fixed or definitive criteria by which it is possible to assess or judge the validity of a study's interpretations and conclusions, so that the "results" of any particular study do not necessarily follow from the premises, but rather constitute a plausible interpretation, drawn from 
a body of facts (Blindheim, 2012, following Danermark et al., 1997). This thesis seeks to construct a plausible explanation for use of the comply or explain or quota approach in terms of its practicality and effectiveness in particular contexts.

In this thesis, the phenomenon of interest is: increased numbers of women on corporate boards of Canada, the role of the comply or explain approach in achieving increased numbers of women on corporate boards (with data for the early years of implementation of the law showing progress being made), and the practicality and effectiveness of this approach, when compared with adopting a quota approach. The theoretical frame of reference adopted for this thesis is institutionalist in nature, in which the institutional context in which comply or explain and quota approaches operate. As used in this thesis, "theory" is defined as "a statement of relations between concepts within a set of boundary assumptions and constraints" (Bacharach 1989). A "theoretical approach" as understood here is a perspective on social life derived from a particular theoretical tradition (Giddens 1989: 732). In this thesis, a "concept" is 'a set of properties that are associated with each other in memory and thus form a unit' (Gelman 1996: 118).

Synthesizing the work of a wide number of scholars, a summary description of key constituent parts of an institutionalist theoretical frame of reference was provided by Webb (2012):

An institutionalist perspective holds that firms are embedded in a larger social environment beyond the marketplace, which induces firms to adhere to social norms. An institution has been defined ....as "a relatively stable collection of practices and rules defining appropriate behavior for specific groups of actors in specific situations." Firms evaluate among options of potential behavior according to a "logic of consequences" (considering costs and benefits) or a "logic of appropriateness" (considering the alignment of options with conceptions by the firm of its role and identity). Rational choice institutionalism assumes that actors are motivated by a logic of instrumentality but that their actions are institutionally constrained. From this perspective, it is not just the presence of a norm or law that matters, but also the extent to which there is stakeholder monitoring of conformity with the norm or law, and some form of enforcement. Nonstate actors such as NGOs and networks of such actors.... can play important roles in monitoring corporate behavior and mobilizing pressure on firms to act in conformity with norms...... 
Webb (2012) goes on to say that:

[a] firm's ....."organizational field" consists of actors that purport to articulate acceptable behavior, including governments, NGOs, industry associations, and others. A firm's motivations to address concerns about its perceived legitimacy to engage in certain activities, may drive it to adopt practices and standards of its peers (isomorphic behavior, catalyzed through coercive, mimetic and normative mechanisms....) and to address distinctive local legal, cultural and other factors that may vary from one country to another. [Legitimacy has been defined] as "a generalized perception or assumption that the actions of an entity are desirable, proper, or appropriate within some socially constructed system of norms, values, beliefs, and definitions." (references omitted) This thesis adopts the above institutionalist description of the broader environment in which firms operate, and the importance of this broader environment in understanding how and why firms make particular decisions, since this broader environment constitutes a possibly important part of the "real circumstances" relevant to the practicality and effectiveness of a particular law.

The line of inquiry adopted in the thesis is as follows: (a) develop an understanding of how the comply or explain and quota laws operate, and in particular examine the distinctive characteristics of the two laws that could assist in gaining an appreciation of factors affecting the practicality and effectiveness of the two types of laws in particular institutional contexts; (b) develop an understanding of the array of socio-cultural factors that could assist in gaining an appreciation of the challenges and opportunities associated with women being appointed to corporate boards in particular institutional contexts; (c) identify facts about the Canadian institutional context in comparison with the institutional contexts of selected jurisdictions where the quota approach has been adopted that could assist in understanding the practicality and effectiveness of the comply or explain and quota approaches in particular institutional contexts; (d) through semi-structured interviews, collect and analyze the insights of persons from the private sector, government and civil society who are knowledgeable about the board diversity issue, concerning the practicality and effectiveness of the comply or explain law in Canada.

In brief, the interpretation being put forward in this thesis concerning the practicality and effectiveness of the comply or explain vs the quota approach for achieving increased participation of women on corporate boards in the "real circumstances" of Canada can be summarized as follows: 
(1) analysis of the distinctive features of the comply or explain law vs quota law as two different approaches to achieving gender diversity reveals that the comply or explain approach requires public disclosure by firms concerning how the firm is addressing gender diversity, but does not compel gender diversity, thus triggering a public airing among a variety of actors that may bear on decisions by individual firms concerning how they will approach the gender diversity issue. In contrast, the quota approach simply requires firms to appoint a stipulated number of women. Underlying these different approaches seems to be an assumption about how gender diversity should be achieved, with comply or explain involving a range of actors in implementation and starting from the premise that the consent of firms is important, and quotas starting from the assumption that only governments and companies need to be involved in implementation, and it is acceptable for firms to simply be required to have a certain number of women on their boards. In short, implicit in the two types of laws seem to be assumptions about the "real circumstances" that affect practicality and effectiveness of laws in different contexts.

(2) the ecological model (Cukier et al., 2014) and sustainable governance approaches (Webb, 2005) are theoretical approaches and concepts in the institutionalist tradition drawn on in this thesis to better understand the socio-cultural contexts that may have a bearing on norm implementation. In essence, they both are institutionalist perspectives, with the one adopting a individual-organizational-societal lens (ecological model), and the other focusing on the range of state and non-state rule-instruments, processes, institutions, and actors that can be involved in achieving particular societal objectives (sustainable governance). In short, analysis using the ecological model and sustainable governance approach suggest that a rich diversity of factors and actors are or could contribute to the adoption or non-adoption of particular norms.

(3) examination of the actual institutional contexts of Canada and Norway (the country selected in this thesis as a leading example of a quota approach country) suggest that there are socio-cultural and other observable institutional differences between the two jurisdictions that could affect the practicality and effectiveness of laws (e.g., differences in the degree of state support for programs that facilitate women participating in society, in evaluations of cultural dimensions in terms of power distance and masculinity pursuant to Hofstede's framework, in approaches to corporate social responsibility, and in participation of non-state actors, instruments, institutions and processes supporting achievement of board gender diversity). These observable differences help to explain why the comply or explain approach could be 
characterized as practical and effective to achieve gender diversity objectives in the Canadian context and the quota approach is seen as practical and effective in the Norwegian context.

(4) analysis of the semi-structured interviews of Canadian private sector, government and NGO participants knowledgeable concerning gender diversity that were undertaken for this thesis provides support for the practicality and effectiveness of the consensual, comply or explain approach in Canada at this time.

(5) bearing the above points in mind, the thesis puts forward the proposition that the comply or explain approach is practical and effective in Canada at this time, and the quota approach would not be, taking into consideration the distinctive characteristics of the comply or explain law when compared with a quota law, and taking into consideration the Canadian institutional context, which reveals distinctive institutional attributes compared with countries such as Norway which have adopted the quota approach, and also taking into consideration the insights derived from the semi-structured interviews undertaken as part of this thesis.

It should be noted that there are many other possible initiatives underway in a number of jurisdictions to address diversity in corporations more generally, not just women at the board level (MacDougall et al., 2017). For example, gender diversity could be addressed as part of broader research examining how to increase both gender and visible minority diversity (MacDougall et al., 2017). However, for the purposes of this thesis, the focus of this research is exclusively on corporate boards, and on the use of two possible approaches: comply or explain or quotas to increasing the appointments of women on corporate boards. It is possible that the results will reveal insights that will be useful to address broader related issues.

\section{Research Objectives}

Briefly stated, the research objectives of this thesis are as follows:

(1) To better understand the strengths, weaknesses, and operational characteristics of "comply or explain" and quota approaches, put in place to increase the number of women on corporate boards.

(2) To explore institutional and contextual factors (i.e., the importance of institutional settings, micro/meso/macro aspects within the ecological model (Cukier et al., 2014), and the array of state/non-state regulatory initiatives in operation, drawing on Webb (2005)'s sustainable governance framework that can assist in ascertaining the most practical and effective approach to increase the number of women on Canadian corporate boards). 
(3) To make recommendations as to which legal approach at this time would be the most practical and effective for Canadian jurisdictions.

\section{The Value of Gender Diversity}

As is evidenced by the fact that provincial and now federal comply or explain laws are now in operation across the country, governments in Canada have made the decision at the legislative level that increasing gender diversity is a public policy objective worthy of pursuing. This thesis starts from that premise. But before discussing research methods, limitations, and the structure of the thesis, it is useful to briefly review the scholarly literature concerning the value of gender diversity in the boardroom.

Some commentators have suggested that gender diversity is increasingly being valued and positively influences all areas of an organization because when an organization's workforce is diverse, the work environment itself can improve, leading to employees feeling both more comfortable and better supported (Kujala \& Pietiläinen, 2007). There have also been suggestions that a diverse workforce can lead to a greater variety of points of views and opinions, that can lead to increased creativity, innovation, and better decision making (Kujala \& Pietiläinen, 2007).

Women now make up half of the population and statistics suggest that they are entering a greater range of occupations, resulting in them having a variety of skills and background experience to bring to an organization (Adams, 2015). The reasoning that is being suggested by commentators in terms of the importance of having more women on boards, needs to be acknowledged. The first reason being provided by commentators is that it is seen as a competitive advantage (Adams, 2015). From a decision making standpoint, it has been suggested that female directors approach and analyze situations from different perspectives, tending to be more ethical (Kang \& Payal, 2012). Also, they place more importance on social concerns and activities than males do (Kang \& Payal, 2012). Furthermore, having women on the board and in executive positions is suggested to provide additional support to other women throughout the organization and indicate that they too can strive for promotions and reach high positions within the company (Kang \& Payal, 2012). This additional support can also mean women will be both more comfortable and confidant, knowing that any issues related to women in the workplace will be addressed with a female perspective in mind (Kang \& Payal, 2012). Having females in senior management positions can mean more time being devoted to diversity, than there would be if it were all males in those positions (Johansen \& Zhu, 2017). 
Another reason some commentators have given is the business case that can be made for having more women on corporate boards (Campbell \& Mínguez-Vera, 2008). The benefits suggested to make up the business case will be discussed. The first is that more diverse boards tend to result in a greater range of the population being represented, meaning that there will be a better understanding of both employee and consumer needs (Campbell \& Mínguez-Vera, 2008). This is related to the suggestion of some commentators, that taking into consideration a wide range of stakeholders during the decision making process, is a basic act of ethical behavior (MacDonald, 2009). It can be suggested that it is important to board decision making, to consider the interests of all affected stakeholders and when the board is more diverse, this can be achieved, while also more realistically reflecting consumer needs (Arfken et al., 2004).

Another potential proposed benefit associated with the business case is that with a range of perspectives, situations will be approached and decisions evaluated, in an improved manner (Campbell \& Mínguez-Vera, 2008). There is also research to suggest that gender diversity on boards also improves an organization's image, which has become increasingly important as consumers now look at this, among other things, when trying to determine which companies they are going to choose to buy their goods from (Campbell \& Mínguez-Vera, 2008). Investors can also choose to place importance on this as they evaluate companies based on their corporate governance, which includes gender diversity (Górriz, 2014). However, it needs to be noted that no direct causation can be proved between more women on corporate boards resulting in financial success, a correlation can be seen but not a causation (Górriz, 2014).

Despite the suggested benefits for gender diversity on boards, arguments against increased diversity do exist and need to be acknowledged. There are commentators that take the position that the wider range of opinions can negatively impact communication because if a board was composed of all males, then it is likely that they would have similar opinions and decisions would be made with greater ease (Campbell \& Mínguez-Vera, 2008). A wider range of opinions can also lead to conflict when it comes to discussion and decisions making, which can be regarded as ineffective (Campbell \& Mínguez-Vera, 2008).

\section{Research Methods}

There are two research methodologies being employed for this thesis, they are: (1) a review of laws, policies, academic articles, and other material pertaining to gender diversity, more specifically the "comply or explain" and gender quota approaches, as well as, impactful 
institutional and contextual factors. A literature review was used in the discussion and analysis in Chapters 2, 3, 4, 5, and 6; (2) semi-structured interviews with knowledgeable persons working in the government, private sector and social society, to gain insight on what their understanding is, in terms of the existence of any implementation issues, as well as, any other factors that might bear on female representation. Discussion and analysis of the semi-structured interviews is in Chapter 7 of this thesis. These methodologies, both the literature review and semi-structured interviews, as well as, the limitations associated with each one, will be described and discussed in greater detail below.

\section{Literature Review}

The literature review undertaken for this thesis involves an analysis of laws, policies, academic articles and other material pertaining to gender diversity. It specifically looks at the "comply or explain" approach as a regulatory framework and the gender quota approach as a legislative means. Canada's experience with comply or explain will be the focal point of this approach's analysis in this thesis paper. As for gender quotas pertaining to women on corporate boards, they have been utilized in Europe, therefore, references will be made to European laws and examples and Norway will be the focus of analysis given that it was the first European jurisdiction to adopt a quota approach to increasing the appointment of women on corporate boards. The laws, policies, articles and other material are used to better understand how the two laws work and identify the strengths and weaknesses associated with both approaches.

Academic articles and reports will be used in the analysis of institutional contexts, the ecological model, and sustainable governance, as they can help improve the understanding of what the most practical and effective approach is, in terms of gender balance on corporate boards. Initial findings suggest that the current "comply or explain" regulatory framework in place in Canada, has shown change in terms of numbers and company policy, but there are gaps within the framework that may be halting greater improvement. There are a broad set of factors that can impact gender diversity in the boardroom and bring light to any implementation issues that have a bearing on female representation but these factors can also indicate what kind of approach is best suited for a jurisdiction. These gaps can be addressed with changes to the framework itself but also by the use of sustainable governance, which involves state and nonstate rule instruments, processes, institutions and actors. 


\section{Semi-Structured Interviews}

Semi-structured interviews are the second methodology for this thesis. This involves conducting interviews with key participants from the government, investor, private sector, non-governmental organizations (NGOs) and an industry association, related to the gender diversity. The participants included: three participants from the provincial government, three participants working from the investor sector, four in the private sector, two that are board members and two that work closely with the board, two participants from NGOs, and one participant from an industry association. The purpose of conducting the interviews with the selected knowledgeable persons was to gain additional insight on what they know and think about the two legal approaches, in order to supplement what was found in the literature. Interviews were chosen as the method of choice to gain insights from knowledgeable persons because participants can share more information as they are given more time to elaborate and there is additional flexibility in how participants answer. Semi-structured interviews were specifically selected as being best suited for this thesis because participants from five different sectors were interviewed, therefore their experiences, opinions, and thoughts, do vary based on their sector, as well as, position within their organization. The interviews were conducted either in person or by phone, if more practical for the participant, and took around one hour. As five different sectors were interviewed, each sector had its own set of questions. A copy of the interview questions used for each sector, can be found in the appendix.

As the participants interviewed were from business, government and the private sectors, the questions consisted of some that were the same across all sectors and others that were sector specific. There were common themes related to gender diversity and specifically women on corporate boards. The themes were the following:

1. What are the strengths and limitations to the current "comply or explain" approach?

2. What are possible changes to the current "comply or explain" approach?

3. What is the general opinion of the gender quota approach and is it something Canada should consider?

4. What are some underlying factors that negatively impact female representation on boards?

5. What is the importance of the media and organizations like investors, NGOs, and industry associations, in addition to the law, in the achievement of diversity? 


\section{Limitations}

I have already noted some of the significant limitations of research such as, including challenges concerning causality and attribution to any one particular factor, the fact that the Canadian comply or explain approach has only been in operation for a short time, and an "apples to apples" comparison of two comparable Canadian provinces, one using quotas, the other using comply or explain, does not exist. I should also note that due to the fact that Ontario was the first Canadian jurisdiction to adopt the "comply or explain" approach, and other jurisdictions followed, Ontario is referred to more than other jurisdictions, and the Canadian experience is used as the focal point of this analysis. I also earlier noted that given that I do not speak Norwegian (the focus of my analysis in terms of a jurisdiction that has adopted the quota approach), I have not been able to access and understand comparable amounts of information concerning the practicality and effectiveness of the Canadian and Norwegian approaches.

In terms of conducting semi-structured interviews, the results collected are limited to the number of respondents interviewed and this limits how representative of the population the results will be. Due to limitations in terms of both time and resources, only a small group of participants could be interviewed. Therefore, it is important to note that information gathered from the interviews should not be considered as a conclusive representation of all Canadian viewpoints on the issue of gender diversity. The information gathered provides us with an understanding of the views held concerning the practicality and effectiveness of the comply or explain approach and the quota approach, specifically concerning as applied to gender diversity on corporate boards.

It is for these reasons that the abductive analytical approach has been adopted, whereby an attempt is made to develop a plausible explanation for why the comply or explain approach is adopted as practical and effective in Canada, but this explanation should be the subject of further exploration on the basis of enhanced data that was not available to me.

\section{Structure of the Thesis}

In general, the thesis is organized around understanding how the "comply or explain" and quota approaches work, as well as, the many suggested reasons that exist for increased female representation on boards and in executive positions. This thesis also discusses and analyzes various institutional contexts and contextual factors, that include utilizing both the ecological model and sustainable governance framework, in order to improve understanding of what is the 
most practical and effective approach to enhancing gender balance on corporate boards for a particular jurisdiction.

In Chapter 2, this thesis analyzes how the "comply or explain" approach functions, key features and characteristics, the strengths and weaknesses said to be associated with it, as well as, look at the Canadian experience in greater detail. Chapter 3 examines gender quota approaches, distinctive attributes, the strengths and weaknesses said to be related to it, as well as, how gender quotas have worked in Europe, with an specific focus on the Norway experience. Chapter 4 is an assessment of how increased participation has been achieved in Canada in two different contexts, the Supreme Court of Canada and Canadian law schools. Chapter 5 is an analysis of the ecological model, which covers a broad set of factors in its three levels, micro (individual), meso (organizational), and macro (societal). Chapter 6 is an examination of sustainable governance institutionalist approach, and its application to the comply or explain law in Canada. Chapter 7 discusses key insights from the semi-structured interviews that were conducted with participants from five different sectors. Then conclusions and recommendations follow.

\section{Value of the Research}

This research can potentially be beneficial to both state and non-state actors in terms of better understanding how to approach gender diversity on corporate boards in terms of different legal approaches and the importance of institutional contexts. Through the analysis that takes place in this thesis, the current "comply or explain" approach is analyzed in terms of its distinctive attributes, strengths, weaknesses and possible approaches for improvement. The gender quota approach is similarly examined. The best option may be a variation of comply or explain, with some of the gaps that currently exist in the approach, being addressed. Then two institutional contexts will be analyzed in order to see how gender representation has been addressed in other sectors. The research suggests that different legal approaches to achieving greater participation of women on boards have features which call for less or more involvement and participation of non-state actors in implementation of the goals of the legislation, and these features connect with institutional factors that assist in explaining the practicality and effectiveness of different legal approaches in different jurisdictions.

In summary, with a view to better understanding which is the most practical and effective approach for Canada at this time, the purpose of this research is to conduct a comparative analysis of the comply or explain experience in Canada and the gender quota experience 
elsewhere, while also exploring the relevant institutional and contextual factors that have a bearing on gender diversity (e.g. using the ecological model and sustainable governance concept). Possible recommendations on how existing approaches could be improved are also put forward. 


\section{Chapter 2: The "Comply or Explain" Approach}

This chapter discusses how the "comply or explain" approach works, its distinctive attributes and its associated strengths and weaknesses as identified by commentators. It also forms part of the examination into how practical and effective the law has been in Canada since its implementation (supplemented by other chapters, such as the semi-structured interviews that are the subject of Chapter 7). As noted in the introduction, comply or explain laws do not actually require that corporations appoint women to their boards. Rather, the laws require disclosure concerning how boards are addressing the issue.

This chapter looks at ways in which the comply or explain approach could be characterized as a practical and effective driver of positive change in the Canadian context but also highlights possible gaps and areas for improvement that could make the approach more effective. While recalling the attribution and causality issues discussed in Chapter One, analysis in this chapter suggests that the "comply or explain" approach seems to be at least a factor that is driving Canadian corporations to have more gender diverse boardrooms. But the progress has been considered by some to be slow (Calleja et al., 2019; Catalyst, 2016; Halabi, 2019), and is discussed, there are aspects that could be improved. If these improvements were made, the suggestion is made here that approach could be more effective at achieving gender diversity, and perhaps in a more rapid manner.

\section{The "Comply or Explain" Approach: What it Entails and How it Works}

As previously noted, comply or explain laws require that companies disclose the initiatives they have in place to promote gender diversity and if they have none, they must explain why (Willey, 2017). They must also disclose how many women they have on their boards (Willey, 2017). Companies are required to outline both the provisions they have and have not complied with, as well as, provide an explanation for any non-compliance: this is the "explain" portion of the disclosure framework (Arcot et al., 2010). The suggested objective behind requiring this disclosure is so that both stakeholders and investors have increased transparency in relation to female representation on boards and in executive positions (Canadian Securities Administrators [CSA], 2019). Organizations will be found to be in compliance with this policy if they either adopt the recommended practices or if they explain why they have not (Salterio et al., 2013). This may entail discussing alternative practices they have implemented or simply explaining why they have none at all (Salterio et al., 2013). If companies choose to not adopt the recommended 
practices and also do not provide an explanation for that, they are in violation of the comply or explain (Salterio et al., 2013). Some commentators have suggested that due to its particular characteristics as a public disclosure mechanism the comply or explain approach may over the long run have considerable impact on culture and lead to significant societal change (Klettner et al., 2016).

Suggestions have been made that implementation of the comply or explain approach has been in some ways weak, focusing on explanations and monitoring aspects. Explanations are said to be significant to this approach because if companies choose to not have any policies in place, if they simply explain their reasoning behind this decision, then the comply or explain approach has been followed, since the issuers are still disclosing as required (Nerantzidis, 2015). However, commentators have pointed out that explanations can be nonspecific and in that not meet the purpose of the "explain" part of the law (Galle, 2016). Later in this chapter, proposed weaknesses and issues of this approach will be discussed (Sealy, 2014).

The United Kingdom is another country that has implemented a comply or explain approach to increase the appointment of women on corporate boards. Their experience with the approach found non-compliance from less than $10 \%$ of issuers, indicating that compliance is generally high (Arcot et al., 2010). However, there are indications that they too have problems with explanations and monitoring (Arcot et al., 2010). Commentators suggest that little importance is placed on the kind of explanations being provided and that shareholders and the market in general appear to not be paying attention to the explanations (Arcot et al., 2010).

We see here that there can be three outcomes in terms of company adoption of the "comply or explain" approach. The first is where an issuer adopts the recommended set of best practices (Salterio et al., 2013). The second is the issuer has chosen not to adopt the recommended best practices but has explained their alternative practices that are still aimed at achieving gender diversity or explained why they have no other practices in place (Salterio et al., 2013). Finally, the third possible outcome is that the issuer did not meet the disclosure requirements (Salterio et al., 2013).

\section{The Strengths and Weaknesses of Comply or Explain}

As alluded to in Chapter One, there has been gradual but noteworthy improvements in the percentage of women on corporate boards since the time the "comply or explain" approach has been introduced in Canada. The first strength is that this approach does not compel a particular 
number of women to be on the board (Klettner et al., 2016). Rather, it prompts such changes of behaviour and then it is up to the individual targeted entity to change practices if they are persuaded of the merits of so doing. It is consensual in nature: thus, organizations are agreeing to engage in a particular form of behaviour because they want to, not simply because the law requires it. It has been said that consent is the most effective form of governance.....

.....since it is most likely to lead to controlled behaviour, even when formal monitoring and enforcement mechanisms are weak or ineffectual. By contrast, non-consensual decision making, while technically possible for governments, increases the potential for grievance. And the more widespread and the more intense the feelings of grievance, the more difficult it is to control behaviour. (Purchase, 2004)

Doing something because one is told to do it can lead to resentment, and legalistic "I'm-onlydoing-this-because-I-have-no-choice attitudes which could undermine sustainable achievement of the aims of the law.

Closely related to this is the second strength, which is that it also appears to allow for increased flexibility, which enables firms to work out the best strategy for addressing the issue (Luo \& Salterio, 2014). Companies can create and implement policies that are tailored to their organization, which can potentially increase organizational efficacy (Luo \& Salterio, 2014). This can result in diversity practices and disclosure policies that are customized to the organization and that the organization wants to engage in and can also lead to better financial performance (Luo \& Salterio, 2014). This having been said, it should be recalled no direct causation can be proved between having more women on corporate boards and financial success: a correlation can be seen but not a causation (Górriz, 2014).

When the comply or explain approach was implemented in the United Kingdom, it was said that it was done so because companies needed to address gender equality but believed that it should be done by each individual issuer, tailored to their organization (Sealy, 2014). When the comply or explain approach is used, the issue of increasing the number of women on corporate boards is being addressed, but in a manner that gives companies increased discretion to implement changes as they see best fit for their organization, in a more gradual manner (Labelle et al., 2015). Some commentators suggest that this also means that with the use of comply or explain, there can be a more positive impact on cultural change, as firms are given the discretion to create policies and are not forced to have a particular number of women on their boards 
(Klettner et al., 2016). This is why some suggest that this approach is considered to be better in the long run (Klettner et al., 2016).

There are also suggested weaknesses to this approach. As previously mentioned, explanations are an important component of the comply or explain model. Explanations can be said to be key to this approach, however, research suggests that as commonly formulated, some explanations provided by firms tend to be non-specific and fail to be adequately transparent (Galle, 2016). When explanations are provided they can be lacking in specificity. Some companies seem to be purposely choosing to disregard the explain portion of this approach (Arcot et al., 2010). Non-meaningful explanations can undermine the effectiveness of the comply or explain model (Willey, 2017). If a key goal of the comply or explain model is improved transparency, then ambiguous explanations do not achieve this goal (Galle, 2016).

Another suggested weakness to this approach pertains to the penalties (Sealy, 2014). When companies fail to comply or fail to explain why they chose not to comply, the penalties for non-compliance (e.g., failing to disclose) are small. In Ontario, for example, the penalty for noncompliance for failing to disclose is not a penalty per say,_comments are raised in regards to failure to disclose, then notes are left asking for future disclosure, and finally, there is a followup (Ontario Securities Commission, 58-101, 2014). This brings a question to light, what would drive companies to comply if there are not significant penalties for non-compliance? This could work against the success of comply or explain and its enforcement (Sealy, 2014). The role of non-state actors in promoting compliance is discussed later in the chapter.

The Dutch also use the "comply or explain" approach and a study conducted on how it was received in their jurisdiction, ranks the explanations provided, as well as, identifies the most common ones given (Galle, 2016). The study looked at explanations over a two year period (Galle, 2016). Some explanations provided were that companies were choosing to put emphasis on diversity and were taking action to towards this (Galle, 2016). Some companies chose to say nothing at all and then there were companies that stated that they had not looked into any provisions yet (Galle, 2016). Some companies also provided the explanation that there were no qualified women available for the positions (Galle, 2016). For the second year of the study, one of the top five explanations had changed. The new explanation provided, was that if male and female applicants were equally qualified, females would receive preferential treatment (Galle, 2016). This new explanation indicated that within a year, there was an improvement from 
comply or explain, in terms of how companies were filling board positions (Galle, 2016). The quality of explanations were also assessed. The study found that over $50 \%$ of companies provided general explanations, but only around $10 \%$ gave specific reasoning in their explanations (Galle, 2016).

Even though statistics indicate that comply or explain can lead to an increase in the percentage of women on corporate boards, some commentators suggest that this may stop at the board level and this can be seen as another weakness (Klettner et al., 2016). There is no guarantee of a trickledown effect to other levels of an organization (although this criticism applies equally to gender quotas) (Kelttner et al., 2016). Finally, even though there are visible improvements from the use of the "comply or explain" approach, they are gradual, from one year to another (Galle, 2016).

In Australia, they also have a comply or explain approach but their model goes one step further. They require companies to create a policy related to diversity and to disclose the details of that policy (Willey, 2017). They also specify that the policy should include the board establishing objectives for attaining gender diversity and that those objectives be assessed, as well as, progress evaluated, on an annual basis (Willey, 2017). Companies have to comply with this disclosure or they have to explain why they are choosing not to (Willey, 2017). The difference with the Canadian "comply or explain" approach is that companies are not required to have a policy related to gender diversity, they just need to provide an explanation for why they do not (Willey, 2017). This may be something that could be considered as an addition to the Canadian model, as it may improve the effectiveness of the approach, while still not pressuring companies to have a certain number of women on their boards.

There are certain distinctive characteristics of the comply or explain approach which may indirectly address some of the suggested weaknesses discussed above (Webb, 2019). Because a comply or explain approach is in essence an information disclosure law, it could be said that the act of disclosure sets in motion a process involving other non-state actors, instruments, and institutions that can assist in galvanizing positive conduct and discouraging negative conduct by the disclosing businesses. Once a corporation publicly discloses the legally required information about gender diversity (e.g., "our goal is X by 2025," "we have Y on our board," "we have decided against having a policy to encourage diversity on our board"), at that point, a set of other interested actors (e.g., shareholders and investors, the media, non-governmental organizations 
interested in promoting diversity, business organizations, researchers, and others) are in a position to interpret, amplify that information and otherwise directly or indirectly engage with the corporation in question.

For example, consider this comment from SHARE, an advocacy organization that submits shareholder proposals to companies on societal issues they perceive as important: When voting proxy ballots, SHARE votes against the nominating committees of boards with no female directors and no diversity policy. We voted against directors at 21 companies for this reason during the second quarter of 2018.....Constellation Software is another company that has no women on its board or in its executive ranks. The Fonds de solidarité FTQ filed a proposal with the company, asking it to adopt a formal policy on board diversity and plans for increasing the number of women on its board and in its upper management. The proposal won the support of $49.16 \%$ of Constellation's shareholders at the company's annual meeting on 26 April. Following the vote, the company asked SHARE for examples of board diversity policies and best practices. This is an encouraging sign that the company may develop its first diversity policy (SHARE, 2018).

In the Constellation Software example, what can be seen is how: (1) disclosure of perceived unacceptable behaviour led to (2) non-state action (a shareholder proposal), that in turn led to (3) engagement by the company on this issue, and (4) praise for the company for changing its behaviour.

Engagement can take the form of: diversity-oriented thinktanks or other organizations making comparisons of the company response with guidelines or benchmarks that they have created (Canadian Gender and Good Governance Alliance, 2018); media and other organization can engage in "good or bad" rankings of a company's diversity response with others (Catalyst, 2020); shareholder proposals can be made by investors urging particular action re: diversity (MacDougall et al., 2017) and awards for perceived outstanding behaviour can be provided (Catalyst, 2019). In so doing, the adequacy of a business response and the incentives or disincentives for positive diversity behaviour are the subject of action by nonstate entities beyond the immediate legal sanctions.

In effect there is structured nonstate action in support of the goals of the comply or explain law that is spurred by the disclosure. And there is engagement in a "norm conversation" 
(Webb, 2004) in the broader society that is not needed when companies are simply required to meet a quota. There is thus a socio-cultural and extra-legal sphere of normative action that is promoted by the disclosure law, in keeping with the ecosystem approach (Cukier et al, 2014) and sustainable governance concept (Webb 2005) that are discussed later in this thesis.

The logic model of an information disclosure law is quite different from a conventional command and control law that simply requires certain behaviour. An excellent description is provided by Stephan (2002), who states the following:

At its most basic, information disclosure serves as a form of intervention by government in the negotiation process between two (or more) social actors. Government in these cases serves as a "facilitator" rather than a "coercer" ..... These actors include corporations, corporate shareholders, citizens (unorganized or as members of community or grassroots groups), professional interest groups, state or local public officials, and the media.....(references omitted)

Note here the key role played by non-state actors, as they essentially become important parts of the aforementioned "norm conversation" (Webb, 2004). Stephans (2002) goes on to note:

The standard concern is that the [targeted activity] may in some way negatively affect the public..... In cases such as this, the government does not regulate [the problematic activities of] private industry but rather allows other actors to be made aware [of particular behaviour] ..... It is then the right and responsibility of these other actors to deal with these businesses as they see fit. Other actors could use the tools of government (e.g., lawsuits or public policy pressure), the market (e.g., consumer boycotts or shareholder reactions), or civil society (e.g., media exposure or political protests) to negotiate change. (references omitted)

The aforementioned example provided by SHARE concerning Fonds de solidarité FTQ filing a shareholder proposal against a company that did not disclose a policy that in turn triggered engagement with that company is exactly the sort of societal involvement in the construction and implementation of the "need for women participation in corporate decision making" norm that is implicit in the comply or explain approach. Greater elaboration on this important role played by non-state actors in support of comply or explain laws and a mapping of the interconnections among actors, instruments, institutions and processes is provided in the chapter on sustainable governance included later in the thesis. 


\section{The "Comply or Explain" Approach Implementation to Date}

In Ontario, Canada, "comply or explain” was implemented by the Ontario Securities Commission in 2014 (Willey, 2017). Companies listed on the Toronto Stock Exchange (TSX) and other non-venture issuers are expected to follow this regulatory framework (Willey, 2017). In 2014, amendments were made to the Form 58-101F1 Corporate Governance Disclosure of National Instrument 58-101 Disclosure of Corporate Governance Practices (the disclosure requirements) (CSA, 2019). These disclosure requirements/rules were enclosed in the "comply or explain" approach implemented by the OSC (Halabi, 2019). This policy was first adopted in Ontario, then six other jurisdictions followed; Alberta, Manitoba, New Brunswick, Nova Scotia, and Saskatchewan (CSA, 2019).

There are five areas in which disclosure is required to be provided and these include the mechanisms suggested to be implemented by companies. The first area is the percentage of women on the board of directors and in executive positions (CSA, 2015). The second area is targets, particularly disclosing if there are any targets in place in relation to women on the board and executive positions (CSA, 2015). The third area of disclosure is board policy, whether there is a written policy in regards to the nomination of female directors (CSA, 2015). The fourth area is board renewal and whether there are director term limits or any other instruments in place related to board renewal (CSA, 2015). Finally, the fifth area is in regards to director identification, the selection process, and appointments of executive officers, in terms of whether the representation of women is considered in these areas (CSA, 2015). For all areas except for the first, if the issuer does not have anything in place, they must provide a reason as to why not (CSA, 2015).

Companies must disclose the percentage of women on their boards and in executive positions, then also the above stated policies, initiatives, mechanisms, and targets they have in place to address gender diversity (CSA, 2015). This makes up the "comply" portion of the framework (CSA, 2015). If the said policies, initiatives, mechanisms, or targets are not adopted, or alternative measures in relation to female representation, are not considered, they have to explain why that is (CSA, 2015). This is the "explain" portion of the framework (CSA, 2015).

When the first progress reports came out in 2015, the percentage of board seats held by women was $11 \%$ (CSA, 2019). For 2016, the percentage of board seats held by women was 12\%, then for 2017 , it was $14 \%$, then for $2018,15 \%$, then finally for $2019,17 \%$ of boards seats were 
held by women (CSA, 2019). The $6 \%$ change from $11 \%$ in 2015 to $17 \%$ in 2019 , represents a $54.5 \%$ increase in the number of women on boards, over the 5 year period. In $2015,49 \%$ of issuers had at least one woman on their boards, by 2019, this was at 73\% (CSA, 2019). In terms of issuers with three or more women on their boards, in 2015 , there was $8 \%$, this rose to $15 \%$ by 2019 (CSA, 2019). From 2015 to 2018, there were no female board chairs, however in 2019, 5\% of chairs of boards were women (CSA, 2019).

In terms of targets, in $2015,7 \%$ of issuers had implemented targets for women on boards, in 2019, this was at 22\% (CSA, 2019). Then in terms of policies, in 2015, 15\% of issuers had implemented a policy in relation to female representation on boards, by 2019 , this rose to $50 \%$ (CSA, 2019). For term limits, in 2015, 19\% of issuers had implemented term limits, in 2019, this was $21 \%$ (CSA, 2019). Statistics do indicate that issuers with targets and/or policies, do have more females on their boards (CSA, 2019). Issuers with targets in place had 24\% women on their boards, versus $15 \%$ women on the boards of issuers without targets (CSA, 2019). Then for issuers with policies, they had 21\% women on their boards, versus $13 \%$ women on the boards of issuers without policies (CSA, 2019).

The Canadian law firm Osler has released a report every year, for the past five years on diversity disclosure practices for women in leadership roles in companies listed on the Toronto Stock Exchange (TSX) (MacDougall et al., 2019). In itself, these annual reports constitute an example of the value of the disclosure law, since it creates the data that then can become the basis for the reports, and in turn those reports can become the basis for societal involvement in implementation of the underlying norm in favour enhanced corporate board gender diversity. In the Osler reports, the percentage of boards with women are tracked. In 2016, there were 54\% of boards with women, then in $2017,62.7 \%$, then in $2018,68.7 \%$, and finally for $2019,75.9 \%$, which equals to 499 companies, of the 657 companies that reported (MacDougall et al., 2019). This can be seen in Figure 1 below. 


\section{Figure 1}

Percentage of Boards With Women

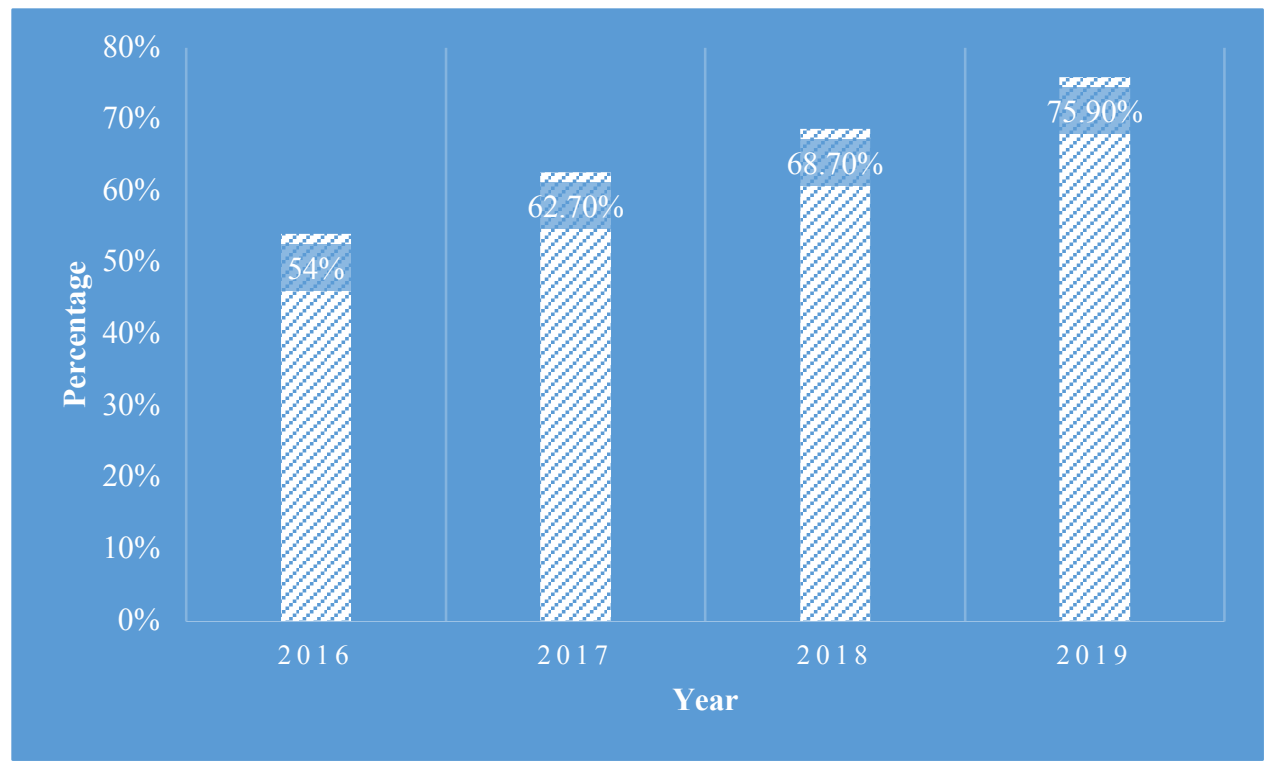

(MacDougall et al., 2019).

As previously mentioned, one of the main suggested problems with the "comply or explain" approach are the poor quality of explanations. For issuers that chose not to implement targets, the main explanation provided is that "candidates are selected based on merit" (CSA, 2017 , p. 16). $64 \%$ of issuers provided this reason in 2017, an explanation that was previously discussed and by some commentators, said to be alarming (CSA, 2017). As previously mentioned with the discussion of the Dutch study, one of the top explanations provided was that there are no qualified women (Galle, 2016). Giving the reasoning that candidates are selected based on merit, can signal the belief that there are simply not enough female candidates. Studies have found that men tend to believe that gender parity is an issue because there are not enough qualified women (Halabi, 2019). However, often times candidates are selected based on the networks of those already sitting on the board and their networks often do not include many women (Halabi, 2019). This can also lead to issues related to gender bias. It has been suggested that often times certain skills and work experience are associated with a specific gender, this can impact decision making and can also be present when issuers are providing explanations (Halabi, 2019). Board and executive positions often times require certain experience from candidates, however, research suggests that women tend to not have the same opportunities as men and therefore may not have those experiences, which can leave them out of the running (Halabi, 
2019). This can leave out a group of female candidates that may not bring the asked for experiences, but bring others, as well as, significant skills, that could be useful to companies, therefore organizations could be missing out (Halabi, 2019). Gender bias and stereotypes will be discussed in detail in Chapter 5. The active role of non-state actors in countering problematic practices and attitudes is an important part of the comply or explain approach. This point was alluded to earlier and will be discussed in detail in the chapter on sustainable governance.

While it cannot be said that comply or explain has failed to bring about change, some commentators have expressed concern about the progress to date (Halabi, 2019). According to this author, it will take more than 30 years to reach gender parity and this brings about the question of whether or not more stringent measures are needed (Halabi, 2019).

In summary, this chapter has analyzed how the "comply or explain" approach works, the strengths and weaknesses associated with it, as well as, how effective it has been. It has been shown that the law adopts a consensual approach towards achievement of the objectives of greater participation by women on corporate boards. Consent has been described as the most effective approach to governance, since those who agree to engage in behaviour are not simply doing so because it is required. Also discussed was the potential of the disclosure law to galvanize action by non-state actors in support of the objectives of law. In essence, the logic model underlying the comply or explain approach is that in the specific context in which the law operates, it is practical and effective for government to facilitate a norm conversation on a particular norm, and then allow other actors to construct the support for that norm. This logic model stands in contrast with the logic model of command and control laws that simply impose a behaviour change. From the time that the "comply or explain" approach was introduced in December, 2014 to 2019, there has been a gradual but significant increase in women on the board, as might be expected with an approach that allows boards to work out their own way of bringing women on the board rather than requiring a specific number of women on boards. 


\section{Chapter 3: The Gender Quota Approach}

This chapter discusses the gender quota approach: how it works, its key attributes and characteristics, what are said to be its strengths and weaknesses, and its effectiveness, focussing on the experience in Norway, the first country to implement a gender quota for women on corporate boards (Hughes et al., 2017). In Europe, a gender quota is a legal approach that has been used first for women in politics (Paxton \& Hughes, 2015) and then for women on corporate boards (Labelle et al., 2015). Results discussed here suggest that the gender quota approach can lead to an increased number of women on boards and within a short length of time but cultural factors distinctive to Norway might play a role that are not necessarily transferable to Canada.

\section{The Gender Quota Approach: How it Works focusing on the European-Norway}

\section{Experience}

The gender quota approach is a legislative approach that has been applied to corporate boards (Labelle et al., 2015) whereby government sets a minimum percentage of women that must be on corporate boards. Failure to achieve this can result in a penalty (Hughes et al., 2017). There may be a transition period provided, usually ranging between three to five years, for companies to comply with the law (Hughes et al., 2017). Gender quotas were initially used to increase the percentage of women in politics, then later they were applied to increase gender diversity on corporate boards (Paxton \& Hughes, 2015).

The quota approach has been used both with and without sanctions (Kirsch, 2018). Norway, France, Belgium, Italy and Germany have a legislated corporate board quota in place that involves sanctions for failing to comply (Kirsch, 2018). These sanctions can include, warnings, fines, directors facing suspension of their benefits, the cancelling of board elections, and even court ordered dissolution of companies (Kirsch, 2018). In France, their quota required issuers to achieve $40 \%$ by 2017 and in Germany, the requirement was to reach $30 \%$ by 2017 . Both countries were able to achieve the required percentage by the set date (MacDougall et al., 2017). The Netherlands, Spain, Iceland, India, Malaysia, and Israel have quotas in place but without sanctions (Kirsch, 2018).

Gender quotas tend to often be linked to Norway, as they were the first country to implement a gender quota for women on corporate boards (Willey, 2017). In Norway, at the end of 2002, before the implementation of the quota, the percentage of women on public company boards was 10\% (Dale-Olsen, Schøne, \& Verner, 2013). In 2003, the Norwegian government 
implemented the legal quota that required companies to have a minimum of $40 \%$ of each gender on their corporate boards (Øystein Strøm, 2015). State-owned firms were required to comply by 2006, while publicly traded companies had until 2008 to achieve compliance (Terjesen et al., 2015). Therefore, by 2008 , businesses had to have $40 \%$ women on their boards and they were able to reach that representation within the set time frame (Øystein Strøm, 2015). Norway's penalties for non-compliance range from companies paying fines until they comply, to companies being dissolved (Terjesen et al., 2015). Prior to implementing a quota, Norway had a voluntary approach in place for increasing women on corporate boards (Labelle et al., 2015).

\section{The Strengths and Weaknesses of Gender Quotas}

The gender quota approach does lead to the achievement of visible results in a short length of time, therefore there are some strengths associated with this approach. Quotas are said to be effective because they can take a company that has evident inequality and underrepresentation of women, and quickly eliminate the imbalance (Adams, 2015; Isidro \& Sobral, 2015). They are considered to be effective because companies must hire women, therefore there is no need for discussion (Klettner et al., 2016). Quotas force companies to put in the effort to find qualified women to fill board positions (Klettner et al., 2016). It is important to acknowledge that this approach is successful because companies have no choice but to comply (Nacevska \& Lokar, 2017). This approach can quickly address gender inequality, which is why some commentators suggest that it is better in the short run (Klettner et al., 2016). The change achieved from quotas is also suggested to benefit female advancement throughout the entire organization as they can also start to break down existing barriers (Isidro \& Sobral, 2015).

As previously mentioned in Chapter 1, there are suggestions that having more women on corporate boards can improve decision making, as a greater variety of opinions and experiences are brought into the process and in turn can lead to more organizational effectiveness (Wang \& Kelan, 2013). With a work environment that is gender diverse, some commentators may take the position that this will lead to increased productivity and creativity (Hughes et al., 2017). This is related to the business case, also discussed in Chapter 1, as it can also be made for gender quotas. With increased female representation on boards, it is suggested that decision making can improve, as can financial success, and the organization can be more ethically and socially responsible (Isidro \& Sobral, 2015). Once again, it should be noted that no direct causation can 
be proved between more women on corporate boards resulting in financial success, a correlation can be seen but not a causation (Górriz, 2014).

By simply imposing by law that a percentage of the board be women, quota laws have the clear advantage over comply or explain disclosure laws, in the sense that there is no leeway for businesses to do anything other than meet the quota or face penalties for non-compliance.

Despite how effective quotas are, there are some weaknesses suggested to be associated with this approach. Firstly, quotas are said to be quite controversial for companies because there is no leeway for businesses to achieve diversity goals other than exactly as required (Grosvold et al., 2016). When this approach is adopted, studies suggest that there is the potential for the appointment of women to be perceived as a token (Willey, 2017). Tokenism is the idea that women are being appointed to boards based on gender, not on merit (Willey, 2017). This would mean that women were placed on boards just for numbers and not to actually contribute to the organization (Isidro \& Sobral, 2015). This perception can potentially result in women feeling like no matter how much experience, skill, and qualifications they bring to a position, that they will be seen as being appointed to boards based gender, not on merit (Isidro \& Sobral, 2015).

Quotas do not allow firms to tailor the board selection process to their unique circumstances, therefore it can be considered invasive because companies are forced into it (Willey, 2017). The gender quota approach can also be costlier than an approach where firms choose to appoint women (Willey, 2017). In some cases, they have even been referred to as discriminatory and going against the principles of democracy (Hughes et al., 2017).

Another suggested weakness of the gender quota approach is referred to as "the golden skirt phenomenon" (Willey, 2017, p. 207). This is where women who have experience on boards become particularly valuable (Klettner et al., 2016). This would mean that when companies look for women to fill board positions, they will ask women who are already sitting on boards as they have already shown their abilities (Klettner et al., 2016). Thus, in the interest of complying with the law, a small number of women are selected, but widespread appointment of women is not necessarily forthcoming. This was seen in Norway's experience with gender quotas, where women were sitting on multiple boards at once, some as many as nine at a time (Klettner et al., 2016).

According to a 2010 study conducted by the University of Michigan, when Norway implemented a $40 \%$ quota for women on corporate boards, company performance suffered 
(Women on Board, 2010). However, this was not a result of gender, but due to the fact that the $40 \%$ quota led to companies recruiting women for their boards that were both younger and did not have the same or as many experiences as the current directors (Women on Board, 2010).

The quota experience in its application to politics can be looked at for additional data concerning strengths and drawbacks. As previously discussed, quotas result in quicker and visible change, greater than usually seen with a comply or explain approach (Meier, 2008). However, some commentators suggest that when organizations adhere to quotas, this is not a guarantee that at a micro level, there is support for the goals of the quota (Meire, 2008). The micro level includes individuals both within and outside an organization (Meire, 2008). Even though the requirements of quotas may be met and change is visible, this could be interpreted as being done just because organizations are forced to, not because they actually want to or that they believe in the benefits related to having more women on boards (Meier, 2008).

However, it is important to recognize that many of the strengths and weaknesses discussed, that are associated with quotas, are not definitive. Sometimes these strengths and weaknesses contradict each other and they are more predictions about what the approach could lead to, as opposed to conclusive statements (Dahlerup \& Freidenvall, 2010). Quotas do lead to clear results in a shorter period of time, which can indicate effectiveness but it is also more interventionist than a comply or explain approach (Labelle et al., 2015; (Nacevska \& Lokar, 2017).

Despite apparent societal progress achieved when quotas are used, there is some evidence from quota countries that men and women are still treated differently in the workplace, such as men are not often asked to justify their competence and skill, or fight for more inclusivity, whereas, women are (Murray, 2014). It has been suggested that when women are being considered for positions, their qualifications are extensively analyzed, and this is less likely to be the case for men (Murray, 2014). When the quota approach is implemented and women are given board positions, the perception can be that those positions were being filled because companies are forced to, not because the women deserve them (Murray, 2014).

As previously mentioned, in Europe, quotas were first applied in political contexts before they were implemented for women on corporate boards. In politics, some commentators found that the issue shifted from female underrepresentation, to male overrepresentation (Murray, 2014), so the issue was re-framed as "how do we get the percentage of elected males to go down 
to $50 \%$ " rather than how to enhance diversity (Murray, 2014).

Finally, in comparison with the comply or explain approach, the top-down unilateral imposition of a quota does not encourage the broader interaction of state and nonstate actors, instruments, institutions and processes in the way the comply or explain approach does, as discussed in Chapter 2. Thus, with the quota approach, there is not the same possibility for a broader "norm conversation" (Webb, 2004) concerning diversity among the broader community in the manner encouraged via the comply or explain approach.

In summary, this chapter has analyzed how the gender quota approach works, the Norway experience, as well as, its suggested strengths and weaknesses. Despite any downfalls that are associated with the gender quota approach, it can be an effective method for the short run, to increase the percentage of women on corporate boards. However it is not clear that the interventionist, unilaterally imposed quota approach is transferable beyond the European experience. While the current comply or explain approach used in Canada may have its flaws, the answer might be adjustments to it rather than a quota (Willey, 2017). 


\section{Chapter 4: Institutional Contexts}

This chapter examines two institutional contexts that can help to explain and/or improve understanding of what is the most practical and effective approach to enhancing gender balance on corporate boards in Canada: the Supreme Court of Canada, and Canadian law schools. In both, significant progress towards gender diversity has been achieved, without use of a quota or a comply or explain approach. An examination of how these institutional actors are addressing the issue of gender balance may shed light on what is the most effective and practical approach to achieve gender diversity on Canadian corporate boards in the particular context of Canada.

\section{The Judiciary}

The judiciary is responsible for making adjudicative decisions concerning the application of the law and its proper interpretation, on behalf of the Canadian society. The focus here is on diversity of the judges of the Supreme Court of Canada. It would be useful to study the appointment of other judges in Canada, but this was beyond the scope of this thesis. On the Supreme Court of Canada, there is a Chief Justice and eight Justices that are appointed by the Governor in Council (Iacobucci, 2002). In 2016 a new process was announced for the appointment of Supreme Court of Canada Justices (Canadian Bar Association, 2019). This new process has an independent, non-partisan Advisory Board whose responsibility is to identify candidates that would be best suited for positions that become vacant (Canadian Bar Association, 2019).

The Advisory Board consists of seven members and after assessing all applicants, they submit a list of three to five candidates, that will be given to the Prime Minister (CBA President's Statement, 2019). There is a questionnaire that applicants are required to answer and

this is the assessment criteria used by the Advisory Board, some of the answers will also be made public (CBA President's Statement, 2019). This new process is said to be more open and transparent (CBA President's Statement, 2019). The process can be characterized as an attempt to ascertain the perspectives of a variety of actors. There is no requirement that the Advisory Board recommend persons of a particular gender. In effect, the approach can be characterized as what the government considers to be a practical and effective way of engaging with a variety of actors concerning the best qualified judge, in which norm conversations (Webb, 2004) may occur, but there are no mandated normative outcomes imposed. 
Currently, on the Supreme Court of Canada, one third of the members are female (Iacobucci, 2002). From 2000 to 2017, Beverley McLachlin was the Chief Justice of the Supreme Court of Canada, the longest-serving chief justice in Canadian history. Although women play a very significant role on the Supreme Court of Canada, a quota has never been used to mandate that women play this role. The improvement in female representation is said to have taken place in response to the changes in societal culture (Iacobucci, 2002).

Decisions about appointments are made based on experience and the number of years worked (Iacobucci, 2002). To ensure regional representation, the Court must consist of two Justices from the Western provinces (which requires one to be from British Columbia), three from Ontario, three from Quebec and one for an Atlantic province (Iacobucci, 2002). However, there are no specifications as to the number of female justices (Iacobucci, 2002).

Some commentators propose that female judges can contribute valuable perspectives and views when analyzing cases, which can result in different decision making when it comes to specific areas of the law (Songer et al., 2016). Studies have indicated that when there is a criminal or community related case, women approach it more conservatively (Songer et al., 2016). Also, in cases related to women's rights or involving sexual harassment, they are likelier to have increased support from female judges (Songer et al., 2016). On the Supreme Court of Canada, there is evidence to indicate that female judges do impact male decision making (Songer et al., 2016). It is suggested that it is not only because they bring a different perspective to decision making, but males are also likelier to vote and make decisions more swayed towards the point of view of the female judges (Songer et al., 2016). This is similar to the business case that is often made for increasing women on corporate boards and was previously discussed. The business case for women on boards is that a more diverse board will result in more consumer reflective representation (Campbell \& Mínguez-Vera, 2008).

In the United States judiciary, there is an ABA Model Code of Judicial Conduct and it includes zero tolerance for gender and racially biased conduct (Shapiro, 2001). In the 1970s, when many women were graduating from law schools and beginning to practice law, they would come before all male judges and receive differential treatment, such as being referred to by their first name when in court (Shapiro, 2001). Some states also implemented gender and racial awareness programs to educate judges (Shapiro, 2001). These programs did result in 
improvements but the selection of judges was said to still not be female and minority diverse (Shapiro, 2001).

The suggested benefits of having more female judges (i.e. an increase in perspectives) are the same benefits of having more women in organizations and on corporate boards. Despite there not being any formal rules for female representation of the judiciary in Canada and the United States, in the United States there are programs and codes of conduct to promote gender equality. Looking at how the Supreme Court of Canada's female representation increased without legal intervention, can support the comply or explain approach being appropriate for Ontario. Creating more programs, such as the ones discussed, may help improve the effectiveness of an approach like comply or explain without the need to move to a more mandatory approach. On the other hand, the judiciary is said to represent the public and therefore should be reflective of it. This could be a reason for the changes taking place without formal intervention. Whereas, on private company boards, representativeness is not as great of a concern as for public enterprises.

It should be made clear that the Supreme Court is different from other institutional contexts, such as a corporate board. The Supreme Court of Canada is a public institution, operating on behalf of the public, where selections were ultimately made by the Governor in Council. However, even though decisions were made by the Governor in Council, this individual drew on the views of a number of sources, to assist in decision-making. There is a broader sociocultural environment around decision making that appears to have a bearing on how decisions are made on who is appointed, which supports the proposition that in Canada, it seems the approach that is most practical and effective, is one that taps into a broad range of actors, but does not require that a certain percentage of appointments to the Supreme Court of Canada must be women.

\section{Law Schools}

Over time, the number of women entering and completing degrees has increased substantially (Kay \& Gorman, 2008). In 1970 in Canada, for every twenty lawyers, one was a woman (Kay \& Gorman, 2008). In 2006, this had increased to every one in three being female (Kay \& Gorman, 2008). Law school admittance and attendance in Canada and the United States has reached the point where in most jurisdictions, the percentage is the same for both males and females (Krakauer \& Chen, 2003). Some jurisdictions have even experienced women surpassing males in terms of law school attendance (Krakauer \& Chen, 2003). 
In the 2000s, in Canada, the United States and other European Countries, the percentage of women in the legal profession has now climbed to over thirty percent (Kay \& Gorman, 2008). In Canada the increased percentage of women law students and lawyers was achieved without a quota or a comply or explain approach. However, some suggest there continue to be negative stereotypes and discrimination impacting female law students (Kay \& Gorman, 2008).

There is some indication of the classroom environment in law schools is less than accommodating for both females and minorities (Krakauer \& Chen, 2003). It has been suggested by some that this could lead to issues with self-esteem and confidence (Krakauer $\&$ Chen, 2003). There is indication that female students have the desire for more support in terms of both career guidance and development (Krakauer \& Chen, 2003). The difficulties women face in the law school classrooms are similar to those women face on corporate boards (see the discussion in the next chapter).

When academic performance is looked at, studies suggest that female students tend to not participate as much as male students (i.e. not asking as many questions and sharing opinions) (Kay \& Gorman, 2008). However, when academic success was looked at, there appeared to be no difference based on gender (Kay \& Gorman, 2008). In terms of career paths, females often face career interruptions that men usually do not, such as leaving their jobs to have and take care of their children (Krakauer \& Chen, 2003). This can result in more men advancing to positions of higher rank because they do not experience the same interruptions (Krakauer \& Chen, 2003). Some commentators suggest that this is associated with the existence of traditional gender roles within a society that associate women with specific jobs and characteristics, this will be discussed in more detail in a following chapter. This can also impact how women are perceived as leaders and on boards. In the public sector, there appears to be an overrepresentation of women because positions are paid less (Krakauer \& Chen, 2003). The career counselors in law schools could help prepare female students for the barriers they may face once they graduate and begin their careers (Krakauer \& Chen, 2003). Nonetheless, it appears as though there are no longer problems in respect to female attendance in law schools, but affirmative action is still used for the acceptance of minorities.

In short, while there is parity in terms of men and women students in law schools, Canada has not used a mandatory approach to increase the number of females. This arguably provides 
support for the proposition that diversity on corporate boards can be achieved without using a quota approach.

In summary, this chapter analysed two institutional contexts, specifically from the Canadian perspective, in regards to how each one addresses diversity and how successfully. At both the Supreme Court of Canada and in Canadian law schools, significant progress in terms of gender diversity has been achieved without use of a quota or a comply or explain approach. This provides support for the proposition that in the Canadian context the approach that has been found to be practical and effective in increasing the participation of women has not been a quota approach. 


\section{Chapter 5: The Ecological Model}

This chapter examines the ecological model (Cukier et al, 2014), which consists of three levels of socio-cultural factors that can or do affect behaviour: macro (societal), meso (organizational), and micro (individual). The ecological model is a complex systems approach used to assist in understanding the diverse range of socio-cultural factors that can affect decisions and behaviour. It is in essence a model which aligns with institutionalist theoretical perspectives (as discussed in Chapter One). This model attempts to understand the wide range of socio-cultural factors that can influence or affect corporate board decision making, including the impact of media, the existence of gender stereotypes, the process of recruitment and selection, as well as, others. These factors assist in understanding how the three societal layers can impact gender diversity policy implementation and perception.

\section{The Ecological Model: How it Works}

The Ecological Model is a three layered approach to public policy analysis and decision making. The three levels are macro (societal), meso (organizational), and mirco (individual), and can also be looked at as three groups of factors. The macro (societal) level starts from the premise that an organization does not simply operate within itself: there are external factors that have an influence on its decision making and action (Cukier et al., 2014). This level takes into consideration both social and cultural factors, including the media, as they impact the values, beliefs, and behaviours within an organization (Cukier et al., 2014). As applied to the issue of gender diversity, the meso (organizational) level focuses on practices within an organization that have or could have an impact on the advancement and recruitment of underrepresented groups (Cukier et al., 2014), such as the recruitment and selection process, organizational culture, as well as leadership influence (Cukier et al., 2014). Finally, the micro (individual) level looks at the influences and experiences surrounding an individual that shapes the individual's skills, knowledge, abilities, aspirations, and preferences (Cukier et al., 2014). The ability of underrepresented groups to advance within organizations and achieve success is impacted by factors at the individual level (Cukier et al., 2014).

\section{The Macro (Societal) Level}

The macro (societal) level analysis involves assessment of the impact of the media, stereotypes and cultural norms (social psychology aspect), and an analysis of the impact of culture and social welfare policies. The media can be an important actor that can influence norm changes on 
subjects such as the participation of women on corporate boards (Kirsch, 2018). The media can and often does publicize problematic practices. How they portray certain issues can influence the attitudes and behaviours of many actors including shareholder/investor behaviour and priorities which in turn could impact company decisions, including board appointments (Kirsch, 2018). Even if these norms do not become engrained in company culture or society, they can still influence organizational decisions concerning women on corporate boards (Kirsch, 2018).

Psychological factors are said to involve stereotypes that impact how women are perceived in society, as well as, how they perceive themselves. This can then impact which fields women go into. The following aspects will be addressed: the kinds of stereotypes and gender roles that exist within society, whether women are perceived as having the specific traits that either positively or negatively impact them in terms of taking positions of leadership, and in general how ideas such as these have impacted gender diversity. Analyzing these aspects can be valuable to women on corporate boards because these perceptions can lead to lowered female confidence, when entering positions of higher rank. They can also make men perceive women negatively in terms of their capabilities, which can then impact the percentage of women on boards but once taken into consideration, they can also help in determining which approach is best for a jurisdiction to adopt.

Scholars suggest that there are three main reasons for the shortage of women on boards: the first revolves around the idea that women tend to take on greater family responsibilities and therefore are less available to take on senior positions in corporations (Chizema et al., 2015); the second pertains to gender stereotypes (the idea that society has determined that women and men have particular traits in terms of how they behave and how they make decisions) (Chizema et al., 2015), and the third are gender role attitudes (the idea that society has established that women and men are best suited for undertaking certain roles in the family and beyond) (Chizema et al., 2015).

In some societies, traditional gender roles call for women to stay home and take care of their children, while men go out and work, holding the responsibility of financially supporting their family (Chizema et al., 2015). The existence of these gender role attitudes vary based on the country. There are societies where they accept that both men and women share financial and household responsibilities (Chizema et al., 2015). This is something that can assist in understanding why a gender imbalance exists in a particular jurisdiction (Chizema et al., 2015). 
These gender traditional stereotypes are also associated with views that women are best suited for certain occupations, such as nursing and social work, even though there are men in those fields of work as well (Chizema et al., 2015). In terms of applying these stereotypes to the issue of women on boards, stereotypes suggesting that females do not possess the qualities that are associated with and required for, can negatively impact gender diversity in the boardroom (Chizema et al., 2015).

On the issue of the connection between gender stereotypes and possession of particular traits, research suggests that women are considered to be more communal, which means they are friendly and nurturing (Chizema et al., 2015), and that men are more agentic (independent and a strong leader), which means they are assertive, and competitive (Chizema et al., 2015). This can be problematic for women trying to get on boards because women may be viewed as not as agentic as men (Bongiorno et al., 2014). This can mean that for a woman to get appointed to a board, she would need to visibly outperform male candidates (Bongiorno et al., 2014). Then, if a woman is sitting on a board and displays agentic behaviour, there is research to suggest that they are not as accepted because that behaviour is not generally associated with women (Bongiorno et al., 2014).

Scholars have provided evidence suggesting that women in what are considered to be masculine professions are negatively perceived by both men and women (Lawson \& Lips, 2014). When women behaved in an agentic manner, they were viewed as hostile therefore not liked (Lawson \& Lips, 2014). Such negative associations can discourage women from attaining positions of power due to the perceived backlash, reinforcing the perception that men should occupy the top positions (Lawson \& Lips, 2014). Commentators suggest that other women also have negative impressions of women in power (Lawson \& Lips, 2014). If a woman sees a job as being unattainable or not associated with her character traits, she may feel the need to degrade successful women (Lawson \& Lips, 2014).

Research shows that women being assertive and aggressive are increasingly being accepted and one reason could be the desire for women to show that they are equivalent to men and also, to show that they are suited for leadership roles (Bongiorno et al., 2014). It has been suggested that when men engage in non-agentic behaviour, they do not experience the same form of judgment and scrutiny that women do (Bongiorno et al., 2014). Men are not socially penalized 
to the same extent that women are because males are considered to be natural leaders (Bongiorno et al., 2014).

It appears that in some societies, there has been a decrease in the existence of these stereotypes over time. Economic, political and cultural changes appeared to have played some role but the progression is not consistent, varying from country to country (Chizema et al., 2015). Research suggested that an increase in female representation in Parliament corresponded with an increase of women on boards (Chizema et al., 2015). Studies have also suggested that when females lead banks, they were associated with taking better consideration of stakeholders because they were more conservative (Palvia, Vähämaa, \& Vähämaa, 2015).

Stereotypes and gender roles such as women being sensitive and nurturing do still appear to exist (Chizema et al., 2015). They make women seem to be best suited for jobs within nursing and teaching (Chizema et al., 2015). Leading to the suggestion that men are considered to be natural leaders and more assertive, making them the appropriate candidates for roles associated with higher rank and leadership (Chizema et al., 2015). These beliefs can negatively impact how women perceive themselves and how they are perceived in society, as well as, by men, which bear on the kinds of roles women enter, as well as how they are treated in them (Nielsen \& Huse, 2010). This can lead to lowered confidence and women questioning their capabilities (Nielsen \& Huse, 2010). Some commentators suggest that as cultural changes have taken place, there has been a decrease in the prevalence of gender stereotypes and roles (Chizema et al., 2015).

These stereotypes and perceptions of gender roles are the backdrop upon which particular organizations operate, and can affect the workplace dynamic, such as if women are negatively perceived, making them less comfortable and not as likely to contribute (Nielsen \& Huse, 2010). This will be discussed further in the next section, regarding boardroom environment and work dynamic because these stereotypes can make the functioning of a board, and workplace in general, more difficult.

A society's culture, level of religiosity and policies related to social welfare, can also play a role in understanding whether a particular policy approach such as increasing gender diversity will be successful, and can have a bearing on why a country/jurisdiction chooses to take a specific approach to addressing gender diversity.

Cultural conditions have also been suggested by commentators, to impact gender diversity and particularly women on boards (Dewally et al., 2017). Research suggests that 
religiosity within a society can impact female inclusivity and presence on boards (Dewally et al., 2017). If a country was rated higher in terms of religiosity, there was a decrease in women on boards because the religious beliefs tend to be more in line with the traditional gender stereotypes, previously discussed (Chizema et al., 2015). This can make it difficult to balance and change the attitudes associated with a religion (Chizema et al., 2015). When policies and practices are altered due to the fact that social ideals and norms are engrained within a society, change to the actual culture can be very slow (Guppy \& Luongo, 2015). There is indication that in societies in which there are more educated and qualified women, there are more women on boards (Dewally et al., 2017).

Hofstede's Cultural Dimensions can also shed light on the impact of culture on issues such as gender diversity of boards (Carrasco et al., 2015). Hofstede's Cultural Dimensions look at how specific values associated with a society's culture impact behaviour (Carrasco et al., 2015). Hofstede defines culture as "the set of values, beliefs, principles, and attitudes that are widely shared within a group of people (Hofstede 1980)" (Carrasco et al., 2015, p. 430). A country's culture and perspective on gender are said to be directly related (Carrasco et al., 2015). The dimensions of a country's culture that most impact representation of women on boards are power distance and masculinity (Carrasco et al., 2015).

According to Hofstede, power distance refers to how much a society is willing to accept unequal power distribution, with this applying to both institutions and organizations (Carrasco et al., 2015). If there is a high level of power distance within a society, then the presence of inequalities in terms of power and wealth are more accepted (Carrasco et al., 2015). When this is applied to the context of women on boards, if there is a high level of power distance, there will tend to be a lower percentage of women on boards because the idea of an "old boys' club" is more acceptable (i.e. an organization's informal network that is mainly composed of men) (Carrasco et al., 2015). The other dimension, masculinity, according to Hofstede, refers to the gender roles that exist within a society (Carrasco et al., 2015). These are associated with social psychological suggestions that men are assertive and tough, whereas women are sensitive and modest (Carrasco et al., 2015). If a society is more masculine, this means that these types of gender stereotypes are prevalent, which can decrease the likelihood that women will be on boards (Carrasco et al., 2015). 
When you compare Canada and Norway's scores for each of the 6 dimensions, we see that one reason why a simple transfer of Norway's quota approach to Canada might be problematic, are the significant differences between Hofstede's cultural dimension for masculinity in Norway and Canada, and to a lesser extent the difference related to power distance (refer to Table 1 for a comparative graph). Thus, due to distinctive features of the socio-cultural institutional context of one jurisdiction when compared with another such as identified through Hofstede's cultural dimension framework, an approach to gender diversity may be practical and effective in one jurisdiction in one jurisdiction (e.g., a quota approach in Norway), while another approach may be practical in another jurisdiction (e.g., a comply or explain in Canada).

\section{Table 1}

A Comparison of Canada and Norway's Scores For Hofstede's 6 Cultural Dimensions

$$
\text { Canada } \times \text { Norway } \times
$$

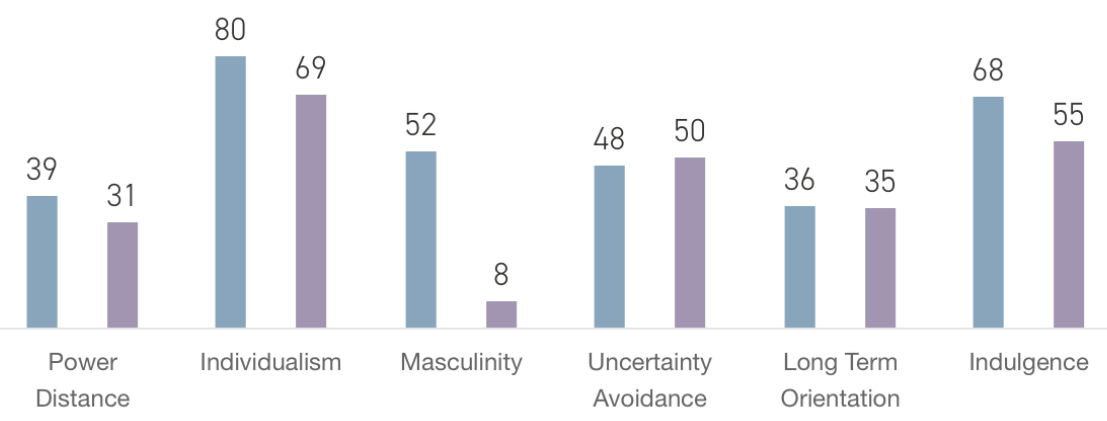

(Hofstede Insights - Country Comparison, 2018).

Progressive social welfare and gender equity polices are also said to be good indicators of a society's level of female representation on boards. Research suggests that countries that have better social policies and offer more family healthcare benefits, tend to have more women in the workforce (Terjesen et al., 2015). For example, the maternity leave offered in Norway, a country that has gender quotas, is between 43 and 53 weeks and also covers between 80 and 100 percent of wages (Terjesen et al., 2015). 
Then looking at childcare policies, Canada does not have a national daycare program (Guppy \& Luongo, 2015). Families are given funding but it is up to them to decide how they will use those funds (Guppy \& Luongo, 2015). In Europe, childcare policies seem to be considerably better (Guppy \& Luongo, 2015). Scandinavian countries are even often referred to as gender utopias (Nordmeyer et al., 2017). In Norway and Sweden, as mentioned above, parental leave is utilized and there are good parental policies, such as affordable childcare (Nordmeyer et al., 2015). Women are not placed in positions where they must choose to either pursue their career or take care of their children (Nordmeyer et al., 2015). These differences can be another socio-

cultural factor that potentially assists in understanding why a quota approach may be considered practical and effective in one jurisdiction (where the norm in support of greater participation of women in the workforce is already well embedded in society).

In terms of religion, a religious society tends to be one with a lower representation of women on boards, suggesting that religion is impactful (Dewally et al., 2017). Some commentators suggest that religion also affects the existence of gender roles, if a society is more religious, they are more likely to have traditional ideas about the role of women (Dewally et al., 2017). Based on an analysis of Hofstede's Cultural Dimensions, there are important differences between Canada and Norway, and these could factor into why different approaches to board gender diversity might be undertaken in each jurisdiction.

\section{The Meso (Organizational) Level}

The meso (organizational) level analysis will include a look at the process of recruitment and selection, candidates resembling existing board members, and the incentives behind female board member appointments.

The environment within a workplace and on boards can be indicative of the previously discussed gender stereotypes. The benefit of better understanding this area of factors is that if a workplace has a hostile and non-inclusive environment, women may not feel comfortable to contribute once they are on boards. The important aspects that will be analyzed here are the following: how stereotypes impact women entering positions of higher ranks and how women are treated, once they are on boards or in leadership roles. If these problems exist and are known within society, it can potentially make men and women have certain perceptions of how a gender diverse environment functions and therefore, can impact female representation on boards. 
There are many suggested benefits to having more women on corporate boards. As discussed earlier, the business case suggests that women bring a different point of view and can add value to an organization (i.e. an increase in perspectives leading to an increase in innovativeness) (Mathisen et al., 2013). Some commentators take the position that when both men and women are on boards, they should be treated equally, with everyone's opinions being respected (Mathisen et al., 2013). However, it has been suggested that once women are on boards, there is evidence that they can often feel out of place and this negatively impacts the dynamic on boards (Mathisen et al., 2013). The social identity theory holds that people tend to listen to the views presented by the majority, not the minority (Mathisen et al., 2013). On boards, if females are in the minority, this could make them feel as though they are outsiders (Mathisen et al., 2013).

Other studies suggest that female directors are welcomed on boards because they bring knowledge, experiences, and skills that are beneficial to board decision-making (Mathisen et al., 2013). Research shows that conflicts mainly arise when women with non-traditional education backgrounds are on boards because they may then be perceived as being incompetent to be sitting on a board and contributing to decision making (Mathisen et al., 2013). Diversity is said to increase the variety of perspectives, which can ultimately be beneficial to decision making (Nielsen \& Huse, 2010). However, this can also sometimes negatively impact the dynamic and performance of a team because of conflicting views (Nielsen \& Huse, 2010). Some commentators would suggest that when the majority of the board is composed of traditional directors, then there is more hesitation/resistance to appoint more diverse directors (Kirsch, 2018). However, if board composition is more diverse, then there is less resistance when appointing (Kirsch, 2018).

Societal norms and stereotypes are also applicable to this area of research. As previously mentioned, there is some belief that certain occupations are more suited for a specific gender. Some occupations are dominated by a single gender (Bell et al., 2002). For example, women tend to dominate the occupations of nurses, flight attendants, and secretaries, whereas, men tend to dominate the occupations of executives (Bell et al., 2002). This means that it is likelier that women will fill lower positions and be managed by males (Bell et al., 2002). This is related to the workplace environment and dynamic created because it may make females reluctant to enter certain occupations that are male dominated (Bell et al., 2002). This can be associated with the 
fear of not fitting in, or even worse, experiencing workplace harassment (Bell et al., 2002). Due to the fact that boards have been predominately male, some commentators suggest that women may feel as though they are unequal once they are on the board and hesitant to contribute (Nielsen \& Huse, 2010).

These ideas are related to the barriers women face and the suggestion that in order for women to gain the experience needed to fill the requirement to be on a board, they need to actually be able to go out and get that experience (Bell et al., 2002). This can be problematic because women tend to have fewer available opportunities (Bell et al., 2002). Not all women in executive positions have experienced these problems but these stereotypes do still seem to exist and can lead to visible discrimination (Bell et al., 2002).

Nominating committees are an example of a meso level actor as their role is directly within the organization and specifically, it is to identify board candidates (MacDougall et al., 2019). Nominating committees can be influenced by, investors and NGOs, for example (MacDougall et al., 2019). Investors can have direct involvement because they can have a policy around voting and therefore can vote against the board directors. NGOs can release their own reports around progress, they can also create certifications, and give awards to organizations and/or directors that may be excelling. As we have seen, the comply or explain approach relies on the involvement of these type of actors to construct and support the achievement of a particular social norm. The role of these non-state actors will be further discussed in next chapter, on sustainable governance.

\section{The Micro (Individual) Level}

The micro (individual) level analysis examines the recruitment and selection process as well, but specifically the processes that applicants go through to gain board positions. This level encompasses some factors that were discussed at both the macro and meso levels. For this level, social networks are significant and there are concerns over the existence of a "corporate elite" or “old-boys club." In terms of social networks, activities like playing golf, can be considered a social networking tool for positions, including those on corporate boards, women are often left out of this (Kirsch, 2018). Some studies would argue that current board members will tend to recommend and support candidates that resemble them demographically and therefore women are often left out of this and do not attain board positions (Kirsch, 2018). The current and long standing members of a board are considered to be the corporate elite (Kirsch, 2018). They 
sometimes do prevent outsiders from getting board positions (Kirsch, 2018). Appointments of more diverse directors tend to be based on if the current directors, CEOs, and others responsible for selection, desire it (Kirsch, 2018). Some would argue that there is hesitancy to have too much diversity on boards as the "corporate elite" dominates and with more diversity, that domination would weaken (Kirsch, 2018). Studies have presented evidence of women having less of a chance of being appointed if there is already a woman sitting on the board and a greater chance for a board seat, if a woman has recently left the position (Kirsch, 2018). There is also evidence of women who are directors for the first time, having more difficulty gaining additional appointments because they do not receive the same level of mentoring from current directors, as men do (Kirsch, 2018).

The chapter has drawn on the ecological model (Cukier et al, 2014), with its macro, meso and micro levels of analysis of socio cultural factors. Gender stereotypes and gender roles can impact how men perceive women and how they perceive themselves. Even once women are on boards, when they behave as a man would and as fitting for that particular role, they can be negatively perceived because that behaviour could be viewed as not suited for a woman. The existence of gender stereotypes and traditional gender roles, when also combined with the problems associated with women once they are on boards, all support the idea that achieving gender diversity is not amenable to silver bullet simplistic solutions.

As noted earlier, the ecological model is a complex systems approach used to assist in understanding the diverse socio-cultural factors that can affect decisions and behaviour. As it is hard to show a linear relationship between any particular factor and an increase of women on corporate boards, the ecological model sheds light on the wide variety of the diverse variety of macro, meso, and micro factors that can impact on women being appointed to boards or wanting to be on corporate boards.

A critical insight emerging from this analysis is its recognition of the importance of evolving socially constructed norms operating on multiple levels that can increase or decrease the likelihood of women wanting to be appointed to corporate boards, and if appointed, increase or decrease the likelihood of women wanting to stay on those boards. Connecting this back to discussions of the comply or explain disclosure model and the quota approach in Chapters 2 and 3 , the quota approach essentially slices through whatever are the intricate and important cultural factors at play and simply imposes a solution in a unilateral, top down manner, regardless of 
those factors.

In contrast, the comply or explain approach, by simply requiring public disclosure on these issues, not arbitrarily and unilaterally imposing a solution, and instead opening up each corporation to examination and engagement on gender diversity issues, involving a range of nonstate actors, instruments, institutions and processes, seems to start from the premise that long term sustainable board diversity is more a product of a multi-variable ecosystem rather than a single government actor mandating a single one-size-fits-all solution. This point is picked up in the next chapter on sustainable governance. 


\section{Chapter 6: Sustainable Governance}

\section{Sustainable Governance: Rules Instruments, Processes, Institutions, and Actors}

As noted in Chapter One, an institutionalist perspective holds that firms are embedded in a larger social environment beyond the marketplace, which induces firms to adhere to social norms (Webb, 2012). From this perspective, it is not just the presence of a norm or law that matters, but also the extent to which there is stakeholder monitoring of conformity with the norm or law, and some form of enforcement. Non-state actors such as investors and non-governmental organizations can play important roles in monitoring corporate behavior and mobilizing pressure on firms to act in conformity with norms.

As noted in Chapter Two, disclosure laws such as the comply or explain law information disclosure serves as a form of intervention by government in the negotiation process between two (or more) social actors. Unlike the quota approach, where government imposes a norm on an actor, with disclosure laws, government in these cases serves as a "facilitator" rather than a "coercer." The individual corporate boards make decisions as to what is best, taking into account the actions and communications of non-state actors such as seen in Chapter 2 when the shareholders put pressure via a shareholder proposal on Constellation Software, and this led to the company engaging with non-state actors on diversity policies.

Mobus (2005) states as follows:

Regulatory agencies are only part of the complex mix of institutional arrangements that have developed in efforts to govern the commons. Whereas these agencies have formal enforcement authority to impose sanctions for rule violations, effective governance of the commons requires inducing, not only enforcing, rule compliance; and pressure to conform to social norms is one means for inducing compliance. Mandatory .... disclosure provides information on ..... performance that can inform public sentiment and, thereby, help internalize the social costs of organizational actions and induce organizational compliance with regulatory regimes. In a social and political environment where public exposure for poor ..... performance is considered to increase risk for the entity, ....disclosures can reveal departures of organizational actions from norms of expected behavior. Mandatory .... disclosure is a potential tool of public policy for governance of the commons. (references omitted)

Commentators have noted the different institutional contexts of state coordinated market 
economies such as those of continental Europe and liberal market economies such as United States, and how this affects corporate social responsibility (CSR).

European countries have been characterized as having particular, formal, mandatory, and codified rules or laws defining the responsibility of corporations (called "implicit CSR"), whereas in liberal market economies corporate social responsibility is normally undertaken through voluntary activities and policies, motivated by the perceived expectations of stakeholders (“explicit CSR”) (Matten and Moon, 2007; Young and Morais, 2012). Specifically, Scandinavian countries have been characterized as "implicit CSR" jurisdictions (Strand et al., 2015). Canada has been characterized as a liberal market economy (Arnold et al., 2020), and therefore would be seen as an "explicit CSR" jurisdiction, where CSR is normally undertaken through voluntary activities motivated by the perceived expectations of stakeholders.

These characterizations of the institutional environment for CSR assist in explaining why mandatory quotas would be accepted as practical and effective in European countries such as Norway and Finland and comply or explain approaches where the state facilitates voluntary, consensual corporate board appointments of women would be accepted as practical and effective in Canada. The comply or explain law looks to and mobilizes the "perceived expectations" of stakeholders as the means of influencing voluntary corporate behaviour on societal issues such as board gender diversity. The sustainable governance approach provides a lens for more clearly understanding the interaction of state and non-state actors in the achievement of societal objectives.

Underlying the sustainable governance concept is the idea that the optimal approach to addressing complex social and environmental societal problems involves a combination of state and non-state rule instruments, institutions, processes and actors (Webb, 2005). As noted in Chapter 2, in this idea of an assemblage of state and non-state approaches all acting in various different ways in support of a particular objective, the sustainable governance concept seems to align well with what is observed as currently occurring with respect to use of a comply or explain gender diversity approach. The objective of this chapter is to "map" the array of state and non-state measures brought into play through use of the Canadian comply or explain gender diversity rules. As discussed in Chapter 2, because a comply or explain approach is in essence an information disclosure law, the corporate disclosure triggers a process involving a range of nonstate actors, instruments, and institutions that can assist in galvanizing positive conduct and 
discouraging negative conduct by the disclosing businesses. Once a corporation publicly discloses the legal required information about gender diversity, at that point, a set of other interested actors (e.g., shareholders and investors, the media, non-governmental organizations interested in promoting diversity, business organizations, researchers, and others) are in a position to interpret, amplify that information and otherwise directly or indirectly engage with the corporation in question.

The government and the comply or explain disclosure law play a central role and are critical, but private sector activities (such as investor pressure) and civil society activities (such as non-governmental organizations creating guidelines and publishing reports on top performers and worst performers) also play important roles (Webb, 2005), and through their interactions and engagements, they assist in construction of the gender diversity norm. Through a combination of state and non-state approaches, a practical and effective approach to gender diversity is taken, and not reliant exclusively on a single regulatory requirement imposed in a top down manner on companies. In effect, sustainable governance recognizes the value of tapping into all available societal resources and energies (governmental, market, community) to address a problem. The more actors, instruments, institutions and processes are directed at a particular problem, the greater the likelihood that the objective will be achieved. In effect, a top down, government-andlaw approach is more likely to be successful, if surrounded by multiple additional private sector and civil society approaches, all addressing the same thing (Webb, 2005). When a sustainable governance approach is adopted, if one actor, instrument, process or institute were to falter or be inadequate in some way, it would not necessarily mean that the objective would not be met: one of the other instruments, processes, institutions, or actors, could potentially fill the gap (Webb, 2005).

Often times, governments do not have the financial resources, sufficient number of inspectors, enforcement actions, or high enough standards in place, to appropriately address a problem (Webb, 2005). The collaborative and competitive/check and balance dynamics at work in a sustainable governance model shares responsibilities and costs amongst the entities involved (Webb, 2005). For example, NGOs and industry associations pushing organizations to do better with the comply or explain rule. However, sustainable governance also says that it creates a certain amount of useful friction -- a check and balance dynamic (Webb, 2005). For example, an NGO or investors being critical of a particular company or a rule instrument for not going far 
enough. Therefore, it is not always a cooperative relationship, sometimes it is organizations being critical of each other but at the same time, pushing each other to do better (Webb, 2005). The dynamics among the various organizations can be found to be quite interesting. These dynamics can be interpreted from research discussed in earlier chapters, as well as, the interview findings that will be discussed in the next chapter. NGOs and industry associations tend to be more critical of comply or explain due to slower progress and some concerns around disclosure, therefore they tend to be supportive of more stringent measures and would be open to a gender quota. However, NGOs can also help companies with their internal initiatives, such as helping them utilize change management principles, therefore they can also be supportive and collaborative. Investors also tend to be critical of comply or explain but they are more supportive of additional measures being added to the current comply or explain and push organizations to do more internally. These are broad examples of organizations pushing each other and stimulating better behaviour but there will be a more in depth discussion in the next chapter.

Each approach has its own strengths and weaknesses and unique characteristics. For example, only law can be backed up by the threat of state-imposed coercion, which is a unique strength, but the amount of resources required to enforce laws is considerable, so if there aren't sufficient resources provided, law implementation may be less than optimal (Webb, 2005). Private sector approaches harness the unique pressures associated with the market, but if not all firms choose to participate in a market based program, there is no way to compel participation as with laws (Webb, 2005). Sustainable governance utilizes all available strategies to address a problem. The more approaches there are addressing the problem, the greater the likelihood that the objective will be achieved (Webb, 2005). Thus, sustainable governance says that a legal approach is more likely to be successful if surrounded by multiple additional private sector and civil society approaches all addressing the same thing (Webb, 2005). It is a collaborative approach and the state or non-state regulatory governance involves, rule instruments, processes, institutions, and actors (Webb, 2005). Each of these has both positive and negative aspects, but when applied together, create a balance (Webb, 2005).

The four governance components (rule instruments, processes, institutions, and actors) are discussed in Webb (2005) and are defined as the following:

- Rule instruments: Sets of objective rules or criteria that exist in order to influence specific behaviour that can be evaluated to determine who is and is not complying, this 
includes law, regulations, and voluntary codes (Webb, 2005).

- Processes: Activities done in support of the achievement of a specific objective or policy, including methods that aid in the ability to make informed decisions (Webb, 2005). This includes both state and non-state entities (Webb, 2005).

- Institutions: Specific bodies or entities whose functions are to achieve a particular objective (Webb, 2005). Institutions are structures that exist within government, industry, and nongovernmental organizations (Webb, 2005).

- Actors: All entities that could or do have some bearing on achieving a particular objective (Webb, 2005). For example, companies, media, advocacy organizations, etc. (Webb, 2005).

\section{Sustainable Governance: Governance Institutions, Processes, Rule Instruments, and Actors Applying to Gender Diversity on Boards in Canada}

The institutions, processes, rule instruments, and actors part of the sustainable governance approach, as applied to the issue of gender diversity on corporate boards in Canada, at various levels (local, provincial, federal, and international) can be displayed through a graphic mapping adapted from Martin and Webb (2020). This mapping is applied in a 3 layer process, depicted below, in figures 2 to 4. Figure 2, includes rule instruments, institutions, processes, and actors that are part of the public sector, then figure 3, brings additions from the civil society, and then finally Figure 4, from the public sector. The roles of each of these institutions, processes, rule instruments, and actors, will be briefly described below. 


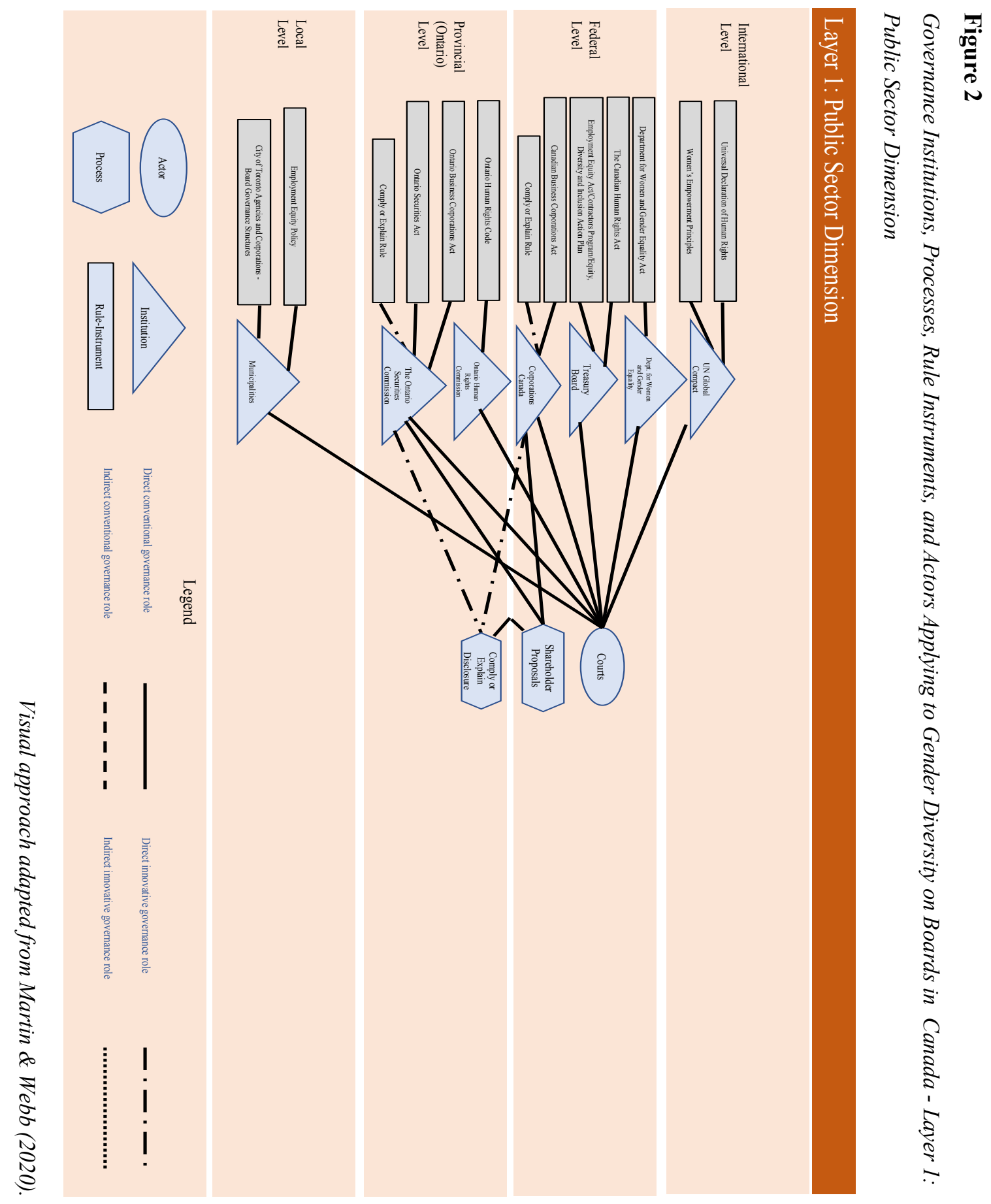




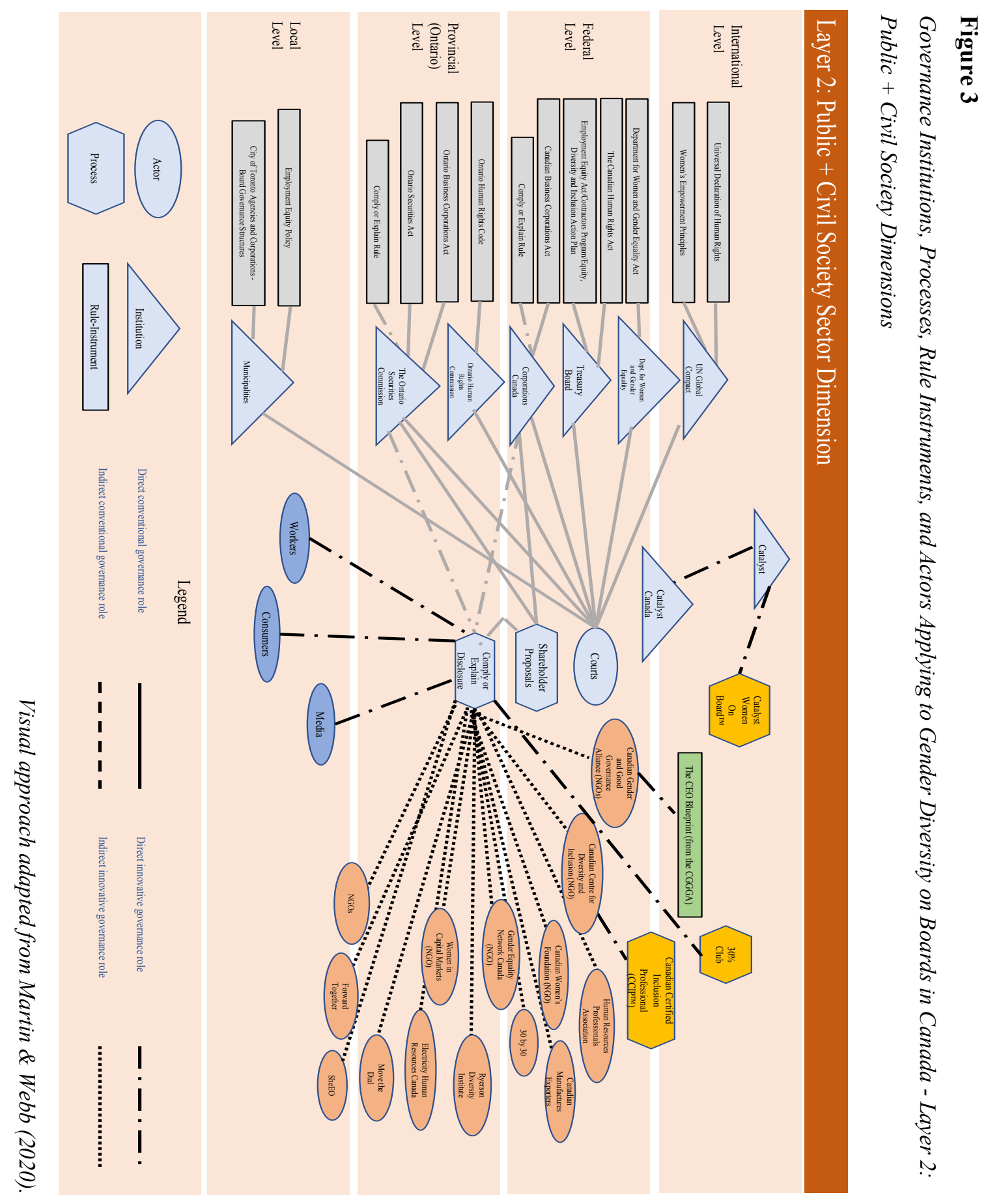




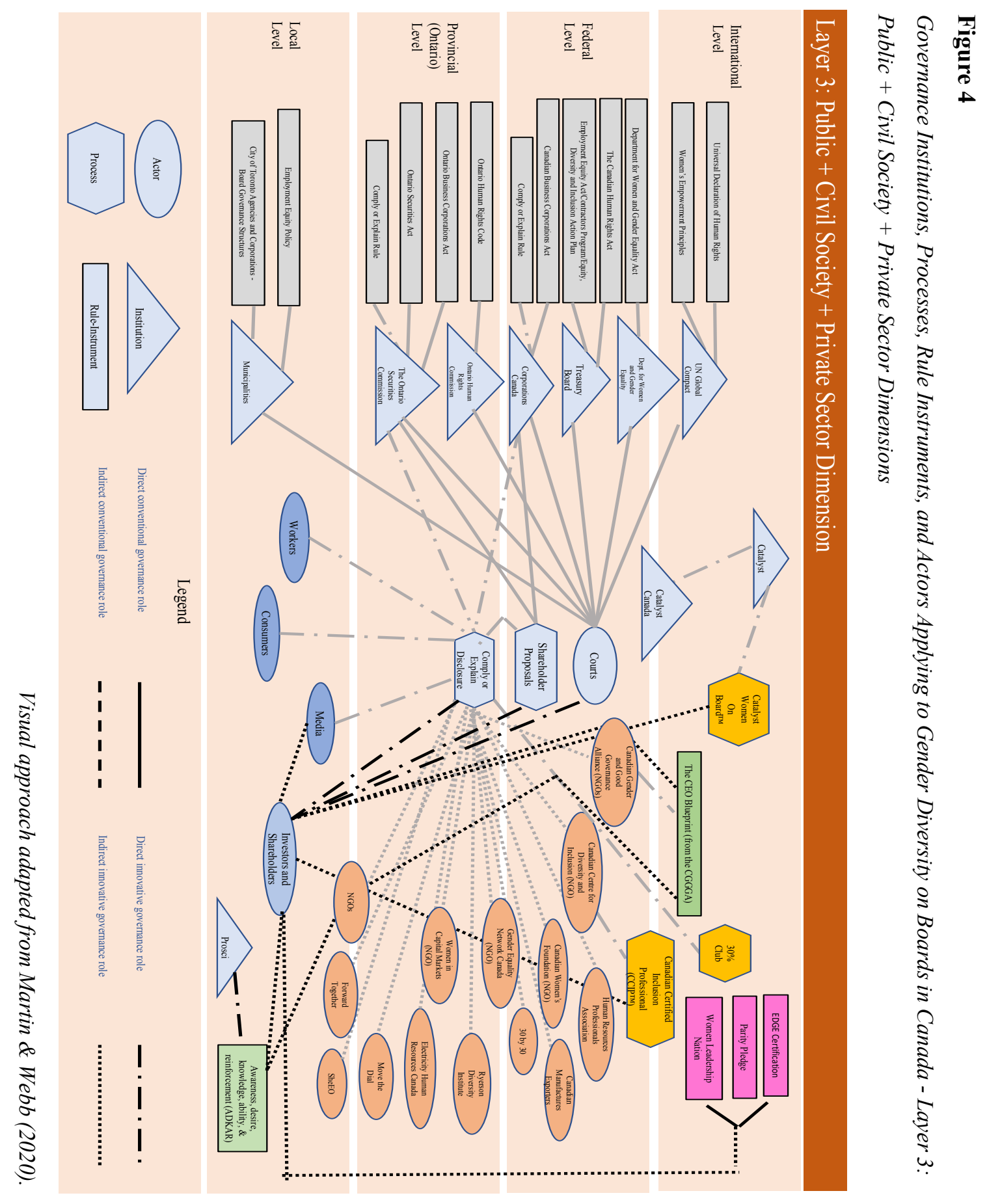




\section{State Rule-Instruments, Institutions and Processes}

Taken together, an assemblage of government institutions and identified rule-instruments and related processes (detailed below) constitute the state-based contextual foundation for pursuit of gender diversity. The comply or explain gender diversity disclosure process established through the federal Canada Business Corporations Act (CBCA) and provincial securities laws such as the Ontario Securities Act constitutes the specific focus for action on corporate board gender diversity via the comply or explain disclosure process. The ability of investors to make shareholder proposals pursuant to the $C B C A$ and Ontario Securities Act in support of board gender diversity represents a law based process that can be and has been used in support of the comply or explain gender diversity process.

\section{State Rule-Instruments}

The state rule-instruments are depicted in Figure 2, the first layer and public sector dimension. At the international level, there is the Universal Declaration of Human Rights, which sets out the human rights that are fundamental and universally protected (The United Nations, 1948). There are also the Women's Empowerment Principles (WEPs) that provide guidance to businesses on how they can empower women in the workforce and community, as well as, promote gender equality, this was established by the UN Global Impact (Women's Empowerment Principles, 2020).

At the federal level, first there is the Department for Women and Gender Equality Act, that was enacted to improve gender equality, as well as, promote diversity and inclusion (Department for Women and Gender Equality Act, 2018). Then there is the Canadian Human Rights Code, which focuses on ensuring equal opportunity for underrepresented groups and individuals who may be targets of discriminatory acts (Canadian Human Rights Code, 1985). There is also the Employment Equity Act, which requires employers under federal jurisdiction to implement employment practices that will increase representation of the four underrepresented groups, these designated groups include, women, people with disabilities, Aboriginal peoples, and visible minorities (Employment Equity Act, 1995). This connects to the Federal Contractors Program, whose purpose is to ensure that contractors who have business with the Government of Canada, aim at having a workforce that is representative of Canada's workforce and this includes the four designated groups discussed under the Employment Equity Act (Government of Canada, 2018). There is also the Equity, Diversity and Inclusion Action Plan, that is focused on 
governance, transparency and monitoring of diversity and equity (Canada Research Chairs, 2018). Finally, there is the Canadian Business Corporations Act, which regulates corporations in Canada and recently implemented the comply or explain rule, for promoting diversity at both the board and executive level (MacDougall et al., 2019).

At the provincial level, there is the Ontario Human Rights Code, which gives everyone in the province of Ontario, equal rights and opportunities, free of discrimination (Human Rights Code, 1990). There is also the Ontario Business Corporations Act, which governs all corporations in Ontario (Business Corporations Act, 1990). Then there is the Ontario Securities Act, which implemented the comply or explain rule, for all companies listed on the Toronto Stock Exchange (TSX) and other non-venture issuers (Securities Act, 1990).

At the local level, there is the Employment Equity Policy, which focuses on an employer's responsibility to ensure fairness and equality in both employment and services (City of Toronto, 2019). There are also Board Governance Structures, implemented by City of Toronto Agencies and Corporations. This instrument involves City Council approving board governance structures for agencies and corporations in Toronto, these address board size and composition, appointment of the chair, board eligibility requirements, etc. (City of Toronto Agencies and Corporations, 2016).

\section{State Institutions}

The state institutions are depicted in Figure 2, the first layer and public sector dimension. At the international level, there is the UN Global Compact, an organization that calls on organizations to build their strategies and operations in line with the universal principles of human rights (United Nations Global Compact, 2020).

At the federal level, there are three state institutions. The first is the Department for Women and Gender Equality, which has the same commitments as the Department for Women

and Gender Equality Act, to improve gender equality, as well as, promote diversity and inclusion (Department for Women and Gender Equality Act, 2018). The second is the Treasury Board of Canada Secretariat, they have many responsibilities, including accountability and ethics (Government of Canada, 2020). The third federal level state institution is Corporations Canada, which is responsible for the incorporation of businesses in Canada, as well as, the laws they are governed by (Government of Canada, 2020). 
At the provincial level, there is the Ontario Human Rights Commission, who are responsible for overseeing the Ontario Human Rights Code (Ontario Human Rights Commission, 2020). There is also the Ontario Securities Commission, they are responsible for the regulation of Ontario's capital markets, they work to ensure fairness and efficiency, as well as, to protect investors from unfair and fraudulent practices (Ontario Securities Commission, 2020). Finally, at the local level, there are municipalities, who have powers to govern over a particular jurisdiction.

\section{State Processes}

There are two processes at the public sector level, they can be found in Figure 2. The first process is shareholder proposals. Investors can propose to companies that they should be doing something or that they need to change something, for example if they have no women on their boards, this proposal is heard at the annual general meeting of that company (MacDougall et al., 2017). The second process is the comply or explain disclosure, which was previously discussed and is where companies must disclose the initiatives they have in place to promote gender diversity and if they have none, they must explain why (Willey, 2017). In Chapter Two, an example was provided of how the comply or explain disclosure process led to identification of a Canadian company that had not put in place a gender diversity policy. This led to an activist organization using the shareholder proposal process to put pressure on that company to address the diversity issue. This in turn led to engagement between the company and the activists regarding how to implement such a policy. This example shows the interconnections between state laws and processes and non-state activity in support of gender diversity.

\section{Non-State Rule Instruments, Institutions and Processes}

In addition to the assemblage of government institutions and identified rule-instruments and related processes described above that support the pursuit of gender diversity, there is an assemblage of non-state institutions, rule instruments, and related processes that constitute the non-state contextual foundation for pursuit of gender diversity. This is detailed below.

\section{Non-State Rule Instruments}

Pertaining to corporate board gender diversity, identified here are four non-state rule instruments, two of which are part of the civil society (Figure 2) and two part of the private sector (Figure 3).

The first civil society rule instrument is the CEO Blueprint, it is a step-by-step framework, which helps CEOs understand and implement gender balance strategies throughout 
their organization, it was created by the Canadian Gender and Good Governance Alliance (CGGGA) (Canadian Gender and Good Governance Alliance, 2018).

The second civil society rule instrument is the ADKAR model (awareness, desire, knowledge, ability, and reinforcement), these are change management principles created by Prosci, that are used to guide both organizations and individuals, using a goal oriented approach (Prosci, n.d.).

On the private sector side, the first rule-instrument is the EDGE Certification, their aim is to improve gender equality, as well as, ensure equal workplace opportunities for both men and women (EDGE, 2020). It requires re-certification every two years because it looks at organizational gender equality as an ongoing process (EDGE, 2020).

A second private sector rule-instrument is the Parity Pledge, which advocates for female representation at both the executive and board levels, by promoting organizations that show they are committed to gender parity, as well as, bringing awareness to it (Parity.org, 2020). When companies are asked to take the Parity Pledge, they are being asked to commit to interviewing at least one qualified woman for every available role within their organization, at the executive level and higher (Parity.org, 2020).

A third private sector rule-instrument is the Women Leadership Nation's Unified Workplace Designation certification program (Whitepaper, 2019). Women Leadership Nation is engaged in advising, training, and development, in order to attract, develop, engage, and retain female leaders (Whitepaper, 2019).

\section{Non-State Institutions}

There are three non-state institutions noted here that are involved in support of gender diversity. The first is Catalyst, a global not-for-profit, that aims to break down organizational barriers and create more inclusive cultures/workplaces, where women can excel (Catalyst, 2020). The second is Catalyst Canada, the Canadian initiative by Catalyst, to advance women in corporate Canada (Catalyst, 2020). Catalyst and Catalyst Canada are civil society institutions, that can be found in Figure 3.

The third non-state institution is Prosci, it can be found in Figure 4, as it is part of the private sector. Prosci is the organization that is responsible for the creation of the ADKAR model for change management principles (Prosci, n.d.). 


\section{Non-State processes}

There are also two processes at the civil society level pertaining to gender diversity included in Figure 3. The first is Catalyst Women On Board, this is where outstanding women in senior executive positions, who are considered to be good candidates for corporate boards, are invited to join Catalyst Women On Board and they are then paired with an experienced board member, who mentors them in their goal towards attaining a board position, this is done for two years (Catalyst, 2020). The second is Canadian Certified Inclusion Professional (CCIP), a certification established by the Canadian Centre for Diversity and Inclusion, this certification is not used to educate, but to evaluate both the experience and knowledge, of diversity and inclusion professionals (Canadian Centre for Diversity and Inclusion, 2020). There is also the 30\% Club, which works with board Chairs and CEOs to improve gender diversity at both the senior management and board levels $(30 \%$ Club, 2020). They are an organization that does not believe in the use of quotas and have an aspirational goal of reaching 30\% board and executive seats held by women by 2022 (30\% Club, 2020).

\section{Actors}

18 civil society actors are identified in Figure 3. The Canadian Centre for Diversity and Inclusion works towards creating awareness, dialogue, and action, around the importance of diversity (Canadian Centre for Diversity and Inclusion, 2020). Then there is the Canadian Gender and Good Governance Alliance, it is a partnership of various not-for-profit organizations that focus on researching, advocating, and educating, about gender diversity (Canadian Gender and Good Governance Alliance, 2018). Canadian Women's Foundation focuses on empowering women and girls, breaking down barriers, as well as, improving gender diversity (Canadian Women's Foundation, 2020). There is also the Gender Equality Network Canada, whose aim is to advance gender equality in Canada by improving inclusivity and advocating for change (Canadian Women's Foundation, 2020). Women in Capital Markets works to improve gender diversity at the industry level through research, advocacy and recruitment (WCM, 2019). There is the Human Resources Professionals Association, an organization that aims to close the gender wage gap (Human Resources Professionals Association, 2020). There is also 30by30, whose goal is to increase female representation in the engineering field and they plan to do those by increasing the percentage of female licensed engineers to $30 \%$ by 2030 (Engineers Canada, 2018). There is also Electricity Human Resources Canada, an organization with an Leadership 
Accord for Gender Diversity in the Canadian Electricity Industry (Electricity Human Resources Canada, 2020). This accord is a commitment that employers, educators, and others, will promote diversity, equality, and inclusion values in their work (Electricity Human Resources Canada, 2020). Then there is Forward Together, whose aim is to bring companies and professional women together to promote learning across all industries (Forward-Together, 2020). There is also SheEO, they support and have a fund for female entrepreneurs (SheEO, 2020). The Canadian Manufacturers and Exporters Association also does work towards attracting and engaging women in the Canadian manufacturing field (Canadian Manufacturers and Exporters, 2020). There is also Move the Dial, an organization whose aim is to get more women in tech (Move the Dial, 2020). The Ryerson Diversity Institute conducts research to determine and tackle the needs of Canada's diverse population, in order to advance inclusion (Diversity Institute, 2020). Many applicable NGOs were listed and discussed above, however a generic NGOs actor was included in the figure, as there are many others not specifically listed, that are both interested and concerned about diversity.

Then there are the courts, they were included because governments, investors, and companies, all go to courts for clarification on meanings, when they think they have been misled, as well as, for other issues, and courts will give definitive decisions. Then there are workers, who can advocate and actively push for gender diversity. Then there are consumers, who can choose to base their purchasing decisions on how diverse an organization is. Finally, at the public sector layer, there is also the media, who can write articles about reporting either being positive or negative, they can shed light on organizations doing really well or organizations doing poorly, therefore some would suggest they are very important.

Then at the private sector level, which can be seen in Figure 4, there are investors and shareholders. Investors can work closely with organizations to create policies but they can also step in with shareholder proposals, if need be. Then there are shareholders, who are responsible for company decision making.

\section{Sustainable Governance: As it Applies to Disclosure Law}

With information disclosure law, the act of disclosing is the legal requirement. There are two important concepts related to disclosure law and how it works. The first is information inductance, which is that the simple act of having to disclose information can bring about a change in behaviour (Information Inductance, 2020). Disclosure can lead to an individual or 
organization taking a closer look at their current practices and this can lead to realizations and changes. The second is isomorphism, which is where people and companies are always looking at what everyone else is doing, wanting to fit in and not negatively stick out of the group, and thus they move in packs (Srikantia \& Bilimoria, 1997). Information inductance and isomorphism show that the legal act of disclosing is only the first step. Once disclosure takes place, other actors get involved (industry associations, non-governmental organizations, media). Comply or explain is an information disclosure law approach. Once the information is disclosed, other actors, institutions, processes, etc. take that information and through the activities they do, bring light to it and what is being done. It is a consent-based approach. The information becomes publicized and these other actors may take the role to praise or shame companies in order to bring light to what is being done and initiate change. As noted in Chapter 2, consent has been described as the most effective form of governance (Purchase, 2004), capable of leading to changes of behaviour even if formal enforcement is not adequate.

It is important to note that the instruments, institutions, processes, and actors involved in sustainable governance need not only be connected with implementation of a law (Webb, 2005). With respect to any particular societal problem, it is possible and not unusual for a range of nonstate (private sector and NGO) actors, instruments, institutions and processes to be conceived and established whether or not a law is in place. (Webb, 2005). Indeed, in Appendix F it can be seen that there were many non-state actors, instruments, institutions and processes created in Canada and still in operation today that predate the time when Ontario officially announced its interest in putting in place a law to address the issue of gender diversity on corporate boards.

\section{Sustainable Governance and the Ecological Model}

Having the comply or explain or gender quota approach in place are legal approaches to addressing increasing gender diversity. These approaches on their own are just the law, without considering the other actors involved, there can be gaps in understanding what is really happening in terms of improvement or change (Webb, 2005). Sustainable governance acknowledges that the law can work in conjunction with other private sector and civil society actors, instruments, institutions (Webb, 2005) and can have the effect of supporting the objectives of a law. But we have also noted that non-state actors, instruments, processes and institutions. can address a problem such as gender diversity regardless of whether there is any law in place pursuing that objective (Webb, 2005). They can all have an impact on the 
achievement of a particular objective (in this case, increasing gender diversity). However, for this thesis, an attempt was made to determine the year of origin of the particular identified nonstate actors, instruments, institutions and processes referred to in this chapter (see Appendix F). A total of 23 of these non-state gender-oriented initiatives were identified and discussed in this chapter. While every effort was made to include all potentially significant initiatives, no assertion is being made here that this represents a comprehensive listing, but rather, this listing represents a best-efforts attempt by the author to identify these initiatives. It is interesting to note that of the 23 non-state initiatives, 9 were introduced from the time that Ontario announced its intention to put in place a disclosure law to encourage the participation of women on corporate boards. This is a correlation, and no assertion is being made that the introduction of the law was an important stimulus for the creation and establishment of these non-state initiatives. All this having been said, application of the sustainable governance framework to the Canadian context assists in understanding the ways in which non-state actors, instruments, institutions and processes can interact and support the achievement of the comply or explain law. With a quota law, only a bilateral interaction between the state and companies is needed, without the support of non-state initiatives. As has been discussed above, the practicality and effectiveness of the comply or explain law disclosure law depends on there being a set of non-state actors that take the information disclosed and use it to influence companies to achieve the goals of the law. In this chapter, we have seen that a rich and diverse set of non-state actors, instruments, institutions and processes is in place, capable of performing this function. This institutional backdrop of non-state actors, instruments, institutions and processes is an important institutional piece of the puzzle allowing the comply or explain law to be effective and practical in Canada. 


\section{Chapter 7: Interview Findings}

This chapter discusses the findings from semi-structured interviews with a cross-section of thirteen persons knowledgeable about board gender diversity in Canada. The participants included: three participants from the provincial government, eight from the private sector (three participants working for investors, four corporate officials with two being board members and two working closely with the board, and one from an industry association), and two participants from non-governmental organizations. Of the 13 interview respondents, 11 were women and 2 were men. The semi-structured interviews were conducted in accordance with the stipulations set out by the Ryerson Ethics Board. This chapter constitutes a review and analysis of the interview findings, in support of the findings discussed earlier in the thesis.

The purpose of conducting interviews with the selected knowledgeable persons was to gain additional insight on the two legal approaches, in terms of what they know and think about the practicality and effectiveness of the comply or explain law and the value and need of a quota law, in order to supplement the findings from and analysis of the literature that were explored in Chapters 2 through 7. Interviews were specifically chosen as the method of choice because participants can share more information, as they are given more time and flexibility to elaborate on their answers. By soliciting the views of participants from government, the private sector and civil society, it was hoped that a diversity of perspectives would be reflected. Because the interview respondents were from government, private sector and civil society the questions were tailored somewhat to be relevant to their sector. A copy of the interview questions used for each sector can be found in the appendix to this thesis.

Given that only 13 respondents were interviewed, it is important to note that information gathered from the interviews should not be considered as a conclusive representation of all Canadian viewpoints on the issue of gender diversity.

In terms of participant selection, publicly available information was used to identify individuals on boards, within the government, and within other organizations (NGOs, investor organizations, industry associations). These individuals were identified because they all had some responsibility, knowledge, or expertise on the issue of board diversity. More than 30 persons were contacted but only thirteen participants agreed to be interviewed.

\section{Data Coding}

The data coding was conducted based on five issues: 
1. Adequacy of the current "comply or explain" approach.

2. The possibility of a gender quota.

3. Changes or alternatives to the current comply or explain approach.

4. Underlying factors that negatively impact female representation.

5. Importance of organizations/actors, in addition to the law.

For each of the five themes, the total number of comments by respondents and the number from each specific sector, can be seen in Figures 5 to 9 below.

\section{Figure 5}

Issue 1 -Comments concerning the adequacy of the current "comply or explain" approach

(TOTAL \# OF COMMENTS: 96)

- Private Government $\quad$ NGO

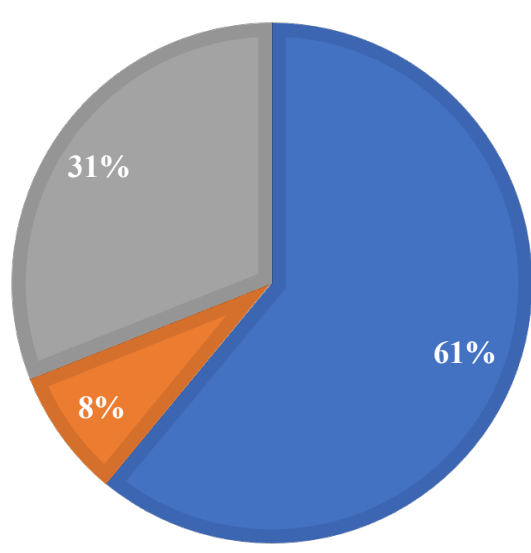

Boards $-20.8 \%$ Investor $-32.3 \%$

Industry Association $9.4 \%$

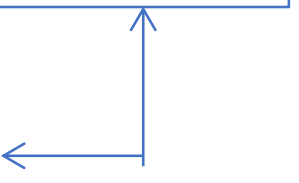




\section{Figure 6}

Issue 2 - Comments concerning the possibility of a gender quota

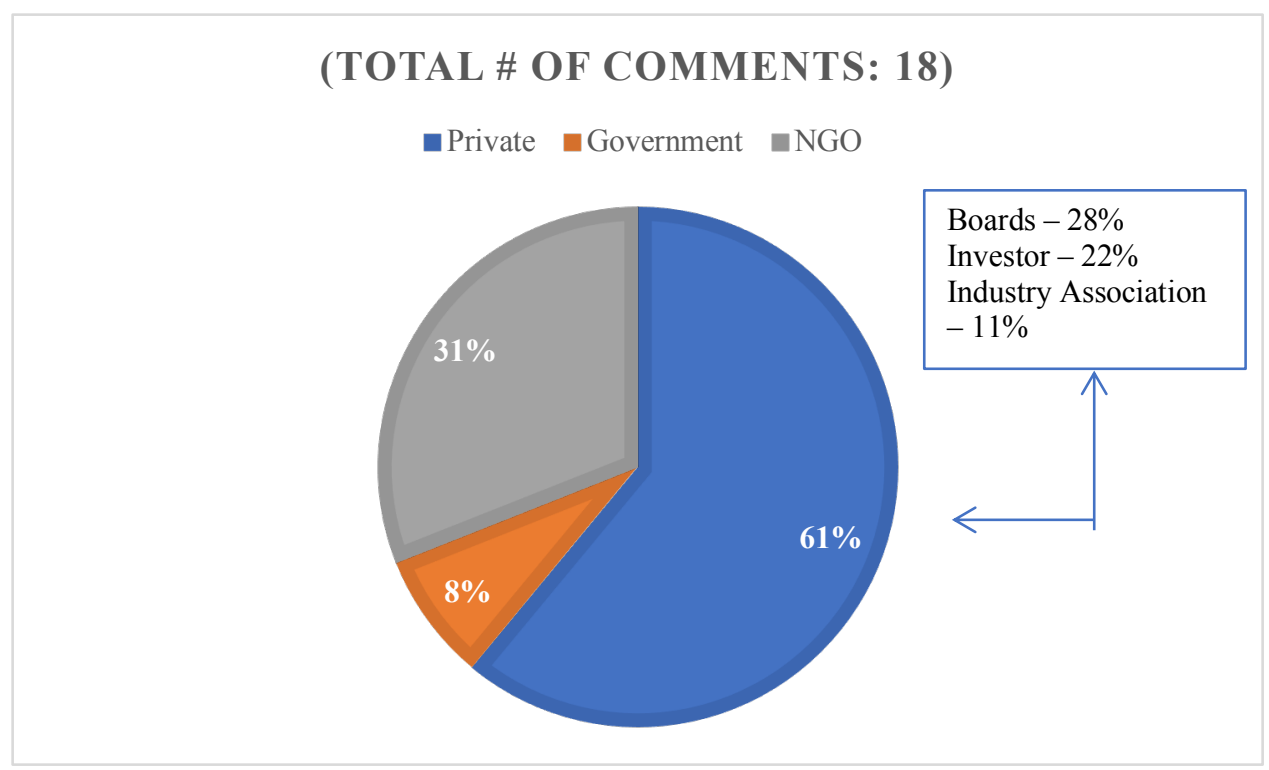

\section{Figure 7}

Issue 3 -Comments concerning changes or alternatives to the current comply or explain approach

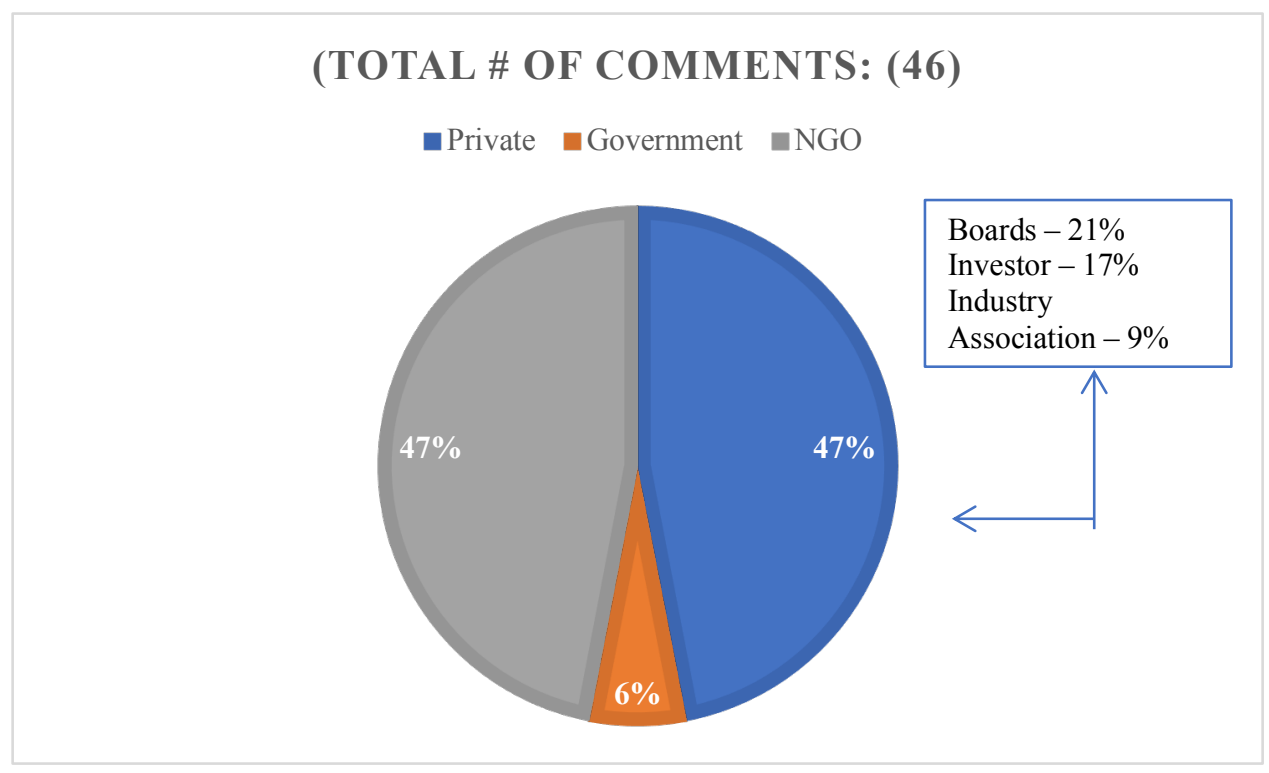




\section{Figure 8}

Issue 4-Comments concerning underlying factors that negatively impact female representation

\section{TOTAL \# OF COMMENTS: 46)}

arivate $\quad$ Government $\quad$ NGO

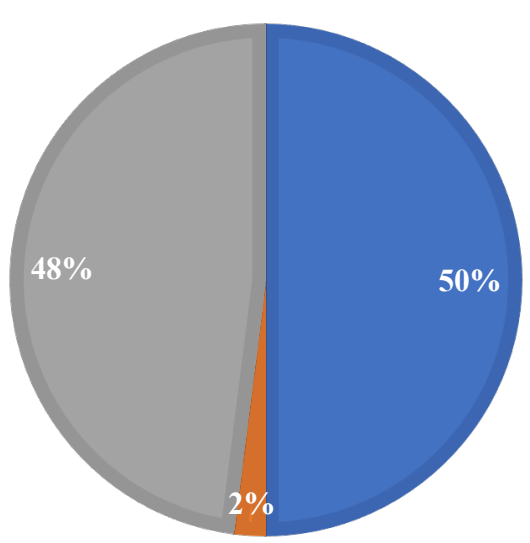

Boards $-50 \%$

Investor $-0 \%$

Industry

Association $-0 \%$

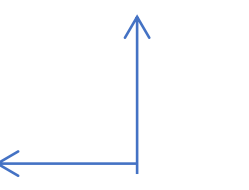

\section{Figure 9}

Issue 5 - Comments concerning the importance of non-state organizations/actors, in addition to the law

(TOTAL \# OF COMMENTS: 36)

- Private Government $\quad$ NGO

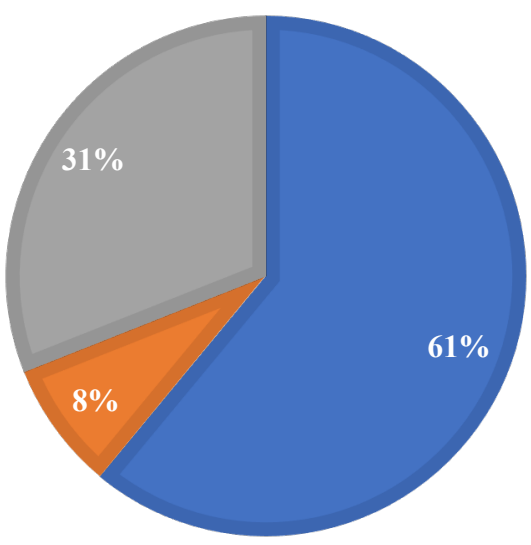

Boards $-25 \%$

Investor $-22 \%$

Industry Association

$-14 \%$

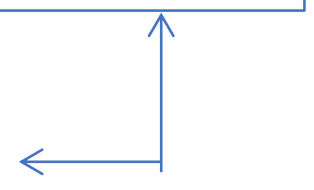




\section{Key interview Findings}

In the following discussion of the interview findings, participants will be solely referred to by their professional affiliation (e.g., an "industry association" participant or an "NGO" participant)“. The findings from the interviews have been grouped into 4 themes:

1. The current "comply or explain" approach is no longer enough.

2. The gender quota approach is not the best option for Canada at this time.

3. Investors, NGOs, and industry associations, devoted to encouraging greater diversity, as well as, pressure from the media and public are important.

4. There are underlying factors that negatively impact female representation on boards.

\section{The current "comply or explain" approach is no longer enough}

One of the research objectives for this thesis is to determine the strengths and weaknesses of the "comply or explain" and gender quota approaches, as these are related to the two first coding issues, as well as, the first theme. The literature review portion about comply or explain, conducted in a previous section, highlighted various strengths and weaknesses suggested to be associated with this approach, as well as, existing gaps in the policy. From discussion with respondents, specifically about the current "comply or explain" approaches strengths, weaknesses, and overall progress, the first theme, that this approach in its current form is no longer enough, was developed.

The adequacy of comply or explain will be discussed first in the analysis of its strengths and weaknesses. The first strength given by $39 \%$ of respondents was that it is flexible. It allows organizations to tailor and adapt their approaches to their circumstances. One participant from the NGO sector said, "It is every palpable and easy to agree with." In referring to its agreeableness, this aligns with the consensual nature of the comply or explain approach. This is a strength that was previously mentioned in discussion of the literature and relates to the policy itself, as it is one that requires disclosure of any policies and the percentage of women, without directly requiring companies to have policies in place. Flexibility is a strength that was given by respondents from the government, $\mathrm{NGO}$, and private sector.

The second strength is that comply or explain has gotten people talking about the issue of gender diversity: this was said by $54 \%$ of participants. At least one respondent from every sector, but the government, listed flexibility as a strength. Respondents in both investors and the industry association sectors said, it "shed a light on the issue." This approach achieves basic 
disclosure, which then can create the basis for subsequent action. A respondent from the investor sector said that comply or explain is a good first step and a strong signal, also that, "if a company doesn't have a great interest in this, they still have to say why they are not doing anything about it." Information is now public, which it was not before. An NGO respondent said that: "the legislation provides minimum standards that people have to comply with. Without such requirements, many organizations would just not do it at all and more boards are unhappy that they have to report that they are doing nothing." This comment supports the point that the comply or explain approach creates an information disclosure spring board for broader societal discussion and action. However, it is important to note, as a government respondent explained, compliance with this approach is about whether or not the disclosure was made. It does not require companies to have any policies in place.

A third strength noted by participants was that the comply or explain approach has led to change, specifically an increase in the percentage of women on corporate boards: $46 \%$ of respondents said this. Respondents from all three of government, the private sector and civil society acknowledged that to some extent the comply or explain has led to some progress and that the numbers of women on boards has gone up. One government respondent stated: "we would note that is progress, because you don't see a complete turnover of the board in any given year, that would be unusual. So we have made progress." However, not all sectors are satisfied with that progress. This will be discussed further in the remainder of this section.

The first weakness noted by some respondents was that progress has been slow: $77 \%$ of respondents said this. An investor respondent said: "The numbers have moved but they are nowhere close to $30 \%$ on every board in Canada." This gets at the speed of implementation of the comply or explain approach. If after a period of time, the current approach or a revised version does not achieve significant results, then perhaps a different approach should be considered.

The second weakness identified by some respondents pertained to the inadequacy of the explanations provided by some companies. An NGO respondent stated: "It has been very easy to explain away the lack of women on boards with reasons I don't believe are true." This gets at the issue of the adequacy of the explanations of the current comply or explain approach. As discussed earlier in the thesis, this is an area where reform might be possible. Many boards have board ready lists but organizations are complaining about the lack of qualified women, which 
makes it seem as though those lists are not being used. This point and the existence of board ready lists, were discussed by respondents in both the NGO and private sector.

A third weakness identified was the inadequate sanctions for non-compliance. A government respondent noted that what happens when issuers do not disclose is that comments will be raised and notes left as to where disclosure was missing, issuers will be asked to disclose in the future and they will follow up. $31 \%$ of respondents discussed the inadequacy of sanctions for non-compliance, from the private sector, NGO, and the industry association. This weakness was also identified in the literature.

Both investor respondents pointed out that some boards are only adding one women to show that they have done something but there are no actual changes taking place within the organization, in terms of policy or culture. Respondents also discussed how smaller and medium sized companies were lagging in terms of increasing female representation. One respondent from the private sector related talent acquisition to company size as well, saying that "Smaller companies beneath a certain size may find it harder to attract women of certain skill sets, quality, and background because the risks that are faced as a director are the same in a small company as in a big company."

The first issue, the adequacy of the current "comply or explain" approach, was used in developing this theme, that the current "comply or explain" approach is not enough. Figure 5 above, can be used as reference. The strengths and weaknesses that were discussed in the interviews align well with scholarly commentary provided earlier in the thesis. Respondents did acknowledge that there has been progress with the approach over the past 5 years since its implementation, but they did note important weaknesses as discussed above. These comments support the idea that the current comply or explain approach could be improved.

\section{The gender quota approach is not the best option for Canada at this time}

As previously mentioned, one of the research objectives of this thesis is to determine the strengths and weaknesses of the "comply or explain" and gender quota approaches. Early on in this thesis, the question arose about whether or not a gender quota approach would be a practical and effective option to use in Canada, now that the comply or explain approach has been in place for five years. Respondents were asked about their opinions of gender quotas and a possible place for them in Canada. Figure 6 above is a graphic depiction of the percentage of respondents that commented on the possibility of a quota. And respondents were asked if they would like to 
see changes to the current "comply or explain" approach. Few participants were in support of quotas and thought they had a place in Canada's society, and others indicated that they thought that improvements to the comply or explain approach could be made.

What can be seen in Figure 10 below is a visual depiction that only $23 \%$ of respondents were in support of quotas. $73 \%$ of respondents were in favor of either the comply or explain as it currently is or a modified version of it. Focusing particularly on the 8 industry participants, all 8 speaking in their official capacity were in support of the comply or explain approach in its current form or a modified version of it. This supports the idea that the comply or explain approach, or a modified version of it, was seen as practical and effective in the Canadian context, and that on the whole, the quota approach was not.

\section{Figure 10}

Depiction of percentage of respondents supporting comply or explain, modified comply or explain and quota approaches

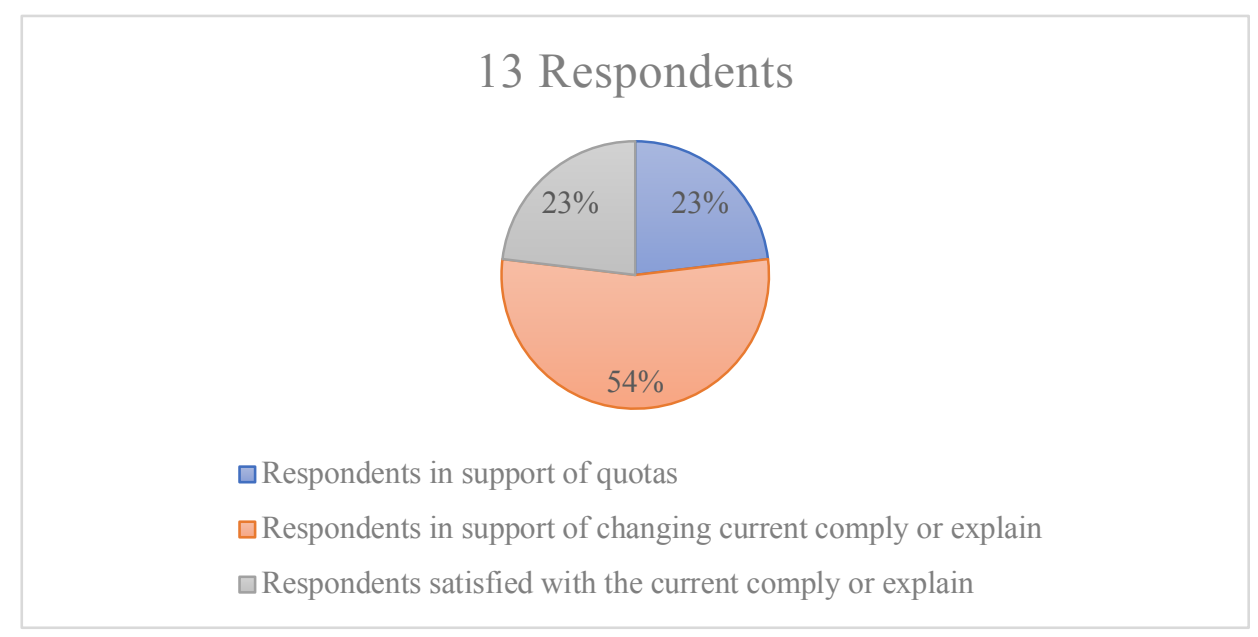

Government respondents upon being asked about the gender quota approach, indicated that the Ontario Securities Commission (OSC) would not be the one to introduce a gender quota, as their approach to corporate governance is more of a disclosure based regime. Therefore, if a gender quota approach were to be taken, it would not be the OSC implementing it.

As research has suggested and as discussed in earlier portions of this thesis, quotas increase percentages fairly significantly and quickly, this was also a point acknowledged by some respondents. As mentioned in the previous theme's discussion, there were participants in 
the investor, NGO, and private sector, that stated that they have heard people in other organizations saying that the "comply or explain" approach may not be enough. A respondent from the investor sector stated that on top of people talking about comply or explain not being enough, they had also heard people saying that quotas may be the only thing to push us fast enough.

Support for quotas was provided by 3 respondents, two from NGOs and one from the investor sector. One NGO respondent said, "comply or explain was a complete failure, we have waited long enough so now we can tap at different things." Another NGO respondent said, "we weren't ready for a quota system so they wanted to put something in place to show that it wasn't going to work. So that would be the basis for creating something more stringent." When respondents discussed gender quotas, they had no problem with acknowledging that they lead to significant and quick results. However, when speaking about actual implementation and support for them, it was only seen from the NGO respondents. In addition to them, one respondent from the investor sector did say that speaking based on personal opinion and not the organization's, they would be in support of quotas. Also, two respondents from the private sector indicated that quotas would be useful for change at the board level but are opposed to them due to their failure to impact representation at other levels. It should be noted that all five respondents mentioned to have spoken positively of quotas, were women and that actual support of the implementation of quotas, was only present in the investor and NGO sectors.

Despite the support from the mentioned respondents, in regards to the implementation of quotas, a majority of participants were opposed or felt they were not appropriate. One respondent from the private sector said, "The incentive for them is no quota. So the better we do with comply or explain, the less need we have for a quota, they definitely don't want a quota." Another respondent, also from the private sector said, "Quotas would be a huge error."

Speaking about the actual operation of quotas, an NGO respondent discussed that there are complications with implementing quotas, that culture and current government attitudes are possible complications. As mentioned in an earlier section of this thesis, socio-cultural factors can play an important role affecting the practicality and effectiveness of particular approaches.

One NGO respondent discussed a study where men and women were asked about their support for gender quotas. According to this NGO respondent, over 50\% of women supported them but only $20 \%$ of men did and $35 \%$ of men strongly disagreed with having quotas. This is 
another suggested problem because when you look at the structure of a society and who holds the power, which is mainly men, the fact that men are so opposed to quotas, can be seen as a complication.

Most participants made suggestions about changing the current comply or explain approach, as opposed to shifting to a gender quota approach. Participants made suggestions like making policy implementation mandatory or having mandatory targets, and addressing the concerns over small penalties. Overall, the findings support the conclusion that a quota approach is not seen as a practical and effective approach to be adopted in Canada at this time.

\section{Investors, NGOs, and industry associations, devoted to encouraging greater diversity, as} well as, pressure from the media and public are important

Sustainable governance is a concept that was the focus of discussion in Chapter 6 of this thesis, and it emphasized the value of having a combination of state and non-state actors, instruments, institutions, processes and actors all playing important roles in the achievement of particular policy objectives. Respondents were asked about their opinions on the importance of investors, NGOs, and industry associations, as well as, pressure from the media and public, in relation to gender diversity. Discussion of this theme indicated that all sectors acknowledged that these actors are very important and influential to increasing gender diversity on corporate boards.

When participants were asked about the value of non-state actors in support of law and almost $70 \%$ of respondents said that the role of non-state actors was important. 7 out of the 8 private sector participants, said they are important. One participant said, they are "important for research, advocacy and dialogue." This quote gets at the value of information disclosed, being the basis of broader societal discussion and involvement through non-state actors. The investor, NGO, and industry association respondents also emphasized how they need to work together.

A respondent from the government made the point that comply or explain makes the information available, but there is a responsibility on others, especially institutional investors, to take the information and help drive change. An investor respondent provided a point that builds on this, information is being provided but a lot of other actors are needed in order to make change. The need for these actors specifically to create change was something discussed by respondents in the government, investor, and private sectors.

The government, industry association and NGO respondents specifically singled out the importance of investors in driving gender diversity on boards. As we have seen, through law, 
investors have available to them the shareholder proposal process, so they can propose more or less gender diversity (and other issues) to other participants in corporate governance. NGOs were also listed as being very important, however, this point was made by NGO respondents themselves and by the industry association. The industry association respondent said that NGOs have been carrying the weight since the 1960s. These organizations can be very influential and can even work in a consulting capacity, for example, helping with the creation of a strategy for achieving greater diversity within the organization.

Public pressure was also recognized as being important by $31 \%$ of respondents. Public pressure was discussed by NGO and private sector respondents. A respondent in the private sector said that, "There is always pressure to be a part of the club, so when the majority are doing something and you are not, it does create pressure." This gets at how the information discourse law creates peer and societal (isomorphic) pressure to do something without requiring it. The information becomes public and then these actors may either praise or shame companies, in order to shed light on what is being done or even promote change. This can also relate to societal culture and its importance, as discussed in chapter 5 in the ecological model. This also coincides with what was said about sustainable governance and specifically how disclosure laws create a starting point for broader, public "norm conversations". The importance of culture was also highlighted by some respondents. One said, "the comply or explain makes the information available, but there is a responsibility on who, particularly institutional investors, to take that information and engage and help drive that change." This is a significant quote as it aligns very well with what has been said about how the comply or explain approach draws in a host of nonstate actors in the achievement of their objectives.

Much like the sustainable governance framework recognizes, participants from the investor and NGO sectors also acknowledged that legislation comes first and is very important. Sustainable governance recognizes that the law is central and instruments, institutions, processes, and actors, add to the law in order for greater effectiveness. An investor respondent indicated that without the listed actors, we would not have the law, that these groups have glorified the issues that have now become mainstream. A respondent from the NGO sector made the point that, "some kind of legislation is needed as the bare minimum standard and nothing less than that will be accepted, anything less would then be breaking the law." Also, that when the global diversity benchmark is looked at, complying with the law qualifies as level 2, doing nothing is 
level 1 . This means that companies aren't getting praise for simply complying with the law, they get praise for going above the law. Therefore, having a law means that at least a minimum standard is established. Legislation does come first and is crucial but these actors are needed in addition to it.

Participants from all sectors acknowledged the importance of other actors outside of state actors implementing the law. As was stated in the analysis of sustainable governance, the law is central and first, but other actors, instruments, institutions and process also play an important role. A combination of state and non-state actors and initiatives can all work together and fill each other's gaps, in order to have the most well-rounded approach. The answers given by participants related to this theme, support sustainable governance and the idea that investors, NGOs, and industry associations, devoted to encouraging greater diversity, as well as, pressure from the media and public are important.

\section{There are underlying factors that negatively impact female representation on boards}

A portion of the thesis literature review was devoted to discussion underlying socio-cultural factors that could affect participation of women on boards, in alignment with the review of the ecological model undertaken earlier in the thesis. Participants were asked whether or not they have witnessed or heard of the existence of socio-cultural factors that might have a negative impact on female representation on boards. Discussion with respondents in regards to this section's theme, indicated the main factors as culture, perception differences, problems with criteria, skill set, and career development, as well as, bias. These are all factors previously discussed.

The first factor is culture and it was discussed in two different contexts. The first is a country's culture, how it is very impactful and should be taken into consideration when thinking about the right approach. This was said by respondents in the government. When thinking back to the discussion of gender quotas, a potential reason why they would not be appropriate for Canada but were appropriate for Norway, is culture. These two countries have different cultures and culture is suggested to impact policy. Therefore, the government, the body responsible for creating legislation, can acknowledge that culture is impactful to picking the right approach. The second context is culture within an organization. It is also important as organizational culture gets embedded and sets out what is and isn't acceptable. This was a point made by a respondent in the private sector. 
Perception differences were discussed by an NGO respondent using the example that, "if you were to ask the average man how many corporate board seats went to women this year, they would likely tell you $80 \%$ because they feel like all the board seats are going to women, even though the numbers indicate something different." This also ties in with previous discussion of quotas and their being a greater support for them from women, as opposed to men.

The next factors that were discussed by both the NGO and private sector respondents are the criteria and skill set being asked for by board candidates, as well as, recruiting practices. Firstly, it was said that women do not tend to have the same experiences and as many experiences, as men do. Board positions often require experiences and skills that women don't necessarily have as they have not had the same opportunities as men, therefore they do not fill those requirements. Than a big part of recruitment is who you know, therefore, your personal networks. The significance of personal networks was discussed by respondents in both the NGO and private sectors. Typically, new board members are drawn from the same pool as the ones sitting at the table. It was said that you need to connect with a good network in order to find good people. The following point was made by a male respondent in the private sector, "If you have bright women on your board, they are likely to have great suggestions about other competent and able women that could be candidates, either for the board or senior management positions. If you don't, then you are not connected." One private sector respondent stated: "I would say women are out there that are qualified, you are just not finding them in your networks." This also relates to the previous discussion of criteria and women having fewer opportunities and experiences, that tend to be required for board positions.

A private sector respondent also spoke of the importance of an environment that facilitates career development for women. One of the biggest issues women face in their careers is with career development. They need both support and understanding for the early part of their career to allow them to grow because of various family obligations and having children, which are important. This point was made by a male respondent in the private sector. However, when it comes to career development, it is not just about support and understanding early on, it is suggested that there are struggles in terms of actually applying for jobs. As stated by a respondent in the private sector, "I don't know if it's hesitation. We do know through research that women tend to only apply for jobs they think they are $100 \%$ a match on the job requirements. Whereas, men will apply even if they don't meet all the requirements." The 
respondent went on to note that women are also less likely to ask for the job. They expect that if their boss thinks they would be good for the job, that they will "tap them on the shoulder" but this is not true. Women also know that they need sponsorship in a role, especially for roles they have never had before. Whereas, a man is more likely to say they will make it work. However, as previously mentioned, when there are women in senior positions, it encourages more women to apply and that is a positive aspect. Women can feel more confident in their ability to succeed These respondent observations support the discussion earlier in the thesis about the importance of the socio-cultural factors within the ecological model and that the issue goes beyond just the law requiring women on boards.

A final socio-cultural factor negatively affecting the likelihood of increased women on corporate boards that was discussed by respondents was the problem of bias. This factor was mainly discussed by NGO respondents. However, one respondent in the private sector also briefly addressed the existence of bias. It is significant to note that all respondents that discussed bias were female. The following points were all made by one NGO respondent: that we all have bias and people tend to be unaware of their own biases, as well as, do not like to admit that they have them. There is also some indication that people speak differently to men than to women. Research indicates that women tend to do more of the emotional labour, for example, they are asked to get coffee, more than their male co-workers. Women constantly seem to face micro aggressions and micro inequities that are both emotionally and physically taxing. However, in Canadian workplaces, this is subtle.

This relates to the discussion of the ecological model, specifically the macro (societal) level, Hofstede's Cultural Dimensions and the masculinity dimension, which refers to the existence of gender roles within society. When Canada and Norway are compared, Canada scores significantly higher, which can mean that gender stereotypes exist more in our society and make our percentage of women on corporate boards lower. This relates to biases because it means that men and women are spoken to and treated differently, which falls under Hofstede's masculinity dimension. Despite these being subtle in Canadian workplaces, they do still exist.

Taken together, the responses of interview participants provided support for the position that, while the current comply or explain approach in operation in Canada is far from perfect, it or a revised version of it can be considered the most practical and effective in the Canadian context at this time. A quota approach was not seen as a practical and effective approach to be 
introduced at this time. The responses of interview participants also supported the proposition that private sector and civil society organizations play an important role supporting the achievement of the goals of the comply or explain approach, in alignment with earlier discussion of the sustainable governance approach. Finally, the responses of interview participants supported the insights derived from the ecological model, that a host of socio-cultural factors 


\section{Chapter 8: Improving Gender Diversity on Corporate Boards in Canada}

Given that the main objective of this thesis is to develop a better understanding of the most practical and effective approach at this time for addressing gender diversity on Canadian corporate boards, and that the research supported the conclusion that a modified comply or explain approach was the most practical and effective, the purpose of this chapter is to analyze potential changes to the current "comply or explain" approach, as well as, some different approaches that could improve gender diversity on corporate boards.

\section{Changes to the Current "Comply or Explain" Approach}

As previously discussed in earlier sections of this thesis, the strengths of the comply or explain approach are evident in terms of its ability to galvanize broader state and non-state support and activity directed at corporate board gender diversity, and its recognition of the value of allowing businesses a certain amount of flexibility in how that goal is achieved. It has resulted in change, with an increase from $11 \%$ to $17 \%$ women on corporate boards, over a 5 year period. This represents a $54.5 \%$ increase in the number of women on boards over the 5 year period. However, identified weaknesses include: corporations are providing inadequate explanations, possibly inadequate penalties. It is possible that progress could be quickened with changes to the explanations part of the regime, the penalties, and compliance. Therefore, these weaknesses will be discussed in terms of how they can be addressed with changes to the current comply or explain framework.

Note that the focus here is on the improvements to the legal regime. As discussed earlier, the broader assemblage of non-state actors, instruments, institutions and processes can to some extent assist in achievement of the law's objectives, beyond what the law on its own can do, in spite of its inadequacies. Having noted this, let's turn our attention to addressing the identified legal weaknesses. Firstly, compliance is about whether or not the disclosure was made, it is not in terms of what practices are in place or the number of women on boards. It does not require companies to have any policies in places and many still do not. There are five areas in which disclosure is required: the percentage of women on the board of directors and in executive positions, disclosing if any targets have been put in place, whether there is a written policy in regards to the nomination of female directors, whether there are director term limits, and finally, whether during the selection process, female representation is considered (CSA, 2015). Companies must disclose the percentage of women on their boards and in executive positions, 
then also any policies, initiatives, mechanisms, and targets they have in place to address gender diversity: this is the "comply" portion of the framework (CSA, 2015). If policies, initiatives, mechanisms, or targets are not adopted, or alternative measures in relation to female representation, are not implemented, they have to explain why that is: this is the "explain" portion (CSA, 2015). Therefore, a company can comply with the law by simply providing the above noted disclosures, and not actually working to improve diversity through implementation of gender diversity policies or setting targets.

Australia has a variation of the "comply or explain" approach and it was discussed in an earlier chapter of the thesis. Their version requires companies to create a policy related to diversity and to disclose all details related to that policy (Willey, 2017). They also specify the kinds of sections that should be part of the policy (Willey, 2017). Their explain portion is the same as Canada's, where if they fail to comply with the disclosure, they must explain why (Willey, 2017). However, in the Australia model, having a policy is required, whereas in Canada, it is not.

If Canada adopted the Australian model, it would arguably enhance the ability of the Canadian law to stimulate change. Another possible change is requiring mandatory targets, as they are currently not required under comply or explain. This change would still allow for flexibility, more than would be seen with the gender quota approach. The following statistics were already discussed earlier but are significant enough to mention again. In $2019,22 \%$ of issuers had implemented targets, this is an increase from the 7\% in 2015, however, it is still not as high as it could be. In terms of policies, in $2019,50 \%$ of issuers had them, up from $15 \%$ in 2015. Statistics seem to indicate that issuers with targets and policies in place, have more women on their boards (CSA, 2019). Term limits also appear to be a useful mechanism and one that was discussed by NGO respondents during interviews. In 2019, 21\% of issuers had term limits, however, this was only $2 \%$ up from what it was in 2015. Therefore, these points support the first change to the approach, which is in regards to actual compliance and would entail adding mandatory targets, policies and term limits, for female representation on corporate boards.

The next change that could be made to comply or explain is in regards to penalties. Issuers only have to disclose what they are doing and if they are doing nothing, they have to explain why that is. As discussed already, many companies are providing explanations that effectively deflect the company from making progress in terms of gender diversity (e.g., 
indicating that there is a lack of qualified women). Would it be possible to improve this? A respondent from the NGO sector suggested the AODA as a possible model. The AODA is the Accessibility for Ontarians with Disabilities Act and it was passed in 2005. When it was first passed, there was much public excitement as it was a legislation that was both advanced and also had "teeth." The financial penalties for non-compliance were intended on being a fine of $\$ 100,000$ per every day of non-compliance. However, this was then "watered down." Had it remained at $\$ 100,000$ per day, companies would have financially been unable to fail to comply but this did not happen and no companies were ever fined. Organizations will do the calculation and will sometimes choose to not comply will the law because complying with the law would cost them more than paying the penalty. This stresses the need for penalties being created for comply or explain and them being significant so that a majority of companies are not going to choose to not comply.

The experience in the United Kingdom indicated strong compliance with their version of comply or explain. However, their experience also showed problems with explanations and monitoring (Arcot et al., 2010). Companies that are choosing not to comply are continuously providing poor explanations (Arcot et al., 2010). The level of importance placed on the quality of explanations is low (Arcot et al., 2010). Although they have less than 10\% non-compliance, they are struggling with the same weakness as Canada, in terms of poor explanations. However, having policies, targets, and term limits made mandatory, as well as, creating significant financial penalties for failing to comply, could also improve the challenges with the explanations.

\section{What Companies Can Do}

Companies themselves can also make internal changes to their organization that can be helpful to increasing the number of women on corporate boards. These are some ideas that came about through discussion with respondents during interviews. Two aspects companies can focus on are paying more attention to the skill set and criteria being asked by board candidates and also to make changes to their business strategy. The importance of the criteria being required for boards was discussed in both the literature and interview findings. As women tend to not have the same experiences and opportunities as men in their careers, they are also likelier to not have the required experiences and skill sets needed to be on a board. Then in terms of company strategy, as was discussed in the interview findings section, it is important for diversity to be a part of the 
company's business strategy. Ideally, it should not a be a separate diversity strategy, however, companies should at a minimum have a diversity strategy.

A respondent from the private sector gave an example within their organization of women supporting women. The female board members on the board have yearly talks with women throughout the organization, at which they discuss their experiences. This can be beneficial because women feel the support they may need and understanding of the differing life experiences women face, which can also lead to an increase in confidence, as well as, more women applying for leadership positions. This is an example of how one organization, in addition to their diversity strategy, is trying to support and promote women. If all organizations were to facilitate these kinds of initiatives in their organization, it could improve company culture, as well as, female representation, in addition to what the comply or explain approach does. In keeping with the sustainable governance model, many of these suggestions can be facilitated through the activities of non-state actors.

Based on analysis of the literature concerning the comply and explain and quota approaches, drawing on an understanding of insights from the ecological model and sustainable governance concept for insights concerning institutional and governance factors, and learning from comments made in semi-structured interviews, the conclusion reached here is that the practicality and effectiveness of the current Canadian comply or explain approach could be enhanced by requiring policies, targets, and term limits, as well as through inclusion of more stringent financial penalties for failing to comply. In keeping with the sustainable governance model, considerable support in achieving the objectives of the revised comply or explain laws can be facilitated through the activities of non-state actors. 


\section{Conclusions}

The objective of this thesis has been to examine the experience with the comply or explain approach in Canada, and in particular to better understand how practical and effective it is, when compared with the quota approach as used in other jurisdictions. In the course of this thesis a comparative analysis of the comply or explain approach in Canada and the quota approach in Europe was undertaken. As part of this research, the relevance of institutional and contextual factors bearing on gender diversity was considered. The thesis sets out to better understand which is the most practical and effective legal approach to increase gender diversity on corporate boards for Canada at this time, and what possible improvements could be made.

Practical and effective were defined as focusing on what is likely to succeed in real circumstances. The importance of this phrase is that it focuses on the "real circumstances" (i.e., the context) in which success in achieving a result is to be achieved. It was noted at the outset that there are significant challenges associated with making a claim that the comply or explain approach is practical and effective in achieving the goal of increasing the number of women on boards in Canada, when compared with a quota approach, including no capability to make conclusive assertions that the law was the cause of identified improvements in board gender diversity, the small number of years that the law has been in place (making it difficult to make conclusive assertions about its impact over the long term). It was also noted that that within Canada, there were not examples of where a comply or explain approach was used in one province and a quota approach in another which would have facilitated a comparison of the two approaches in similar contexts. So instead, that the use of quota laws in European jurisdictions (notably Norway) were drawn on for comparative purposes. Unfortunately, the author does not speak Norwegian, and so a full review of the Norwegian situation was not possible.

Bearing these points in mind that detract from the ability to make inductive and deductive inferences concerning the practicality and effectiveness of the two types of laws operating in society, the thesis adopted an abductive mode of analysis, whereby the objective is to make a plausible explanation for use of the comply or explain or quota approach in terms of its practicality and effectiveness in Canada at this time. The theoretical frame of reference adopted for this thesis is institutionalist in nature which holds that firms are embedded in a larger social environment beyond the marketplace, which induces firms to adhere to social norms since this 
broader environment constitutes a possibly important part of the "real circumstances" relevant to the practicality and effectiveness of a particular law.

The line of inquiry adopted in the thesis was to (a) develop an understanding of how the comply or explain and quota laws operate, and in particular examine the distinctive characteristics of the two laws that could assist in gaining an appreciation of factors affecting the practicality and effectiveness of the two types of laws in particular institutional contexts; (b) develop an understanding of the array of socio-cultural factors that could assist in gaining an appreciation of the challenges and opportunities associated with women being appointed to corporate boards in particular institutional contexts; (c) identify facts about the Canadian institutional context in comparison with the institutional contexts of selected jurisdictions where the quota approach has been adopted that could assist in understanding the practicality and effectiveness of the comply or explain and quota approaches in particular institutional contexts; (d) through semi-structured interviews, collect and analyze the insights of persons from the private sector, government and civil society who are knowledgeable about the board diversity issue, concerning the practicality and effectiveness of the comply or explain law in Canada.

In brief, the interpretation put forward in this thesis concerning the practicality and effectiveness of the comply or explain vs the quota approach for achieving increased participation of women on corporate boards in the "real circumstances" of Canada can be summarized as follows:

(1) analysis of the distinctive features of the comply or explain law vs quota law as two different approaches to achieving gender diversity reveals that underlying these different approaches seems to be an assumption about how gender diversity should be achieved, with comply or explain involving a range of actors in implementation and starting from the premise that the consent of firms is important, and quotas starting from the assumption that only governments and companies need to be involved in implementation, and it is acceptable for firms to simply be required to have a certain number of women on their boards. In short, implicit in the two types of laws seem to be assumptions about the "real circumstances" that affect practicality and effectiveness of laws in different contexts.

(2) the ecological model (Cukier et al., 2014) and sustainable governance approaches (Webb, 2005) are theoretical approaches and concepts in the institutionalist tradition that were drawn on in this thesis to better understand the socio-cultural contexts that may have a bearing 
on norm implementation, with analysis suggesting a rich diversity of factors and actors are or could contribute to the adoption or non-adoption of particular norms.

(3) examination of the actual institutional contexts of Canada and Norway suggested that there are socio-cultural and other observable institutional differences between the two jurisdictions that could affect the practicality and effectiveness of laws (e.g., differences in the degree of state support for programs that facilitate women participating in society, in evaluations of cultural dimensions in terms of power distance and masculinity pursuant to Hofstede's framework, in approaches to corporate social responsibility, and in participation of non-state actors, instruments, institutions and processes supporting achievement of board gender diversity). These observable differences help to explain why the comply or explain approach could be characterized as practical and effective to achieve gender diversity objectives in the Canadian context and the quota approach is seen as practical and effective in the Norwegian context.

(4) analysis of the semi-structured interviews of Canadian private sector, government and NGO participants knowledgeable concerning gender diversity that were undertaken for this thesis provides support for the practicality and effectiveness of the consensual, comply or explain approach in Canada at this time.

Bearing the above points in mind, the thesis put forward the proposition that the comply or explain approach is practical and effective in Canada at this time, and the quota approach is not, taking into consideration the distinctive characteristics of the comply or explain law when compared with a quota law, and taking into consideration the Canadian institutional context, which reveals distinctive institutional attributes compared with countries such as Norway which have adopted the quota approach, and also taking into consideration the insights derived from the semi-structured interviews undertaken as part of this thesis.

Bearing in mind the limitations of the research as outlined earlier in the thesis, a conclusion reached in this thesis is that, although it would be possible to have a law in place tomorrow that required that a high percentage of women be appointed to corporate boards, analysis of cultural factors undertaken in this thesis, and the results of the semi-structured interviews provided support for the idea that this would not be practical in Canada at this time. In addition, analysis of the way the comply or explain approach operates in Canada, in terms of it providing a process for public disclosure of information by businesses that then is drawn on for 
further supportive action by a range of nonstate actors, as per the sustainable governance approach, provided support for the idea that this comply or explain approach, or an amended version of it, was practical and effective in mobilizing action on board gender diversity in Canada at this time.

Comply or explain was recognized as an approach that is flexible, acts as a good first step, and has led to change. However, a number of aspects could be improved. The gender quota approach is recognized as an approach that leads to fast and significant results but does not appear practical at this time in Canada, as supported by the analysis of distinctive socio-cultural factors of Canada, as well as by the results of semi-structured interviews. The fact that significant progress has been achieved in terms of gender diversity in both the Supreme Court of Canada and in law schools, and in both contexts, it was achieved without use of a quota approach, provides support for use of non-quota approaches in Canada at this time.

A conclusion reached in the thesis is that the practicality and effectiveness of the current Canadian comply or explain approach could be enhanced by requiring policies, targets, and term limits, as well as through inclusion of more stringent financial penalties for failing to comply. In keeping with the sustainable governance model, considerable support in achieving the objectives of the revised comply or explain laws can be facilitated through the activities of non-state actors. The hope is that this thesis adds to the understanding of female representation on boards, specifically, the "comply or explain" approach in Canada, as well as, the gender quota approach, various underlying factors that impact representation and the importance of private sector and civil society. A recommendation emerging from the thesis is that the current comply or explain approach could be improved in Canada, through requirements that a gender diversity policy be disclosed. This approach has been adopted in Australia. Possible reforms were discussed in Chapter 8 of the thesis.

Future research could look into the practicality and effectiveness of diversity comply or explain and quota approaches in other contexts (e.g., visible minority) and jurisdictions. An insight from this research that is a possible contribution to the literature revolves around the distinction made between the unilateral "top down" imposition of the quota approach, in comparison with the more decentralized, state and non-state mode of operation of the comply or explain approach. Because the comply or explain approach is in essence an information disclosure law, it could be said that the act of disclosure sets in motion a "bottom up" process 
involving other non-state actors, instruments, and institutions that can assist in galvanizing positive conduct and discouraging negative conduct by the disclosing businesses. In effect, there is structured nonstate action in support of the goals of the comply or explain law that is spurred by the disclosure. The state and non-state engagement concerning implementation of boardroom gender diversity is a "norm conversation" (Webb, 2004) that revolves around the disclosures made pursuant to the comply or explain disclosures. There is thus a socio-cultural and extra-legal sphere of normative action that is promoted by the disclosure law, that is in keeping with the recognition of socio-cultural factors identified through use of the ecosystem approach (Cukier et al, 2014) as well as with the state/non-state sustainable governance concept (Webb 2005) as discussed in the thesis. In the future, it would be potentially valuable to map out and compare the state/nonstate interplay surrounding the achievement of other policy objectives, to identify areas of similarity and difference and explore reasons for variations. 


\section{Appendices}

\section{Appendices A - E: Semi-Structured Interview Questions}

\section{Appendix A: Government}

1. How long have you been with your organization?

2. How long have you been doing work in the diversity areas?

3. Can you describe your role in the organization concerning diversity? Are you or is anyone else in the organization given the lead role of ensuring that your organization's diversity approach is implemented?

4. In an average day, how much time is devoted to addressing diversity issues?

5. What is your opinion concerning the effectiveness of the current "comply or explain" Ontario legal approach to addressing gender diversity on corporate boards?

6. How do you go about ensuring compliance with the diversity law? When you come across incidents of non-compliance, what do you do?

7. In your opinion, what are the biggest strengths and limitations associated with the "comply or explain" approach?

8. Do you feel that the current laws we have in place, re diversity, are reflective of where societal opinions currently are? Are you satisfied with the progress of these laws? Is there anything you would do differently?

9. Have you thought about alternatives to this approach? Perhaps a gender quota?

10. As you probably know, besides the law, there are some investors, non-governmental organizations, and industry associations, that are devoted to encouraging greater diversity, as well as, pressure from the media. In your opinion, how important do you think these are to the achievement of diversity?

\section{Appendix B: Private Sector}

1. How long have you been with your organization?

2. When did you first become aware of the current Ontario comply or explain law in place pertaining to gender diversity on corporate boards? How soon after were any changes discussed and/or made to your company policies and initiatives?

3. How would you describe your company's approach to complying with the Ontario law? Are you or any other people within your organization taking lead on applying this law 
within the company? How much time and resources are being devoted to addressing these issues?

4. In your opinion, what are the biggest strengths and limitations associated with the current "comply or explain" approach to addressing gender diversity in the boardroom?

5. Can you describe what your company did in this area before this law was implemented?

6. Have you had any discussion with other companies regarding this law and their opinion, as well as, experience with it?

7. How effective do you feel this law is? Is there anything you would change about it? How would you improve things? Do you think a gender quota should be considered?

8. Recruitment and selection plays a significant role in increasing gender diversity. Do you feel there is a large enough body of female candidates? Are there any signs indicating that women are hesitant when it comes to applying for higher-ranking positions?

9. Some studies have indicated the presence of issues related to work dynamic between male and female employees. Have you witnessed or heard of any of these? Do gender stereotypes still exist within the workplace?

10. As you probably know, besides the law, there are some investors, non-governmental organizations, and industry associations, that are devoted to encouraging greater diversity, as well as, existing pressure from the media. In your opinion, how important do you think these are to the achievement of diversity?

\section{Appendix C: Industry association}

1. How long have you been with your organization?

2. What is your opinion concerning the need for gender diversity in corporate boardrooms? What sort of priority should be given to increasing the representation of women on corporate boards?

3. What is the position of your industry association concerning gender diversity on corporate boardrooms? What is your role within your organization in terms of addressing gender diversity on corporate boards?

4. In your opinion, what are the biggest strengths and limitations associated with the current "comply or explain" approach to addressing gender diversity in the boardroom?

5. Have you received any feedback from other organizations about the implementation and effectiveness of this law? 
6. Based on anything you have heard and your own personal opinion, would you change anything about it? Are you satisfied with the progress of this law? Have you thought about alternatives to this approach? Perhaps a gender quota?

7. Prior to this law, in your opinion, how much importance and discussion was actually placed on the representation of women on corporate boards?

8. How successful has the law been in actually improving the percentage of women on corporate boards?

9. How influential do you think the media has been in influencing shareholder priorities and company decisions?

10. As you probably know, besides the law, there are some investors, non-governmental organizations, and industry associations, like yours, that are devoted to encouraging greater diversity, as well as, existing pressure from the media. In your opinion, how important do you think these are to the achievement of diversity?

\section{Appendix D: NGOs}

1. How long have you been with your organization?

2. What do you think about the current "comply or explain" law, for addressing gender diversity in the board room, as it is right now? How well is it achieving its intended goals?

3. Can you describe what your organization's position concerning the current law? What is your role within your organization in terms of addressing diversity?

4. In your opinion, what are the biggest strengths and limitations associated with the current "comply or explain" approach?

5. Based on what you have heard and seen, how well do you think other organizations and companies are doing in terms of implementing change? What are some of the best policies and initiatives you have seen others implementing?

6. Based on anything you have heard and your own personal opinion, would you change anything about it? How would you improve things?

7. Do you feel that this approach is sufficient? If you could choose to change the actual law, how would you change it? Would you consider a gender quota?

8. As an organization that advocates for diversity and is dedicated to creating change, which policy or program do you feel should be applied across all organizations? 
9. What are the biggest barriers within organizations when trying to increase the representation of women on boards? Are gendered stereotypes still a problem?

10. As you probably know, besides the law, there are some investors, non-governmental organizations, like yours, and industry associations, that are devoted to encouraging greater diversity, as well as, existing pressure from the media. In your opinion, how important do you think these are to the achievement of diversity?

\section{Appendix E: Investors}

1. How long have you been with your organization?

2. When thinking about smart investing, how much importance is placed on companies having initiatives in place to address female representation?

3. When assessing companies, how many do you find devote sufficient time and resources to addressing this issue? Have you witnessed companies doing the bare minimum to adhere to the law or going above and beyond?

4. Can you describe what your organization's current position concerning gender diversity on corporate boards? What is your role within your organization in terms of addressing diversity?

5. In your opinion, what are the biggest strengths and limitations associated with the current "comply or explain" approach to addressing gender diversity in the boardroom?

6. How effective do you feel this law is? Is there anything you would change about it? How would you improve things? Do you think a gender quota should be considered?

7. Have you as the investor been able to drive change within organizations in order to increase female representation?

8. Do you find that more diverse organizations achieve better financial success and outperform their competitors?

9. Do companies strive to be diverse and specifically in terms of female representation, in order to be competitive? Is this what is mainly driving energy and resource allocation? Or is it due to a genuine belief in the importance of diversity?

10. As you probably know, besides the law, there are some investors, like yours, nongovernmental organizations, and industry associations, that are devoted to encouraging greater diversity, as well as, existing pressure from the media. In your opinion, how important do you think these are to the achievement of diversity? 
Appendix F: Date of Origin of Non-State Actors, Instruments, Institutions and Processes Addressing Gender Diversity Issue in Canada

\begin{tabular}{|c|c|c|}
\hline Name of Initiative & $\begin{array}{l}\text { Institutions, Processes, Rule } \\
\text { Instruments, or Actors }\end{array}$ & $\begin{array}{l}\text { Date of Origin/When } \\
\text { Founded }\end{array}$ \\
\hline $\begin{array}{l}\text { Catalyst/ } \\
\text { Catalyst Canada } \\
\text { Catalyst Women on } \\
\text { Board }\end{array}$ & $\begin{array}{r}\text { Institution } \\
\text { Process }\end{array}$ & $\begin{array}{l}1962^{1} \\
2007^{2}\end{array}$ \\
\hline $\begin{array}{l}\text { Prosci } \\
\text { ADKAR }\end{array}$ & $\begin{array}{l}\text { Institution } \\
\text { Rule-Instrument }\end{array}$ & $\begin{array}{l}1994^{3} \\
2003^{4}\end{array}$ \\
\hline 30\% Club & Process & $2010^{5}$ \\
\hline $\begin{array}{l}\text { Human Resources } \\
\text { Professionals Association }\end{array}$ & Actor & $1990^{6}$ \\
\hline $\begin{array}{l}\text { Canadian Women's } \\
\text { Foundation (NGO) }\end{array}$ & Actor & $1991^{7}$ \\
\hline $\begin{array}{l}\text { Canadian Manufactures } \\
\text { Exporters }\end{array}$ & Actor & $1996^{8}$ \\
\hline 30 by 30 & Actor & $2018^{9}$ \\
\hline $\begin{array}{l}\text { Gender Equality Network } \\
\text { Canada (NGO) }\end{array}$ & Actor & $1986^{10}$ \\
\hline Ryerson Diversity Institute & Actor & $1999^{11}$ \\
\hline $\begin{array}{l}\text { Women in Capital Markets } \\
\text { (NGO) }\end{array}$ & Actor & $1995^{12}$ \\
\hline $\begin{array}{l}\text { Electricity Human } \\
\text { Resources Canada }\end{array}$ & Actor & $2005^{13}$ \\
\hline Move the Dial & Actor & $2017^{14}$ \\
\hline Forward Together & Actor & $2013^{15}$ \\
\hline SheEO & Actor & $2015^{16}$ \\
\hline $\begin{array}{l}\text { Canadian Centre for } \\
\text { Diversity and Inclusion } \\
\text { Canadian Certified }\end{array}$ & $\begin{array}{l}\text { Actor } \\
\text { Process }\end{array}$ & $2012^{17}$ \\
\hline
\end{tabular}

${ }^{1}$ Catalyst. (2020). About us. https://www.catalyst.org/mission/

${ }^{2}$ Catalyst. (2020). Catalyst Women on Board. https://www.catalyst.org/catalyst-women-on-board/

${ }^{3}$ Prosci. (2020). About us. https://www.prosci.com/about

${ }^{4}$ Prosci. (2020). The Prosci ADKAR Model. https://www.prosci.com/adkar

${ }_{5}^{5} 30 \%$ Club. (2020). Who We Are. https://30percentclub.org/about/who-we-are

${ }^{6}$ Human Resources Professionals Association. (2020). About HRPA. https://www.hrpa.ca

${ }^{7}$ Canadian Women's Foundation. (2020). Our story: It started as a conversation between friends. https://canadianwomen.org/about-us/our-story/

${ }^{8}$ CM\&E. (2020). Our History. https://cme-mec.ca/our-history/

${ }^{9}$ All Together. (2018). Engineers Canada Aim for 30 by 30. https://alltogether.swe.org/2018/06/engineers-canada-aims-for-30-by-30/

${ }^{10}$ Canadian Women's Foundation. (2020). Our story: It started as a conversation between friends. https://canadianwomen.org/about-us/our-story/

${ }^{11}$ Ryerson University. (2020). Diversity Institute. https://www.ryerson.ca/diversity/

${ }^{12}$ WCM. (2019). About WCM Toronto. https://wcm.ca/chapters/toronto

${ }^{13}$ Operational Excellence. (2020). Electricity Human Resources Canada. https://www.oilandgasiq.com/eventsopexsummit/mediapartners/electricity-human-resources-canada-1

${ }^{14}$ The Business Leadership Podcast. (2020). Tag: Move the Dial. https://thebusinessleadership.com/tag/move-the-dial/

${ }^{15}$ Forward Together. (2018). About us. http://forward-together.ca/forward-together/

${ }^{16}$ SheEO. (2020). What is SheEO. https://sheeo.world/about-us/

${ }^{17}$ The Discovery Group. (2020). Canadian Centre for Diversity and Inclusion With Michael Bach.

http://www.thediscoverygroup.ca/2020/01/22/canadian-centre-for-diversity-and-inclusion-with-michael-bach/ 


\begin{tabular}{|l|l|c|}
\hline \multicolumn{1}{|c|}{ Inclusion Professional } & & $2017^{18}$ \\
\hline $\begin{array}{l}\text { Canadian Gender and } \\
\text { Good Governance Alliance } \\
\text { (NGOs) }\end{array}$ & Actor & $2016^{19}$ \\
\hline $\begin{array}{l}\text { The CEO Blueprint } \\
\text { EDGE Certification }\end{array}$ & Rule Instrument & $2018^{20}$ \\
\hline Parity Pledge & Rule-instrument & $2011^{21}$ \\
\hline Women Leadership Nation & Rule-instrument & $2017^{22}$ \\
\hline
\end{tabular}

\footnotetext{
${ }^{18}$ Canadian Centre for Diversity and Inclusion. (2017). BLOG - Canadian Certified Inclusion Professional. https://ccdi.ca/blog/?tag=Canadian\%20Certified\%20Inclusion\%20Professional

${ }^{19}$ Canadian Women's Foundation. (2020). How Do We Get More Women on Boards? The Canadian Gender and Good Governance Alliance says Industry Collaboration is Key. https://canadianwomen.org/blog/how-do-we-get-more-women-on-boards-the-canadian-gender-and-goodgovernance-alliance-says-industry-collaboration-is-key/

${ }^{20}$ Cision. (2020). Canadian Gender and Good Governance Alliance continues to amplify impact with release of the CEO Blueprint. https://www.newswire.ca/news-releases/canadian-gender-and-good-governance-alliance-continues-to-amplify-impact-with-release-of-the-ceoblueprint-697571871.html

${ }^{21}$ EDGE. (2020). What We Do. https://edge-cert.org/about-us/

${ }^{22}$ CISION PR Newswire. (2020). Parity.org Launches; Invites Companies to Take the ParityPledge ${ }^{\text {TM }}$ to Pave the Way for Women in Leadership Positions. https:/www.prnewswire.com/news-releases/parityorg-launches-invites-companies-to-take-the-paritypledge-to-pave-the-way-forwomen-in-leadership-positions-300517601.html

${ }^{23}$ Women Leadership Nation.(2020). Leadership \& Unity Training, Development, Assessment \& Certification.

https://womenleadershipnation.com
} 


\section{References}

30\% Club. (2020). TSX Composite Index - 26.6\%. https://30percentclub.org/about/chapters/canada

30\% Club. (2020). Who We Are. https://30percentclub.org/about/who-we-are

Adams, M. (2015). Board Diversity: More than a Gender Issue. Deakin Law Review, 20, 123152.

All Together. (2018). Engineers Canada Aim for 30 by 30.

https://alltogether.swe.org/2018/06/engineers-canada-aims-for-30-by-30/

Allen, P., \& Cutts, D. (2018). How do gender quotas affect public support for women as political leaders? West European Politics, 41(1), 147-

168. https://doi.org/10.1080/01402382.2017.1320082

Andrews, R., \& Ashworth, R. (2015). Representation and Inclusion in Public Organizations: Evidence from the U.K. Civil Service. Public Administration Review, 75(2), 279-288. https://doi.org/10.1111/puar.12308

Arcot, S., Bruno, V., \& Faure-Grimaud, A. (2010). Corporate governance in the UK: Is the comply or explain approach working? International Review of Law \& Economics, 30(2), 193-201. https://doi.org/10.1016/j.irle.2010.03.002

Arfken, D. E., Bellar, S. L., \& Helms, M. M. (2004). The Ultimate Glass Ceiling Revisited: The Presence of Women on Corporate Boards. Journal of Business Ethics, 50(2), 177-186. https://doi.org/10.1023/B:BUSI.0000022125.95758.98

Arnold, D.H., L. Wheelahan, G. Moodie, J. Beaulieu \& J. Taylor-Cline (2018) Mapping the typology of transition systems in a liberal market economy: the case of Canada, Journal of Education and Work, 31:2, 125-143

Bacharach, S.B. (1989). 'Organizational theories: some criteria for evaluation'. Academy of Management Review, 14:4, 496-515.

Bell, M. P., Mclaughlin, M. E., \& Sequeira, J. M. (2002). Discrimination, Harassment, and the Glass Ceiling: Women Executives as Change Agents. Journal of Business Ethics, 37(1), 65-76. https://doi.org/10.1023/A:1014730102063

Bleindheim, B-T. (2012). Institutional Models of Corporate Social Responsibility: A Proposed Refinement of the Explicit-Implicit Framework, Business and Society, Volume: 54:1, 5288 
Bongiorno, R., Bain, P. G., \& David, B. (2014). If you're going to be a leader, at least act like it! prejudice towards women who are tentative in leader roles. British Journal of Social Psychology, 53(2), 217-234. 10.1111/bjso.12032

Business Corporations Act, R.S.O., c. B.16 (1990). https://www.ontario.ca/laws/statute/90b16 Calleja, D., Brearton, S., \& Pachner, J. (2019, May 31). It's 2019. Where are all the women in corporate Canada? The Globe and Mail. https://www.theglobeandmail.com/business/robmagazine/article-its-2019-where-are-all-the-women-in-corporate-canada/

Campbell, K., \& Mínguez-Vera, A. (2008). Gender Diversity in the Boardroom and Firm Financial Performance. Journal of Business Ethics, 83(3), 435-451. https://doi.org/10.1007/s10551-007-9630-y

Canada Business Corporations Act, R.S.C., c. C-44 (1985). https://lawslois.justice.gc.ca/eng/acts/C-44/INDEX.HTML

Canada Research Chairs. (2018, September). Equity, Diversity and Inclusion Action Plan. https://www.chairs-chaires.gc.ca/program-programme/equity-equite/action_planplan_action-eng.aspx

Canadian bar association statement on supreme court of Canada appointments process. (2019, May 16). Targeted News Service. http://ezproxy.lib.ryerson.ca/login?url=https://searchproquest-com.ezproxy.lib.ryerson.ca/docview/2226463548?accountid=13631

Canadian Centre and Good Governance Alliance. (2018, October 15). Canadian Gender and Good Governance Alliance continues to amplify impact with release of the CEO Blueprint [Press release]. https://irpcdn.multiscreensite.com/df49ced3/files/uploaded/Canadian\%20Gender\%20and\%20Good $\% 20$ Governance\%20Alliance_CEO\%20Blueprint\%20Press\%20Release_Final.pdf

Canadian Centre for Diversity and Inclusion. (2017). BLOG - Canadian Certified Inclusion Professional. https:/ccdi.ca/blog/?tag=Canadian\%20Certified\%20Inclusion\%20Professional

Canadian Centre for Diversity and Inclusion. (2020). CCIP. https://ccdi.ca/ccip/

Canadian Centre for Diversity and Inclusion. (2020). Who we are. https://ccdi.ca

Canadian Gender and Good Governance Alliance. (2018, October 12). CEO Blueprint. https://www.cggga.ca/ceo-blueprint 
Canadian Gender and Good Governance Alliance. (2018, October 12). The Alliance. https://www.cggga.ca

Canadian Human Rights Act, R.S.C., c. H-6 (1985). https://lawslois.justice.gc.ca/eng/acts/h-6/

Canadian Manufacturers and Exporters. (2020). About us. https://cme-mec.ca/about/

Canadian Securities Administrators. (2015, September 28). CSA Multilateral Staff Notice 58307 Staff Review of Women on Boards and in Executive Officer Positions - Compliance with NI 58-101 Disclosure of Corporate Governance Practices. https://www.osc.gov.on.ca/en/SecuritiesLaw_csa_20150928_58-307_staff-reviewwomen-boards.htm

Canadian Securities Administrators. (2017, October 5). CSA Multilateral Staff Notice 58-309 Staff Review of Women on Boards and in Executive Officer Positions - Compliance with NI 58-101 Disclosure of Corporate Governance Practices. https://www.osc.gov.on.ca/en/SecuritiesLaw_sn_20171005_58-309_staff-reviewwomen-on-boards.htm

Canadian Securities Administrators. (2019, October 2). CSA Multilateral Staff Notice 58-311 Report on Fifth Staff Review of Disclosure regarding Women on Boards and in Executive Officer Positions. https://www.osc.gov.on.ca/documents/en/SecuritiesCategory5/sn_20191002_58-311_staff-review-women-on-boards.pdf

Canadian Women's Foundation. (2020). About us. https://canadianwomen.org/about-us/ Canadian Women's Foundation. (2020). Gender Equality Network Canada. Retrieved from https://canadianwomen.org/about-us/

Canadian Women's Foundation. (2020). How Do We Get More Women on Boards? The Canadian Gender and Good Governance Alliance says Industry Collaboration is Key. https://canadianwomen.org/blog/how-do-we-get-more-women-on-boards-the-canadiangender-and-good-governance-alliance-says-industry-collaboration-is-key/

Canadian Women's Foundation. (2020). Our story: It started as a conversation between friends. https://canadianwomen.org/about-us/our-story/

Carrasco, A., Francoeur, C., Labelle, R., Laffarga, J., \& Ruiz-Barbadillo, E. (2015). Appointing women to boards: Is there a cultural bias? Journal of Business Ethics, 129(2), 429-444. 10.1007/s10551-014-2166-z

Catalyst. (2016, June 7). Beyond “Comply or Explain": New Catalyst Report for Ontario 
Government Makes Bold Recommendations to Advance Women on Boards. [Press release]. https://www.catalyst.org/media-release/beyond-comply-or-explain-new-catalystreport-for-ontario-government-makes-bold-recommendations-to-advance-women-onboards/

Catalyst. (2019). Catalyst Canada Honours. https://www.catalyst.org/solution/catalyst-canadahonours/

Catalyst. (2020). About us. https://www.catalyst.org/mission/

Catalyst. (2020). Catalyst Women on Board. https:/www.catalyst.org/catalyst-women-on-board/

Catalyst. (2020). What We Do. Retrieved from https://www.catalyst.org/what-we-do/

Catalyst. (2020). Women in Leadership at S\&P/ TSX Companies. https://www.catalyst.org/research/women-leadership-sp-tsx/

CBA president's statement on supreme court of Canada appointment process. (2019, Mar 26). Targeted News Service. http://ezproxy.lib.ryerson.ca/login?url=https://searchproquest-com.ezproxy.lib.ryerson.ca/docview/2197961303?accountid=13631

Chizema, A., Kamuriwo, D. S., \& Shinozawa, Y. (2015). Women on corporate boards around the world: Triggers and barriers. The Leadership Quarterly, 26(6), 1051-1065. https://doi.org/10.1016/j.leaqua.2015.07.005

CISION PR Newswire. (2020). Parity.org Launches; Invites Companies to Take the ParityPledge ${ }^{\mathrm{TM}}$ to Pave the Way for Women in Leadership Positions. https://www.prnewswire.com/news-releases/parityorg-launches-invites-companies-totake-the-paritypledge-to-pave-the-way-for-women-in-leadership-positions300517601.html

Cision. (2020). Canadian Gender and Good Governance Alliance continues to amplify impact with release of the CEO Blueprint. https://www.newswire.ca/news-releases/canadiangender-and-good-governance-alliance-continues-to-amplify-impact-with-release-of-theceo-blueprint-697571871.html

City of Toronto Agencies and Corporations. (2016, December 15). Board Governance Structures. https://www.toronto.ca/wp-content/uploads/2017/08/966d-BoardGovernance-Structures-ACs-Updated.pdf

City of Toronto. (2019, January 14). Employment Equity Policy. https://www.toronto.ca/citygovernment/accountability-operations-customer-service/city-administration/corporate- 
policies/people-equity-policies/employment-equity-policy/

CM\&E. (2020). Our History. https://cme-mec.ca/our-history/

Cukier, W., Gagnon, S., Mae Lindo, L., Hannan, C., \& Amato, S. (2014). A [critical] ecological model to enabling change: Promoting diversity and inclusion. (pp. 245-275) Emerald Group Publishing Limited. doi:10.1108/S2046-6072(2013)0000002017

Dahlerup, D., \& Freidenvall, L. (2010). Judging gender quotas: predictions and results. Policy and Politics; London, 38(3), 407-425. https://doi.org/http://dx.doi.org.ezproxy.lib.ryerson.ca/10.1332/030557310X521080

Dahlerup, D., \& Gaber, M. A. (2017). The Legitimacy and Effectiveness of Gender Quotas in Politics in Ce Europe. Teorija in Praksa; Ljubljana, 54(2), 307-316.

Dale-Olsen, H., Schøne, P., \& Verner, M. (2013). Diversity among Norwegian Boards of Directors: Does a Quota for Women Improve Firm Performance? Feminist Economics, 19(4), 110-135. https://doi.org/10.1080/13545701.2013.830188

Danermark, B, Ekstrom, M., Jakobsen, L., \& Karlsson, J. C. (1997). Explaining society—Critical realism in the social sciences. London, UK: Routledge.

Davidson-Schmich, L. K. (2006). Implementation of Political Party Gender Quotas: Evidence from the German Länder 1990-2000. Party Politics, 12(2), 211-232. https://doi.org/10.1177/1354068806061338

Department for Women and Gender Equality Act, S.C., c. 27, s. 661 (2018). https://lawslois.justice.gc.ca/eng/acts/W-11.3/page-1.html

Dewally, M., Flaherty, S. M. V., \& Tomasi, S. (2017). The impact of social norms on female corporate board membership inclusion. Managerial Finance, 43(10), 10931116. https://doi.org/10.1108/MF-06-2015-0182

Diversity Institute. (2020). About. https://www.ryerson.ca/diversity/about/

Dolan, K. (2014). Gender Stereotypes, Candidate Evaluations, and Voting for Women Candidates: What Really Matters? Political Research Quarterly, 67(1), 96-107. https://doi.org/10.1177/1065912913487949

EDGE. (2020). What We Do. https://edge-cert.org/about-us/

Electricity Human Resources Canada. (2020). Improving our industry, together. https://electricityhr.ca

Employment Equity Act, S.C., c. 44, (1995). https://lawslois.justice.gc.ca/eng/acts/E- 


\subsection{1/index.html}

Engineers Canada. (2018). 30 by 30. https://engineerscanada.ca/diversity/women-inengineering/30-by-30

Finke, C. L. (1989). Affirmative Action in Law School Academic Support Programs. Journal of Legal Education; Durham, N.C., 39(1), 55-70.

Forward Together. (2018). About us. http://forward-together.ca/forward-together/

Forward-Together. (2020). About. http://forward-together.ca

Gaber, M. A., \& Selisnik, I. (2017). The Slovene Version of a "fast track" to Political

Galle, A. (2016). A Closer Look at the Dutch Gender Quota from Empirical and Theoretical Perspective. In International Conference on Management, Leadership \& Governance; Kidmore End, 118-128. https://search.proquest.com/docview/1779263311/abstract/AC77F2787732452APQ/1

Gelman, S.A. 1996. 'Concepts and theories'. In Gelman, R. and Au, T.K.-F. (Eds.), Perceptual and Cognitive Development: 117-150. San Diego, CA: Academic Press.

Giddens, A. (1989). Sociology. Cambridge: Polity Press.

Górriz, C. (2014). Women on Boards: A European Proposal. Global Jurist; Berlin, 14(1-3), 3166. https://doi.org/http://dx.doi.org.ezproxy.lib.ryerson.ca/10.1515/gj-2013-0018

Government of Canada. (2018, February 21). Federal Contractors Program. https://www.canada.ca/en/employment-social-development/programs/employmentequity/federal-contractor-program.html

Government of Canada. (2020, March 26). Treasury Board of Canada Secretariat. https://www.canada.ca/en/treasury-board-secretariat.html

Government of Canada. (2020, March 27). Corporations Canada. https://corporationscanada.ic.gc.ca/eic/site/cd-dgc.nsf/eng/home

Grosvold, J., Rayton, B., \& Brammer, S. (2016). Women on Corporate Boards: A Comparative Institutional Analysis. Business \& Society, 55(8), 1157-1196. https://doi.org/10.1177/0007650315613980

Grundy, J., \& Smith, M. (2011). Evidence and equity: Struggles over federal employment equity policy in Canada, 1984-95. Canadian Public Administration, 54(3), 335-357. https://doi.org/10.1111/j.1754-7121.2011.00179.x

Guppy, N., \& Luongo, N. (2015). The rise and stall of Canada's Gender-Equity revolution. 
Canadian Review of Sociology/Revue Canadienne De Sociologie, 52(3), 241-265. 10.1111/cars. 12076

Gupta, A, H. (2020, March 3). Why 2019 Was a Breakthrough Year for Women in the Boardroom. The New York Times. https://www.nytimes.com/2020/03/03/us/womencompany-boards-private.html

Halabi, R. (2019). Gender diversity in the boardroom: Raising questions about the "comply or explain" model and targets in canada. Western Journal of Legal Studies, 9(2) doi:10.5206/uwojls.v9i2.8073

Hughes, M. M., Paxton, P., \& Krook, M. L. (2017). Gender Quotas for Legislatures and Corporate Boards. Annual Review of Sociology, 43(1), 331-352. https://doi.org/10.1146/annurev-soc-060116-053324

Human Resources Professionals Association. (2020). About HRPA. https://www.hrpa.ca Human Rights Code, R.S.O., c, H.19 (1990). https://www.ontario.ca/laws/statute/90h19 Iacobucci, F. (2002). The Supreme Court of Canada: Its history, powers and responsibilities. Journal of Appellate Practice and Process, 4(1), 27.

Information Inductance. (2020). Oxford Reference. https://www.oxfordreference.com/view/10.1093/oi/authority.20110803100003358

Isidro, H., \& Sobral, M. (2015). The Effects of Women on Corporate Boards on Firm Value, Financial Performance, and Ethical and Social Compliance. Journal of Business Ethics, 132(1), 1-19. https://doi.org/10.1007/s10551-014-2302-9

Johansen, M., \& Zhu, L. (2017). Who Values Diversity? Comparing the Effect of Manager Gender Across the Public, Private, and Nonprofit Sectors. The American Review of Public Administration, 47(7), 797-809. https://doi.org/10.1177/0275074016634201

Kang, L. S., \& Payal. (2012). Women on Corporate Boards: A Literature Review. Indian Journal of Corporate Governance, 5(1), 33-49. https://doi.org/10.1177/0974686220120103

Kay, F., \& Gorman, E. (2008). Women in the Legal Profession. Annual Review of Law and Social Science, 4(1), 299-332.

https://doi.org/10.1146/annurev.lawsocsci.4.110707.172309

Kirsch, A. (2018). The gender composition of corporate boards: A review and research agenda. The Leadership Quarterly, 29(2), 346-364. https://doi.org/10.1016/j.leaqua.2017.06.001

Klettner, A., Clarke, T., \& Boersma, M. (2016). Strategic and Regulatory Approaches to 
Increasing Women in Leadership: Multilevel Targets and Mandatory Quotas as Levers for Cultural Change. Journal of Business Ethics, 133(3), 395-419.

https://doi.org/10.1007/s10551-014-2069-z

Krakauer, L., \& Chen, C. P. (2003). Gender barriers in the legal profession: Implications for career development of female law students. Journal of Employment Counseling; Alexandria, 40(2), 65-79.

Kujala, J., \& Pietiläinen, T. (2007). Developing Moral Principles and Scenarios in the Light of Diversity: An Extension to the Multidimensional Ethics Scale. Journal of Business Ethics, 70(2), 141-150. https://doi.org/10.1007/s10551-006-9101-X

Labelle, R., Francoeur, C., \& Lakhal, F. (2015). To Regulate Or Not To Regulate? Early Evidence on the Means Used Around the World to Promote Gender Diversity in the Boardroom. Gender, Work \& Organization, 22(4), 339-363. https://doi.org/10.1111/gwao.12091

Lawson, K. M., \& Lips, H. M. (2014). The role of self-perceived agency and job attainability in women's impressions of successful women in masculine occupations. Journal of Applied Social Psychology, 44(6), 433-441. 10.1111/jasp.12236

Lundy, M. (2020, January 28). More than 60 per cent of companies in Canada have boards composed entirely of men. The Globe and Mail. https://www.theglobeandmail.com/business/article-more-than-60-per-cent-of-canadiancompanies-have-boards-composed/

Luo, Y., \& Salterio, S. E. (2014). Governance Quality in a "Comply or Explain” Governance Disclosure Regime. Corporate Governance: An International Review, 22(6), 460-481. https://doi.org/10.1111/corg.12072

MacDonald, C. (2009). Managing for stakeholders: Survival, reputation, success, by R. Edward Freeman, Jeffrey S. Harrison, and Andrew C. Wicks. New Haven, Conn.: Yale University Press, 2007. Hardcover, 200 pp. ISBN: 978-0300125283. Business Ethics Quarterly, 19(4), 621-629. doi:10.5840/beq200919435

MacDougall, A., Valley, J., Adler, J., Bettel, C., Param, A., Schmidt, J.,...Suppa, O. (2017). 2017 Diversity Disclosure Practices Report: Women in leadership roles at TSX-listed companies. Osler. https://www.osler.com/en/resources/governance/2017/2017-diversitydisclosure-practices-report-women 
MacDougall, A., Valley, J., Jeffrey, J., Aziz, R., Black, M., Cao, J.,...Traore, T. (2019). 2019 Diversity Disclosure Practices Report: Women in leadership roles at TSX-listed companies. Osler. https://www.osler.com/en/resources/governance/2019/2019-diversitydisclosure-practices-report-women-in-leadership-roles-at-tsx-listed-companies

Martin, M., \& Webb, K. (2020). Water quality protection of the Canada-US great lakes: Examining the emerging state/nonstate governance approach. International Journal of Innovation and Sustainable Development, 14(1), 102-124. doi:10.1504/IJISD.2020.104245

Mathisen, G. E., Ogaard, T., \& Marnburg, E. (2013). Women in the Boardroom: How Do Female Directors of Corporate Boards Perceive Boardroom Dynamics? Journal of Business Ethics, 116(1), 87-97. https://doi.org/10.1007/s10551-012-1461-9

Matten, D. \& Moon, J. 2008. "Implicit" and "Explicit" CSR: A conceptual framework for a comparative understanding of corporate social responsibility. Academy of Management Review, 32: 404- 424.

Meier, P. (2008). A Gender Gap Not Closed by Quotas. International Feminist Journal of Politics, 10(3), 329-347. https://doi.org/10.1080/14616740802185650

Mentzer, M. S. (2002). The Canadian Experience with Employment Equity Legislation. International Journal of Value-Based Management, 15(1), 35-50. https://doi.org/10.1023/A:1013021402597

Mobus, J. (2005). Mandatory environmental disclosures in a legitimacy theory context. Accounting, Auditing \& Accountability Journal (2005)18(4), pp. 492-517.

Move the Dial. (2020). Our Mission. https://movethedial.com/about Murray, R. (2014). Quotas for Men: Reframing Gender Quotas as a Means of Improving Representation for All. American Political Science Review, 108(3), 520-532. https://doi.org/10.1017/S0003055414000239

Nacevska, E., \& Lokar, S. (2017). The Effectiveness of Gender Quotas in Macedonia, Serbia and Croatia. Teorija in Praksa; Ljubljana, 54(2), 394-412,426.

Nerantzidis, M. (2015). Measuring the quality of the "comply or explain" approach: Evidence from the implementation of the Greek corporate governance code. Managerial Auditing Journal, 30(4/5), 373-412. https://doi.org/10.1108/MAJ-08-2014-1060

Nielsen, S., \& Huse, M. (2010). Women directors' contribution to board decision-making and 
strategic involvement: The role of equality perception. European Management Review, 7(1), 16-29. 10.1057/emr.2009.27

Nordmeyer, K., Teig, T., \& Bedera, N. (2017). “Gender Utopias?”: U.S. Student Reflections on Studying Abroad in Norway and Sweden. Teaching Sociology, 45(4), 324-

333. https://doi.org/10.1177/0092055X16667537

O’Brien, D. Z. (2015). Rising to the Top: Gender, Political Performance, and Party Leadership in Parliamentary Democracies. American Journal of Political Science, 59(4), 1022-1039. https://doi.org/10.1111/ajps.12173

Ohemeng, F. L. K., \& McGrandle, J. (2015). The Prospects for Managing Diversity in the Public Sector: The Case of the Ontario Public Service. Public Organization Review, 15(4), 487507. https://doi.org/10.1007/s11115-014-0285-8

Ontario Human Rights Commission. (2020). About the Commission. http://www.ohrc.on.ca/en/about-commission

Ontario Securities Commission, 58-101. (2014, January 23). 58-101 - Disclosure of Corporate Governance Practices. https://www.osc.gov.on.ca/en/14198.htm

Ontario Securities Commission. (2015, September 28). Regulators Release Results of Compliance With New Disclosure Requirements on Women on Boards and in Executive Officer Positions [Press release]. https://www.osc.gov.on.ca/en/NewsEvents_nr_20150928_disclosure-requirementswoman-boards.htm

Ontario Securities Commission. (2020). About. https://www.osc.gov.on.ca/en/About_about_index.htm Operational Excellence. (2020). Electricity Human Resources Canada. https://www.oilandgasiq.com/events-pexsummit/mediapartners/electricity-humanresources-canada-1

Øystein Strøm, R. (2015). Gender discrimination before mandated quotas? Evidence from Norway: 1989-2002. Scandinavian Journal of Management, 31(3), 303-315. https://doi.org/10.1016/j.scaman.2015.02.006

Page, M., Oldfield, C., \& Ursrad, B. (2008). Why not teach "diversity" to public sector managers? International Journal of Public Sector Management, 21(4), 368-382. https://doi.org/10.1108/09513550810880241 
Palvia, A., Vähämaa, E., \& Vähämaa, S. (2015). Are female CEOs and chairwomen more conservative and risk averse? evidence from the banking industry during the financial crisis. Journal of Business Ethics, 131(3), 577-594. 10.1007/s10551-014-2288-3

Panter, A. T., Daye, C. E., Allen, W. R., Wightman, L. F., \& Deo, M. (2008). Everyday discrimination in a national sample of incoming law students. Journal of Diversity in Higher Education, 1(2), 67-79.

https://doi.org/http://dx.doi.org.ezproxy.lib.ryerson.ca/10.1037/1938-8926.1.2.67

Parity.org. (2020). About us. https://parity.org/about-us/

Paxton, P., \& Hughes, M. M. (2015). The Increasing Effectiveness of National Gender Quotas, 1990-2010. Legislative Studies Quarterly, 40(3), 331-362.

https://doi.org/10.1111/lsq.12079

Politics in CE Europe. Teorija in Praksa; Ljubljana, 54(2), 307-316.

Popescu, S., \& Rusko, R. (2012). Managing Diversity in Public Organizations. Global Business and Management Research; Boca Raton, 4(3/4), 235-247.

Prosci. (2020). About us. https://www.prosci.com/about

Prosci. (2020). The Prosci ADKAR Model. https://www.prosci.com/adkar

Prosci. (n.d.). What is the ADKAR model. https://www.prosci.com

Purchase, B. (2004), “The Political Economy of Voluntary Codes,” in K. Webb, Ed., Voluntary Codes: Private Governance, the Public Interest and Innovation (Ottawa: Carleton University, 2004), pp., $77-96$.

Ryerson University. (2020). Diversity Institute. https://www.ryerson.ca/diversity/

Salterio, S. E., Conrod, J. E. D., \& Schmidt, R. N. (2013). Canadian evidence of adherence to "Comply or explain" corporate governance codes: An international comparison. Accounting Perspectives, 12(1), 23-51. doi:10.1111/1911-3838.12006

Sealy, R. (2013). A “Hands-off” Intervention: The UK's Approach to Increase the Number of Women on Corporate Boards. Women's Policy Journal of Harvard; Cambridge, 10, 2236.

Securities Act, R.S.O., c. S.5 (1990). https://www.ontario.ca/laws/statute/90s05

Shapiro, S. (2001). The Judiciary in the United States: A search for fairness, independence, and competence. The Georgetown Journal of Legal Ethics; Washington, 14(3), 667-686.

SHARE (2018). Gender diversity on boards - Still not good enough. 
https://share.ca/gender_div_boards/

SheEO. (2020). What is SheEO. https://sheeo.world/about-us/

Songer, D. R., Radieva, M., \& Reid, R. (2016). Gender Diversity in the Intermediate Appellate Courts of Canada. Justice System Journal; Williamsburg, 37(1), 4-19. https://doi.org/http://dx.doi.org.ezproxy.lib.ryerson.ca/10.1080/0098261X.2015.1083816

Srikantia, P., \& Bilimoria, D. (1997). Isomorphism in Organization and Management Theory: The case of research on sustainability. Organization \& Environment, 10(4), 384-406. doi:10.1177/192181069701000404

Stephan, M., (2002), Environmental Information Disclosure Programs: They Work, but Why? SOCIAL SCIENCE QUARTERLY, Volume 83, Number 1, March 2002, pp. 190 - 204.

Stevenson \& Lindbery. (2010). effective. New Oxford American Dictionary. : Oxford University Press. Retrieved 27 Apr. 2020, from https://www.oxfordreference.com/view/10.1093/acref/9780195392883.001.0001/m_en_u s1243234.

Stevenson \& Lindbery. (2010). practical. In Stevenson, A., \& Lindberg, C. (Eds.), New Oxford American Dictionary. : Oxford University Press. Retrieved 27 Apr. 2020, from https://www.oxfordreference.com/view/10.1093/acref/9780195392883.001.0001/m_en_u s1280071.

Strand, R., R.Freeman and K. Hockberts (2015) Corporate Social Responsibility and Sustainability in Scandinavia: An OverviewJ Bus Ethics (2015) 127:1-15

Terjesen, S., Aguilera, R. V., \& Lorenz, R. (2015). Legislating a Woman's Seat on the Board: Institutional Factors Driving Gender Quotas for Boards of Directors. Journal of Business Ethics: JBE; Dordrecht, 128(2), 233-251. http://dx.doi.org.ezproxy.lib.ryerson.ca/10.1007/s10551-014-2083-1

The Business Leadership Podcast. (2020). Tag: Move the Dial. https://thebusinessleadership.com/tag/move-the-dial/

The Discovery Group. (2020). Canadian Centre for Diversity and Inclusion With Michael Bach. http://www.thediscoverygroup.ca/2020/01/22/canadian-centre-for-diversity-andinclusion-with-michael-bach/

The United Nations. (1948). Universal Declaration of Human Rights. https://www.un.org/en/universal-declaration-human-rights/ 
Tiessen, R., \& Carrier, K. (2015). The erasure of "gender" in Canadian foreign policy under the Harper Conservatives: the significance of the discursive shift from "gender equality" to “equality between women and men." Canadian Foreign Policy Journal, 21(2), 95-111. https://doi.org/10.1080/11926422.2014.977310

United Nations Global Compact. (2020). The world's largest corporate sustainability initiative. https://www.unglobalcompact.org/what-is-gc

Wang, M., \& Kelan, E. (2013). The Gender Quota and Female Leadership: Effects of the Norwegian Gender Quota on Board Chairs and CEOs. Journal of Business Ethics, 117(3), 449-466. https://doi.org/10.1007/s10551-012-1546-5

WCM. (2019). About WCM Toronto. https://wcm.ca/chapters/toronto

WCM. (2019). About WCM. Retrieved from https://wcm.ca/about

Webb, K (2012), Multi-level corporate responsibility and the mining sector: Learning from the Canadian experience in Latin America. Business and Politics, 2012, vol. 14:3, 1-42.

Webb, K. (2005). Sustainable governance in the twenty-first century: Moving beyond instrument choice. In P. Eliadis et al., Eds. Designing government: From instruments to governance, (Kingston: McGill-Queens Press), pp. 242-280.

Webb, K. (2019) Conversation with Dr. Kernaghan Webb, Associate Professor, Department of Law and Business, Ted Rogers School of Management, Ryerson University.

Webb, K., (2004). Understanding the voluntary code phenomenon. In: Webb, K. (Ed.), Voluntary Codes: Private Governance, the Public Interest, and Innovation (Carleton University: Ottawa), pp. 3 -32).

Whitepaper. (2019). Disrupting How We Close the Gender Gap \& Increase Innovation. Women Leadership Nation. https://womenleadershipnation.com/whitepaper

Willey, K. (2017). Bringing Canadian Women on Board: A Behavioural Economics Perspective on Whether Public Reporting of Gender Diversity Will Alter the Male-Dominated Composition of Canadian Public Company Boards and Senior Management. Canadian Journal of Women and the Law, 29, 182-210.

Women Leadership Nation.(2020). Leadership \& Unity Training, Development, Assessment \& Certification. https://womenleadershipnation.com

Women on Board: Does Forced Diversity Hurt Firm Performance. (2010, Feb 10). US Fed News Service, Including US State News. http://ezproxy.lib.ryerson.ca/login?url=https://search- 
proquest-com.ezproxy.lib.ryerson.ca/docview/471953376?accountid=13631

Women's Empowerment Principles. (2020). About - The Women's Empowerment Principles. https://www.weps.org/about

Yagan, D. (2016). Supply vs. demand under an affirmative action ban: Estimates from UC law schools. Journal of Public Economics, 137, 38-50. 10.1016/j.jpubeco.2016.02.00

Young, S. and M. Marais (2012) A Multi-level Perspective of CSR Reporting: The Implications of National Institutions and Industry Risk Characteristics Corporate Governance An International Review 20(5): 432-450 